PASSIVE FLOW CONTROL IN BOUNDARY LAYER INGESTING SEMI SUBMERGED INLET

A THESIS SUBMITTED TO

THE GRADUATE SCHOOL OF NATURAL AND APPLIED SCIENCES

$\mathrm{OF}$

MIDDLE EAST TECHNICAL UNIVERSITY

BY

UMUT CAN KÜÇÜK

IN PARTIAL FULFILLMENT OF THE REQUIREMENTS

FOR

THE DEGREE OF MASTER OF SCIENCE

IN

AEROSPACE ENGINEERING

MAY 2015 

Approval of the thesis:

\section{PASSIVE FLOW CONTROL IN BOUNDARY LAYER INGESTING SEMI SUBMERGED INLET}

submitted by UMUT CAN KÜÇÜK in partial fulfillment of the requirements for the degree of Master of Science in Aerospace Engineering Department, Middle East Technical University by,

Prof. Dr. Gülbin Dural Ünver

Dean, Graduate School of Natural and Applied Sciences

Prof. Dr. Ozan Tekinalp

Head of Department, Aerospace Engineering

Assoc. Prof. Dr. Oğuz Uzol

Supervisor, Aerospace Engineering Department, METU

Assist. Prof. Dr. Özgür Uğraş Baran

Co-supervisor, Mechanical Engineering Department, TEDU

\section{Examining Committee Members:}

Prof. Dr. Yusuf Özyörük

Aerospace Engineering Department, METU

Assoc. Prof. Dr. Oğuz Uzol

Aerospace Engineering Department, METU

Assist. Prof. Dr. Özgür Uğraş Baran

Mechanical Engineering Department, TEDU

Prof. Dr. Ünver Kaynak

Mechanical Engineering Department, TOBB ETÜ

Assoc. Prof. Dr. Sinan Eyi

Aerospace Engineering Department, METU

Date: 
I hereby declare that all information in this document has been obtained and presented in accordance with academic rules and ethical conduct. I also declare that, as required by these rules and conduct, I have fully cited and referenced all material and results that are not original to this work.

Name, Last Name: UMUT CAN KÜÇÜK

Signature 


\begin{abstract}
PASSIVE FLOW CONTROL IN BOUNDARY LAYER INGESTING SEMI SUBMERGED INLET
\end{abstract}

\author{
Küçük, Umut Can \\ M.S., Department of Aerospace Engineering \\ Supervisor : Assoc. Prof. Dr. Oğuz Uzol \\ Co-Supervisor : Assist. Prof. Dr. Özgür Uğraş Baran \\ MAY 2015, 114 pages
}

Submerged intake designs with high compactness provide lower radar cross sectional area, less noise, higher packaging efficiency and lower drag compared to the conventional designs. However, in such an intake flow exposed to strong adverse pressure gradients both in streamwise and circumferential directions due to the centerline curvature and high diffusion rate through the intake. Since, flow inside submerged intakes is very sensitive to the upcoming flow quality, it is very common to encounter with high total pressure distortion and low total pressure recovery inside boundary layer ingesting submerged intakes. Therefore, flow control methods used for reducing distortion and/or increasing pressure recovery can provide crucial advantageous to the intake designers.

In this thesis, effect of vortex generators used as a passive flow control devices in a semi submerged boundary layer ingesting intake is computationally investigated with commercially available flow solver Fluent 14.0. In order to reach high confidence about 
computational strategy and turbulence model selection validation study is conducted with an available experimental data in the open literature for a serpentine intake with and without vortex generator application. Validation results indicate that $\kappa-\omega$ SST provide more accurate results compared to the computations obtained with Spalart Allmaras and Realizable $\kappa-\varepsilon$ turbulence models.

Base intake geometry developed for a flow control investigation is formed through the conventional design approaches. After computational investigation of performance of clean intake without flow control, effect of vortex generators on intake performance are investigated. Design variables of vortex generator sets are taken as vortex generator height relative to local boundary layer thickness, angle of incidence, number of vortex generators thus lateral spacing and distance between separation point and vortex generator set. Effect of the each design variable on intake performance are discussed in detail at the end of the work. Best vortex generator set provide $80 \%$ reduction in total pressure distortion with only $0.35 \%$ reduction in total pressure recovery at design condition. Moreover it is shown that, passive flow control ensure sufficiently uniform flow reaching engine face such that possibility of the engine surge totally eliminated with only negligible decrease in pressure recovery for not only design condition but also whole angle of attack range that mostly encountered in flight envelope.

Keywords: Intake Aerodynamics, Passive Flow Control, Semi Submerged Boundary Layer Ingesting Inlets, Distortion, Surge, Pressure Recovery, Turbulence Models 


\title{
ÖZ
}

\section{YARI GÖMÜLÜ HAVA ALIĞINDA PASİF AKIŞ KONTROLÜ}

\author{
Küçük, Umut Can \\ Yüksek Lisans, Havacılık ve Uzay Mühendisliği Bölümü \\ Tez Yöneticisi : Doç. Dr. Oğuz Uzol \\ Ortak Tez Yöneticisi : Yrd. Doç. Dr. Özgür Uğraş Baran
}

Mayıs 2015,114 sayfa

Gömülü hava alıkları, geleneksel hava alıklarına göre düş̧ük radar kesit alanı, düşük gürültü, yüksek yerleşim verimliliği ve düşük sürükleme kuvveti sağlamaktadır. Ancak bu çeşit hava alıklarında merkez eğriliği ve hava alığı boyunca var olan yüksek difüzyon hızından dolayı radyal ve çevresel ters basınç gradyanları akışa etki etmektedir. $\mathrm{Bu}$ şekildeki hava alıklarında akış dışardan gelen akışın kalitesine doğrudan bağlı olduğu için, sınır tabakası içindeki havayı emen gömülü hava alılarında yüksek toplam basınç bozuntusu ve düşük basınç korunumu sıkça meydana gelir. Dolayısıyla, bozuntuyu düşürmeyi ve/veya basınç korunumunu artırmayı amaçlayan akış kontrol yöntemleri hava alığı tasarımcılarına çok büyük bir avantaj sağlayabilir.

Bu tezde, sınır tabakası içindeki havayı emen yarı gömülü hava alıklarında pasif akış kontrol yöntemi olarak kullanılan girdap oluşturucuların etkileri hesaplamalı akışkanlar dinamiği yöntemi ile ticari olarak temin edilebilen Fluent 14.0 yazılımı kullanılarak incelenmiştir. İncelemelerde kullanılacak olan yöntem hakkında güven kazanmak ve türbülans modelini seçebilmek amacıyla doğrulama çalışması açık kaynaklarda ula- 
şılabilir deneysel veriler yardımıyla gerçekleştirilmiştir. Doğrulama çalışması, girdap oluşturucuların kullanıldığı ve kullanılmadığı durumları içermektedir. Doğrulama çalışması sonucunda $\kappa-\omega$ SST türbülans modelinin, Spalart Allmaras ve Realizable $\kappa-\varepsilon$ türbülans modellerine göre daha doğru sonuçlar verdiği görülmüştür.

Çalışmalarda temel alınan hava alı̆̆ı geometrisi geleneksel tasarım yaklaşımları ile tasarlanmıştır. Öncelikle bu hava alığının performans değerleri akış kontrolü uygulanmadan elde edilmiş, sonrasında girdap oluşturucularının hava alığı performansı üzerindeki etkileri incelenmiştir. Girdap oluşturucu takımlarının tasarım değişkenleri lokal sınır tabakası kalınlığına göreceli olarak değerlendirilen girdap oluşturucu yükseklikleri, girdap oluşturucuların açısı, girdap oluşturucuların sayısı yani aralarındaki yatay mesafe ve ayrılma noktası ile girdap oluşturucu takımı arasındaki mesafe olarak alınmıştır. Çalışmanın sonunda her bir parametrenin etkisi detaylı bir şekilde tartışılmışıır. En iyi girdap oluşturucu takımı toplam basınç bozuntusunda \%80'lik bir iyileştirme sağlarken yalnızca \%0.35'lik bir toplam basınç toparlama katsayısında azalmaya yol açmıştır. Ayrıca, kullanılan pasif akış kontrol yönteminin yalnızca tasarım koşulunda değil aynı zamanda uçuş zarfı boyunca görülebilecek hücum açısı aralığında da bozuntu katsayısını önemli şekilde aşağı çekerek motorun sağlıklı çalışmasını güvence altına aldığı ve yalnızca önemsiz sayılabilecek ölçüde toplam basınç toparlama katsayısında düşmeye yol açtığı gösterilmiştir.

Anahtar Kelimeler: Hava Alığı Aerodinamiği, Pasif Akış Kontolü, Yarı Gömülü Hava Alığı, Bozuntu, Basınç Toparlaması, Türbulans Modelleri 
Sevdiklerime... 


\section{ACKNOWLEDGMENTS}

First, I would like to thank Dr. Özgür Uğraş Baran who introduced me with intake aerodynamics. His endless support and guidance make this work real.

I am very grateful to Prof. Oğuz Uzol for his advices and finding solutions to all my problems. It has been a privilege to work under his supervision.

Futhermore, I owe Prof. İbrahim Sinan Akmandor a debt of gratitude for sharing his innovative ideas with me. Although we work with only limited time, our meetings were really valuable for me.

I would like to express my deepest gratitude to my family for their endless love and patience. Finally and most importantly, I would like to thank my wife Demet, it is your love always keeps me going forward. 


\section{TABLE OF CONTENTS}

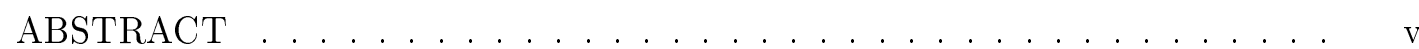

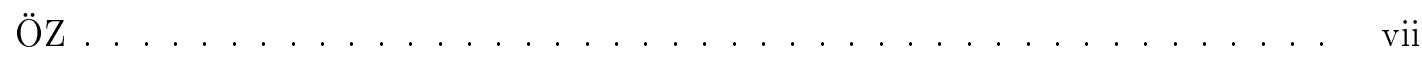

ACKNOWLEDGMENTS .......................

TABLE OF CONTENTS $\ldots \ldots \ldots \ldots \ldots$ xi

LIST OF TABLES . . . . . . . . . . . . . . . . . . . . . . . . . xii

LIST OF FIGURES . . . . . . . . . . . . . . . . . . . . . . . . . . . . xiii

LIST OF ABBREVIATIONS . . . . . . . . . . . . . . . . . . . . . . xiv

\section{CHAPTERS}

$1 \quad$ INTRODUCTION $\ldots \ldots \ldots \ldots \ldots \ldots \ldots$

$1.1 \quad$ Air Intakes $\ldots \ldots \ldots \ldots \ldots \ldots$

$1.2 \quad$ Serpentine Diffusers $\ldots \ldots \ldots \ldots \ldots$

$1.3 \quad$ Flow Characteristics in Serpentine Intakes $\ldots \ldots \ldots$

$1.4 \quad$ Concept of Boundary Layer Ingestion . . . . . . . . . . . . . . 8

$1.5 \quad$ Distortion $\ldots \ldots \ldots \ldots \ldots \ldots$

$1.6 \quad$ Pressure Recovery $\ldots \ldots \ldots \ldots \ldots$. . . . . . . . . . 14

$2 \quad$ LITERATURE SURVEY $\ldots \ldots \ldots \ldots \ldots \ldots$ 
$2.1 \quad$ Flow Control . . . . . . . . . . . . . . . . . . . . . . . 17

$2.1 .1 \quad$ Suction $\ldots \ldots \ldots \ldots \ldots \ldots$

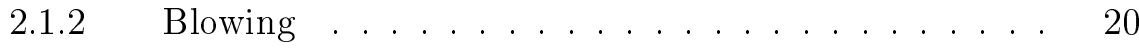

$2.1 .3 \quad$ Vortex Generators . . . . . . . . . . . . . . . . 21

3 VALIDATION STUDY AND TURBULENCE MODEL SELECTION 27

$3.1 \quad$ M2129 Intake . . . . . . . . . . . . . . . . . . . . 27

$3.2 \quad$ Duct With Cowl-Lip $\ldots \ldots \ldots \ldots \ldots \ldots$

3.2.1 Numerical Model and Boundary Conditions . . . . 30

$3.2 .2 \quad$ Mesh Sensitivity Analysis $\ldots \ldots \ldots$. . . . . . . 32

$3.2 .3 \quad$ Convergence Histories $\ldots \ldots \ldots$. . . . . . . . . 33

3.2.4 Comparison of Computational and Experimental Results 36

3.2.4.1 Low Mass Flow Rate Case . . . . . . . . 36

3.2.4.2 HMFR Case . . . . . . . . . . . . . 44

$3.2 .5 \quad$ Comparison of the Computational Results with Previous Work . . . . . . . . . . . . . . . . 51

$3.3 \quad$ M2129 Intake without Cowl-Lip . . . . . . . . . . . . . . . 53

3.3.1 Computational Domain and Duct Geometry . . . . . 53

3.3.2 Mesh Dependency Analysis and Flow Simulations . . 54

3.3.3 Results Obtained with Clean M2129 Intake. . . . . . 56

3.3.4 Results Obtained with M2129 Intake with Vortex Generators . . . . . . . . . . . . . 60

$3.4 \quad$ Post Processing Uncertainties Related to M2129 Intake Flow Calculations and Modelling Errors . . . . . . . . . . . 66 
$3.5 \quad$ Comments About Validation Study . . . . . . . . . . . . . 67

$4 \quad$ PROBLEM DEFINITION $\ldots \ldots \ldots \ldots \ldots$

$4.1 \quad$ Geometrical Properties of Investigated Intake . . . . . . . . . . 71

$4.1 .1 \quad$ Engine Face and Hub Geometry . . . . . . . . . . 74

$4.1 .2 \quad$ Centerline Curvature and Area Ratio . . . . . . . 75

$4.1 .3 \quad$ Throat Area $\ldots \ldots \ldots \ldots \ldots$. . . . . . . . . 77

$4.2 \quad$ Flow Conditions and Intake Performance Requirements . . . . 80

$4.3 \quad$ CFD Modelling and Mesh Dependency Analysis for Baseline

Intake . . . . . . . . . . . . . . . 81

$4.3 .1 \quad$ Mesh Dependency Analysis . . . . . . . . . . . . . 82

$4.4 \quad$ Application of Vortex Generators $\ldots \ldots \ldots$

$4.5 \quad$ Mesh Dependency Analysis for Intake with VGs . . . . . . . . 90

$5 \quad$ RESULTS AND DISCUSSION $\ldots \ldots \ldots \ldots \ldots$

$5.1 \quad$ Effects of Distance Between Vortex Generator Set and Separation Point. . . . . . . . . . . . . . . . . . . 95

$5.2 \quad$ Effects of Vortex Generator Height and Angle of Incidence . . 97

$5.3 \quad$ Effect of the Number of Vortex Generators . . . . . . . . . . 98

$5.4 \quad$ Overview of Effect of Vortex Generators . . . . . . . . . . . . . 99

$5.5 \quad$ Intake Performance with Flow Control Application in Other Flight Conditions . . . . . . . . . . . . . 101

$6 \quad$ CONCLUSION AND FUTURE WORK $\ldots \ldots \ldots \ldots$

REFERENCES . . . . . . . . . . . . . . . . . . . . . 109 


\section{LIST OF TABLES}

\section{TABLES}

Table 3.1 Geometric parameters of M2129 intake . . . . . . . . . . . . . . . . . 29

Table 3.2 Experimental flow conditions for HMFR case and LMFR case . . . . 29

Table 3.3 Results Of the mesh sensitivity analysis $\ldots \ldots \ldots \ldots$. . . . . . . . . . . 32

Table 3.4 Comparsion of the computational results with experiment - LMFR case 36

Table 3.5 Comparsion of the computational results with experiment - HMFR case 44

Table 3.6 Comparison of the results obtained by current and previous work with the experimental results . . . . . . . . . . . . . . . . . . . . . 51

Table 3.7 Results of the mesh sensivity analysis - duct without cowl lip . . . . 54

Table 4.1 Simulated Flight Conditions $\ldots \ldots \ldots$. . . . . . . . . . . . . . . . . . . . 80

Table 4.2 Mesh dependency analysis for baseline intake . . . . . . . . . . . . . 84

Table 4.3 Geometrical properties of investigated vortex generators . . . . . . . 87

Table 4.4 Mesh dependency analysis for intake with VGs . . . . . . . . . . . . 90 


\section{LIST OF FIGURES}

\section{FIGURES}

Figure 1.1 Aerodynamic duct concept[56] . . . . . . . . . . . . . . . . 2

Figure 1.2 Naca submerged air intake illustration[14] . . . . . . . . . . . . 3

Figure 1.3 Intake types mostly used in cruise missiles[9] . . . . . . . . . . . . . 4

Figure 1.4 Velocity contours at the symmetry plane of investigated intke . . . 7

Figure 1.5 Schematic representation of flow characteristics inside serpentine in-

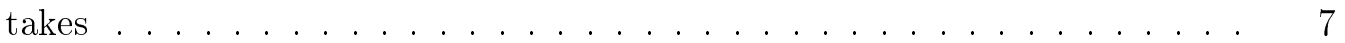

Figure 1.6 NASA/BOEING BWB concept[45] $\ldots \ldots \ldots \ldots \ldots$

Figure 1.7 N3-X vehicle 32$] \ldots \ldots \ldots$

Figure 1.8 Effect of distorted (spoiled) region on compressor stability [35] . . . 11

Figure 1.9 Pressure recovery contours at engine face with $60^{0}$ sector at which lowest mean total pressure is obtained. . . . . . . . . . . . . . . . 13

Figure 1.10 Engine face divided by 24 equal area segments for DC(60 calculations) 14

Figure $2.1 \quad$ Flow past a circular cylinder with suction on one side [54] $\ldots . . .218$

Figure 2.2 Different Bleed System Designs[27] . . . . . . . . . . . . . . . . 20

Figure 2.3 Blowing and suction via single ejector[20] . . . . . . . . . . . . . 21

Figure 2.4 Counter and co- rotating vortex generator configurations[36] . . . . 22 
Figure 2.5 Demonstration of counter rotating vorticies created by the ramp and vane type VGs[60] . . . . . . . . . . . . . . . . . . . . . . . . . . . . . . 24

Figure 3.1 M2129 intake geometry[1] $\ldots \ldots \ldots \ldots$. . . . . . . . . . . . . . 28

Figure 3.2 Capture area and free stream area enclosed by dividing stream Lines 30

Figure 3.3 Computational flow domain $\ldots \ldots \ldots$

Figure 3.4 Surface meshes around M2129 intake with cowl-lip . . . . . . . . . 33

Figure 3.5 Continuity residual in logarithmic scale for HMFR case . . . . . . . 34

Figure $3.6 \quad$ Area weighted total pressure variation at the engine face for HMFR case . . . . . . . . . . . . . . . . . . . 34

Figure 3.7 Continuity residual in logarithmic scale for LMFR case . . . . . . . 35

Figure 3.8 Area weighted total pressure variation at the engine face for LMFR case . . . . . . . . . . . . . . . . . . . 35

Figure 3.9 Static pressure distribution along the STBD side of the intake walls

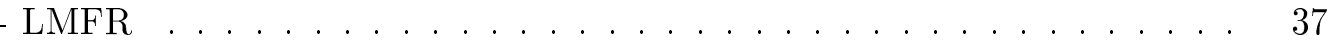

Figure 3.10 Static pressure distribution along the PORT side of the intake walls

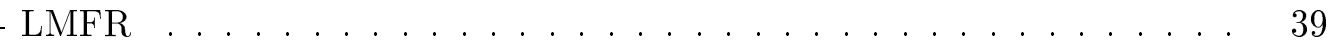

Figure 3.11 Computed Mach number contours with KWSST turbulence model LMFR 40

Figure 3.12 Computed Mach number contours with RKE turbulence model - LMFR 41

Figure 3.13 Computed Mach number contours with SA turbulence model - LMFR 41

Figure 3.14 Turbulence model effect on engine face total pressure recovery contours and tangential velocity vectors . . . . . . . . . . . . . . . . 43

Figure 3.15 Static pressure distribution along the STBD side of the intake walls

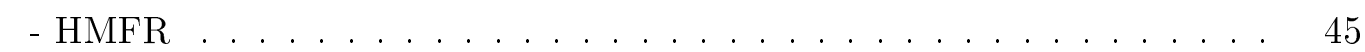


Figure 3.16 Static pressure distribution along the PORT side of the intake walls

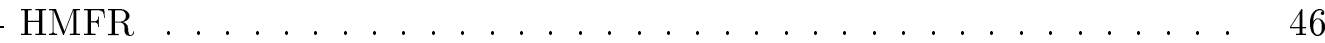

Figure 3.17 Computed Mach number contours with KWSST turbulence model -

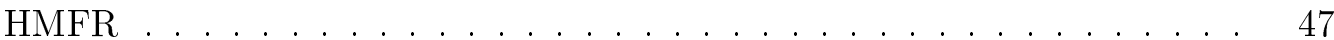

Figure 3.18 Computed Mach number contours with RKE turbulence model -

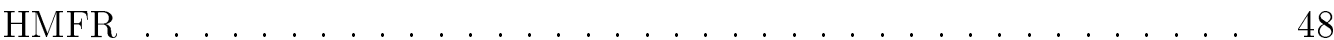

Figure 3.19 Computed Mach number contours with SA turbulence model - HMFR 48

Figure 3.20 Turbulence model effect on engine face total pressure recovery contours and tangential velocity vectors . . . . . . . . . . . . . . 50

Figure 3.21 M2129 inlet geometry used for the CFD analyses . . . . . . . . . . 53

Figure 3.22 Surface meshes on M2129 intake without cowl lip . . . . . . . . . . 55

Figure 3.23 Comparison of the total pressure recoveries at the engine face - clean M2129 intake without cowl lip . . . . . . . . . . . . . . . . 57

Figure 3.24 Comparison of the $\mathrm{DC}(60)$ values at the engine face - clean M2129 intake without cowl lip . . . . . . . . . . . . . . . . . . 57

Figure 3.25 Comparison of the computationally and experimentally obtained engine face total pressure recovery contours . . . . . . . . . . . . . . . . 59

Figure 3.26 Matrix of the designed vortex generator sets used in the reference

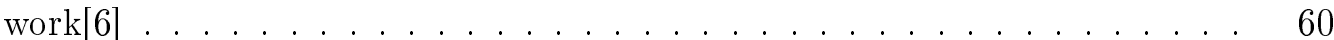

Figure 3.27 Geometrical representation and nomenclature of the vortex generator sets used in the reference work $[6] \ldots \ldots$. . . . . . . . . . . . . . 61

Figure 3.28 Surface mesh around M2129 intake with vortex generator set used for validation and turbulence model selection . . . . . . . . . . . . . . . . 62

Figure 3.29 Comparison of the total pressure recoveries at the engine face M2129 intake with vortex generator set . . . . . . . . . . . . . 63 
Figure 3.30 Comparison of the DC(60) values obtained at the engine face - M2129 intake with vortex generator set $\ldots \ldots \ldots$. . . . . . . . . 63

Figure 3.31 Comparison of the computationally and experimentally obtained engine face total pressure recovery contours . . . . . . . . . . . . . . 65

Figure 3.3272 probe rake used in experimental investigations[44] . . . . . . . 66

Figure 4.1 Inlet entrance and missile body (all lengths are non-dimensionalized with engine face diameter $] \ldots \ldots \ldots$. . . . . . . . . . . . 72

Figure 4.2 Inlet side view (all lengths are non-dimensionalized with engine face

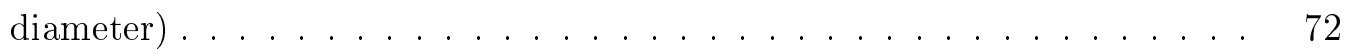

Figure 4.3 Highlight and throat radius $\ldots \ldots \ldots$. . . . . . . . . . . . . . . . 73

Figure 4.4 Effect of contraction ratio and lip shaping on the lip loss[56] . . . . 74

Figure 4.5 Engine face and hub geometry $\ldots \ldots \ldots$. . . . . . . . . . . . 75

Figure 4.6 Definition of inlet centerline curvature[68] $\ldots \ldots \ldots$. . . . . . . 76

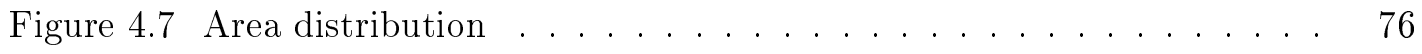

Figure 4.8 MFP vs Mach number $\ldots \ldots \ldots \ldots$

Figure 4.9 A typical subsonic engine corrected mass flow demands[40] . . . . . 79

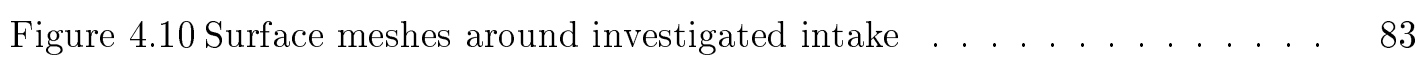

Figure 4.11 PR contours obtained from different size meshes . . . . . . . . . . . 84

Figure 4.12 Continuity residuals in logarithmic scale for baseline intake . . . . . 85

Figure 4.13 Variton of total pressure obtained at the engine face for baseline intake ....................... 86

Figure 4.14 Geometrical representation of vortex generators $\ldots \ldots . . . . \quad 87$

Figure 4.15 Velocity vectors for determination of separation point . . . . . . . . 88 
Figure 4.17 Vortex generator sets placed at Station1 and Station2 . . . . . . . . 90

Figure 4.18 Comparison of the PR contours obtained from Fine VG and Medium VG meshes . . . . . . . . . . . . . . . . . . . . . . . . . . . 9 91

Figure 4.19 Continuity residuals in logarithmic scale for intake with VGs . . . . 92

Figure 4.20 Variton of total pressure obtained at the engine face for intake with

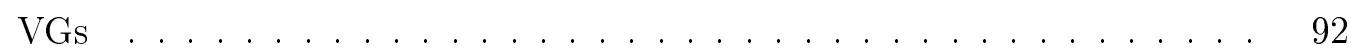

Figure 4.21 Surface mesh around intake with vortex generators . . . . . . . . . 93

Figure 5.1 Effect of distance between vortex generator set and separation point 96

Figure 5.2 Effect of vortex generator height at Station 1 . . . . . . . . . . . . 97

Figure 5.3 Effect of vortex generator height at Station 2 $\ldots \ldots \ldots$. . . . . . . . 97

Figure 5.4 Effect of number of vortex generators at Station $1 \ldots \ldots$. . . . . . . 98

Figure 5.5 Effect of number of vortex generators at Station 2 . . . . . . . . . . 99

Figure 5.6 PR comparison (Clean duct vs Application of VGs) $\quad \ldots \ldots$. . . . 100

Figure 5.7 Effect of vortex generators on total pressure distribution through intake 101

Figure 5.8 Effect of vortex generators on vortex-lift off region . . . . . . . . . . 101

Figure 5.9 Effect of flow control on $\mathrm{DC}(60) \quad \ldots \ldots \ldots$

Figure 5.10 Effect of flow control on PR $\ldots \ldots$. . . . . . . . . . . . 103 


\section{LIST OF ABBREVIATIONS}

\begin{tabular}{|c|c|}
\hline $\mathrm{A}$ & AREA \\
\hline AGARD & Advisory Group for Aerospace Research and Development \\
\hline AIP & Aerodynamic Interface Plane \\
\hline BLI & Boundary Layer Ingestion \\
\hline$\beta$ & Angle of Incidence \\
\hline CFD & Computational Fluid Dynamics \\
\hline CFR & Capture Flow Ratio \\
\hline $\mathrm{DC}$ & Distortion Coefficient \\
\hline$\delta$ & Boundary Layer Thickness \\
\hline FOD & Foreign Object Damage \\
\hline $\mathrm{H}$ & Vortex Generator Height \\
\hline M & Mach Number \\
\hline$\dot{m}$ & Mass Flow Rate \\
\hline MFP & Mass Flow Parameter \\
\hline PR & Pressure Recovery \\
\hline$P_{s}$ & Static Pressure \\
\hline$P_{t}$ & Total Pressure \\
\hline$\rho$ & Density \\
\hline $\mathrm{R}$ & Gas Constant \\
\hline RAE & Royal Aircraft Establishment \\
\hline RCS & Radar Cross Section \\
\hline stbd & Starboard \\
\hline$T_{s}$ & Static Temperature \\
\hline$T_{t}$ & Total Temperature \\
\hline $\mathrm{V}$ & Velocity \\
\hline $\mathrm{VG}$ & Vortex Generator \\
\hline
\end{tabular}




\section{CHAPTER 1}

\section{INTRODUCTION}

Today's aviation design philosophy pushes every single component of the air vehicle to its maximum possible performance with minimum power usage. Since engine inlet directly effects whole air vehicle system performance and its efficiency, design and integration of engine inlet is crucial.

The aim of the engine inlet is providing air to the aircraft engine components with adequate reduction in flow velocity, minimum total pressure loss and maximum flow uniformity. Use of submerged inlets with short ducts and sharp curvatures provide some benefits compared to traditional inlet ducts because of the fact that they decrease the overall weight, radar cross section and total drag of the air vehicle.

However, performance of such an inlet highly depends on the upcoming flow quality and the flow within the serpentine inlets is very likely exposed to flow separation and secondary flows due to the centerline curvature. Therefore ability to control characteristics of flow in such inlets provides tremendous benefits to the designer. In this work application of vortex generators as a passive flow control method on a boundary layer ingesting semi submerged serpentine intake is computationally investigated. However before going further it is appropriate to make brief explanation about air intakes, flow characteristics inside serpentine inlets and measures of performance of an air intake.

\subsection{Air Intakes}

Since intake/engine compatibility has a large scale effect on the performance of whole aircraft system, design process of air intake requires significant amount of effort and 


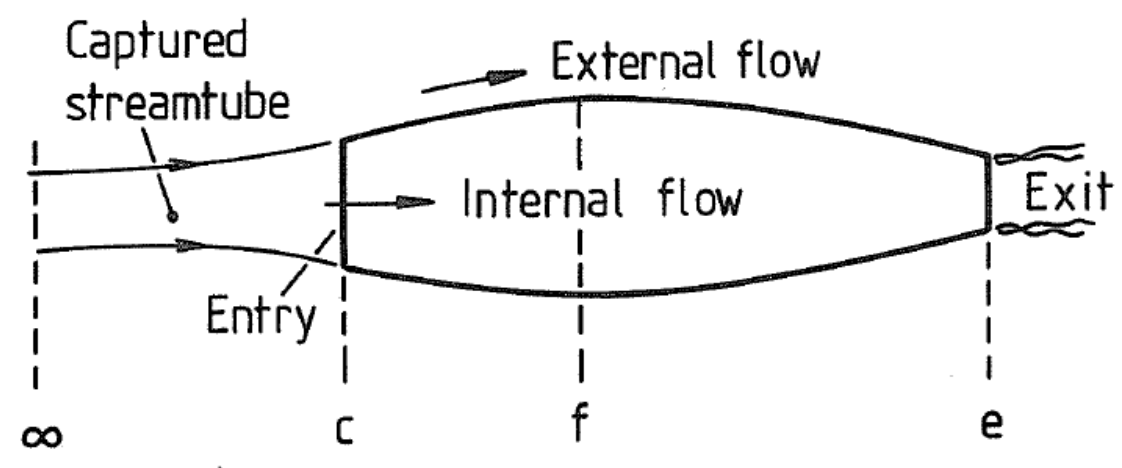

Figure 1.1: Aerodynamic duct concept[56]

time. Basically, the role of an intake is to deal with mismatch between the free stream flow conditions and those required by the engine. Therefore, air vehicle working envelope is shaped by the intake characteristics and engine specifications in a great extent.

Ideally, the intake captures the undisturbed air at the free stream through a stream tube and try to transport captured flow to the engine with minimum loss and maximum uniformity. Captured flow drawn into the engine via intake referred as internal flow as shown in Figure 1.1. Since intake captures only the some part of the incoming flow, there is always intake effect on the external flow around airframe. Therefore, intake designers deal with not only internal flow characteristics but they also have to consider intake effects on the external flow.

Figure 1.1 illustrates the aerodynamic duct concept. Every part of the intake duct shown in this figure has its own characteristics. Throat size, intake area distribution through the throat to engine face must be carefully adjusted in order to meet the engine demand. Intake types vary with the free stream Mach number. Generally, except ground conditions velocity of the free stream flow is reduced such that 0.4 Mach or similar values depending on the engine type is reached at the engine face. For subsonic intake this reduction provided in the stream tube and inside the intake by streamwise area increase. For supersonic speeds pre-designed system of shock waves triggered such that losses lies in the acceptable extent. With the help of pre-designed shock wave pattern some amount of compression can be achieved.

In some particular applications whole or part of intake entrance is buried in to the 


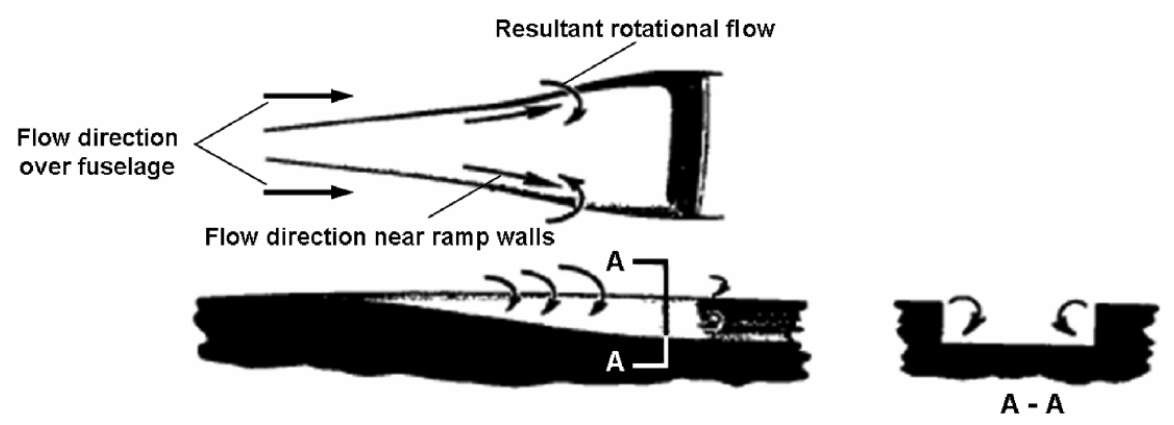

Figure 1.2: Naca submerged air intake illustration[14]

airframe. Demand of reducing overall weight and external drag leads to such design examples. Since this type of intake ducts promises lower radar cross section they gain importance day by day especially in the defence industry. One of the most important example of this type of intake designs are called NACA submerged inlets shown in figure 1.2 The idea behind this particular design is to provide vortex structure such that upcoming boundary layer cleared of before it reaches to the throat. In other words ramp geometry with side walls upstream of the throat operate as a diverter and high entropy flow is sweeped into the external flow. Although this type of design offers several advantages over the intakes which are placed nose of the airframe or leading edge of the wings its application is limited by the severity of upcoming boundary layer and NACA type intake design is unsuitable for supersonic and even high subsonic speeds [56].

Most of the cruise missiles, which generally uses turbojet or turbofan engines, fly in the transonic regime. Typically, fore body sections of missile body carries warhead, seeker and electronics, intakes on such missiles are placed through the aft sections of the fuselage where a thick boundary layer exists. Furthermore, since packaging efficiency, low drag and low radar cross section have crucial strategic importance for military applications, serpentine intake designs shown in the figure 1.3 are very popular among these type of missiles. However, thick boundary layer ingested by the submerged or semi-submerged serpentine duct can lead to severe performance degration on intake which has a significant influence on whole air vehicle system. General trend to solve this problem is to isolate the intake from fuselage with diverter heights equal to or greater than the upcoming boundary layer thickness. However, in some cases like 

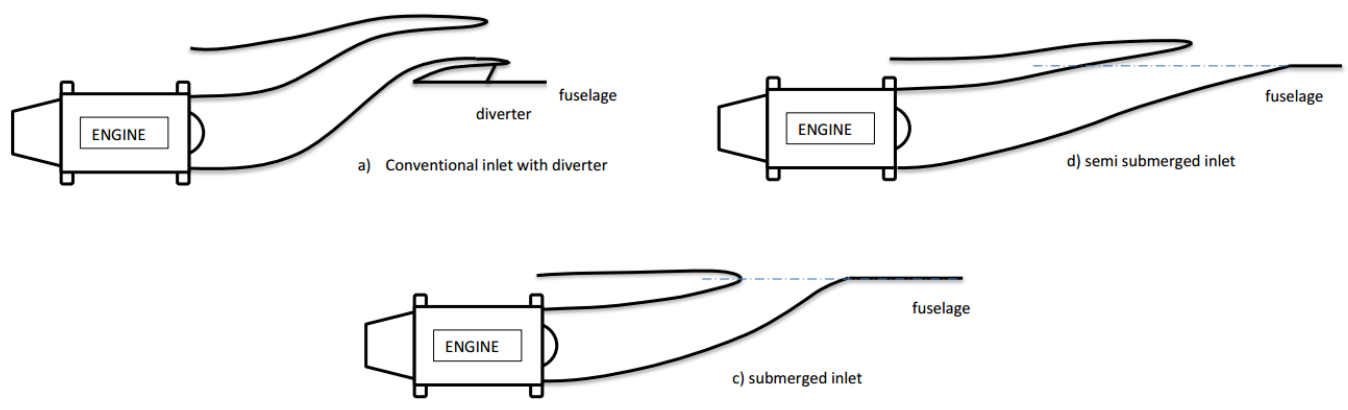

Figure 1.3: Intake types mostly used in cruise missiles 9

missiles hired from internal bay of aircraft or closed tube there can be no enough places to the diverter. In such a cases submerged or semi submerged intake designs become mandatory.

\subsection{Serpentine Diffusers}

Serpentine inlet provides ability for designers to align engine centerline into the body of the air vehicle. This ability offers number of benefits including less weight, less drag, less fuel burn, lower noise and lower radar cross sectional area 19, 17, 25]. The short length of serpentine inlet increases packaging efficiency and reduces the weight of the overall aircraft. This compactness improves the maneuverability which is especially crucial for military aircrafts and missiles. Moreover, serpentine inlets decrease fuel consumption by reducing drag due to viscous forces and drag due to lift since they are directly related to wetted area and weight of the air vehicle. Furthermore, due to very strict regulations noise becomes critical issue especially in commercial engine business and hiding engines into the airframe by using serpentine inlets have potential to reduce noise level significantly.

Besides those advantages of serpentine inlets, there is another important benefit of a serpentine inlet which is especially crucial for military air vehicles. Modern military aviation technology requires stealth technologies in order to gain advantage over the enemy's defense and attack systems. Electromagnetic waves reflecting and scattering from jet engine inlets are the major contributor of the overall radar cross section.[10] By burying engine into the airframe, radar waves cannot fully reach the compressor 
blades and additionally since hot sections of the engine are located into the airframe, shielding the infrared signature of hot spots and exhaust gaseous is more applicable when serpentine inlets are utilized[49].

Because of the benefits mentioned, serpentine inlets gaining importance day by day. Actually serpentine inlet is not a new concept, first serpentine inlet was seen in early 1960's at Hawker-Siddeley Trident which is a commercial aircraft. Some of the example air vehicles which configured with serpentine inlets are Boeing 727, General Dynamics F16, McDonnel Dougles F-18 and F-5EC[21, 66]

However, although serpentine inlets have a number of benefits over the typical inlet configurations, due to the centerline curvature, it is very likely that secondary flows will occur in the serpentine inlet which causes total pressure loss, distortion and swirl.

Next sections include, researches found in literature investigating flow development and characteristics of flow in serpentine inlets, pressure recovery, distortion and flow control methods and devices used in order to manage flow inside submerged serpentine inlets.

\subsection{Flow Characteristics in Serpentine Intakes}

As mentioned earlier, intake geometries with centerline curvature and short lengths provide some benefits over the traditional intake ducts. In todays aircraft business overall air vehicle size, weight and more importantly strategic requirements enforce designers to use shorter ducts with high centerline curvature. However sharp curvatures with high adverse pressure gradients can easily lead to unacceptable flow characteristics inside the serpentine intakes which result in low efficiency or even severe structural damage at compressor blades. Therefore flow characteristics in the serpentine inlets must be well understood.

Almost every work which investigates flow mechanisms in the serpentine ducts shows that there is a pair of vortices which results in total pressure distortion and loss 52,64 , 63]. Work conducted by Rowe at 1970[52] investigates incompressible flow characteristics in a bend. They found that pressure gradients due to curvature of the serpentine inlet trigger the vortex generation. Another experimental study conducted by Well- 
born et al[63]. In their work flow in serpentine inlet was investigated in compressible flow regime and they observed the large stream wise separation region. Additionally they find that duct curvature creates severe pressure driven secondary flows and this secondary flow evolves into pair of counter-rotating vortices. There is also recent computational work[15] which analyses flow in the serpentine inlet with commercial CFD code FLUENT. This work shows direct relationship with vortices and the turn angle of bend. They stated that as the angle of turn increases magnitude of the counter rotating vortices also increase.

Centrifugal force originating from the first bend of the serpentine inlets is the main reason of the pair of counter-rotating vortices which increases total pressure loss and distortion occurred at the aerodynamic interface plane(AIP). For an uniform, inviscid flow with no velocity deficit near the wall, centrifugal forces originating from the curvature of the first bend are only changing with local radius. Therefore flow at the inner region exposed to higher centrifugal forces compared to the flow at the outer region of the first bend. Furthermore, as a result of this force imbalance static pressure increases at the outer region in order to balance this force inequality.

At the same time for a real flow with a velocity deficit in the thin layer developed on the wall, situation becomes much more interesting. Centrifugal forces acting on the low energetic flow in the boundary layer pushes flow to the outside of the first bend where there exist an adverse pressure gradient originating from the centrifugal force imbalance. However, since flow in the thin layer already lost its momentum, centrifugal forces acting on it become insufficient for the flow in the thin layer to pass through the adverse pressure gradient region. Instead flow reversed to the low static pressure region near the wall. This creates pair of counter rotating vortices which induces vortex lift off effect seen in the figure 1.4 . 


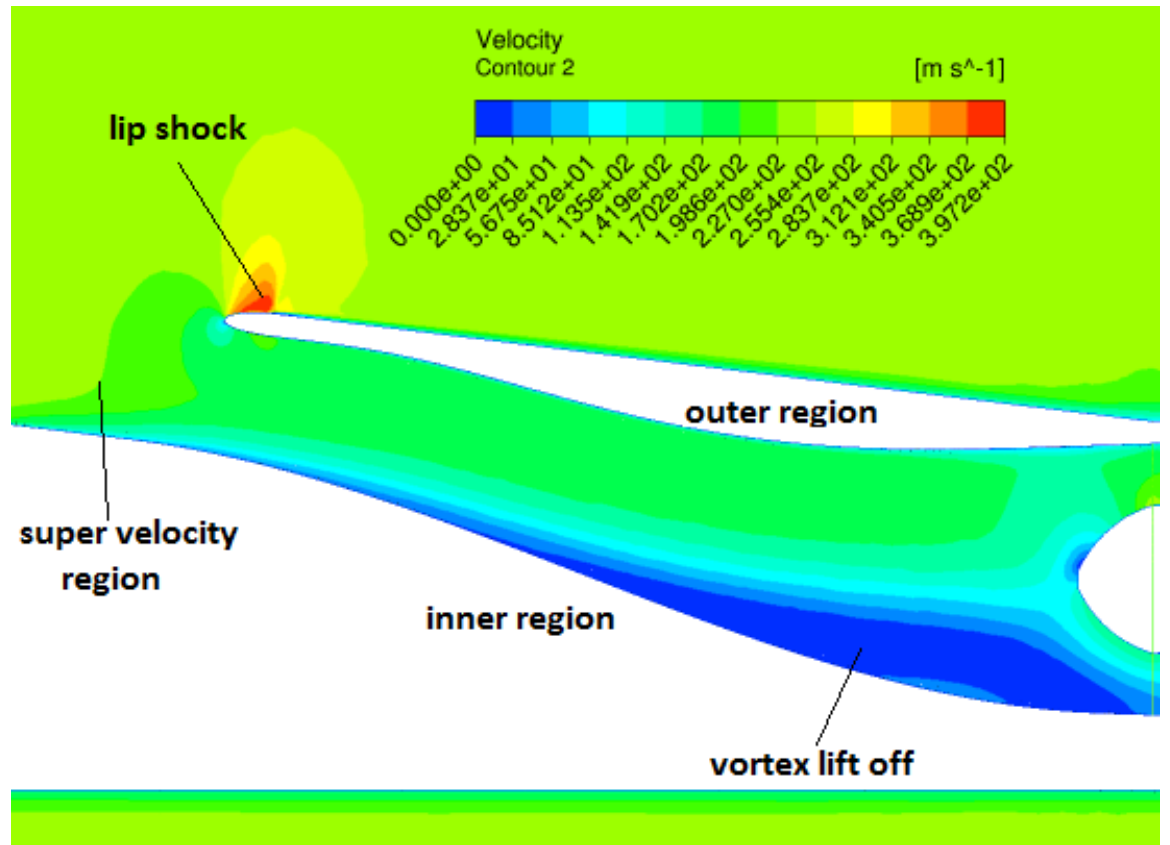

Figure 1.4: Velocity contours at the symmetry plane of investigated intke

Although it seems to be logical that second bend of the serpentine duct balances the negative effects of the first bend due to the its opposite curvature, since low momentum fluid already gathered at the inner region of the duct this is not the case. Therefore migration of the high entropy fluid flow occurred at the serpentine intake is an irreversible process by its nature[4]. Schematic representation of secondary flows developed inside serpentine intakes is given in the figure 1.5

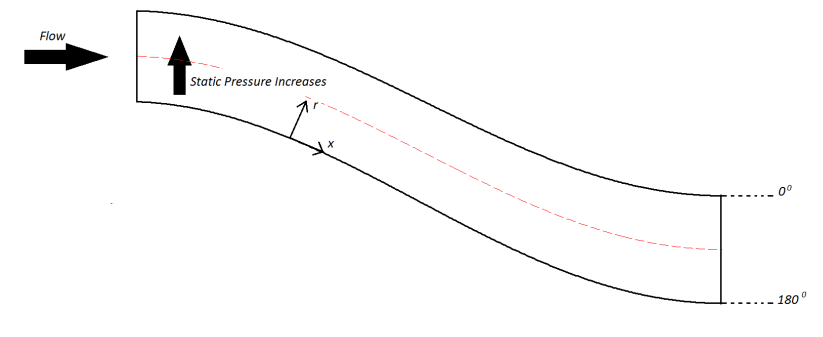

(a) Side View

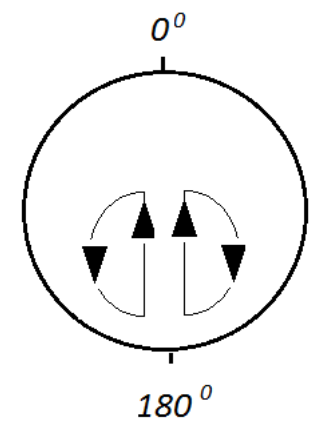

(b) Cross Sectional View

Figure 1.5: Schematic representation of flow characteristics inside serpentine intakes 
The flow curvature originating from geometric offset of the serpentine inlet has another interesting effect on the flow characteristics. The flow curvature at the first bend accelerates the flow at the inner region and it creates favorable pressure gradient at just upstream of the inlet throat. This phenomenon was realized in the experimental study conducted by Blackwelder et al[4]. This study investigates two intakes simultaneously one with centerline offset and the other with same diffusion ratio, length and size but without an centerline offset. After the experiments they realized the difference between the boundary layers formed in front of the inlet throat. Although they carried out the experiments with same conditions and apparatus, the measured boundary layer thicknesses and velocity profiles at the same upstream distance from the inlet throat was inconsistent. They validate their results with different measurement devices several times and at the end they had noticed that strong favorable pressure gradient originating from the flow curvature causes such a difference. This favorable pressure gradient is the reason of high speed region at just upstream of the inlet throat as seen in the figure 1.4. They called this high speed region closer to the first bend as "super velocity region".

\subsection{Concept of Boundary Layer Ingestion}

Boundary layer ingestion(BLI) refers to suction of low momentum flow developed on the airframe to the intake duct. Boundary layer diverters, splitters and bleed methods are widely used by the designers in order to prevent boundary layer ingestion. However this additional components on the airframe creates more drag, more weight and they increase radar cross sectional area which has high importance for military applications. At the same time, consequences of adverse pressure gradient in the cross flow plane originating from the centerline curvature becomes much more severe with boundary layer ingestion. Boundary layer ingestion creates not only total pressure deficit of the flow reaching at the AIP but also it can create severe structural and stability problems to the compressor.

However, theoretically boundary layer ingestion can increase the propulsion efficiency in a significant amount. The actual benefit of boundary layer ingestion is directly related to re-energizing air vehicle wake[47]. In order to reach specific amount of thrust 
more power must be added to the clean(i.e with no boundary layer) flow compared to less energetic(i.e with boundary layer) flow in the aircraft engine. BLI is commonly used for submarines and torpedoes 53 and NASA/BOEING blended wing body concept shown in figure 1.6 aims to benefit from boundary layer ingestion for decreasing fuel consumption[45].

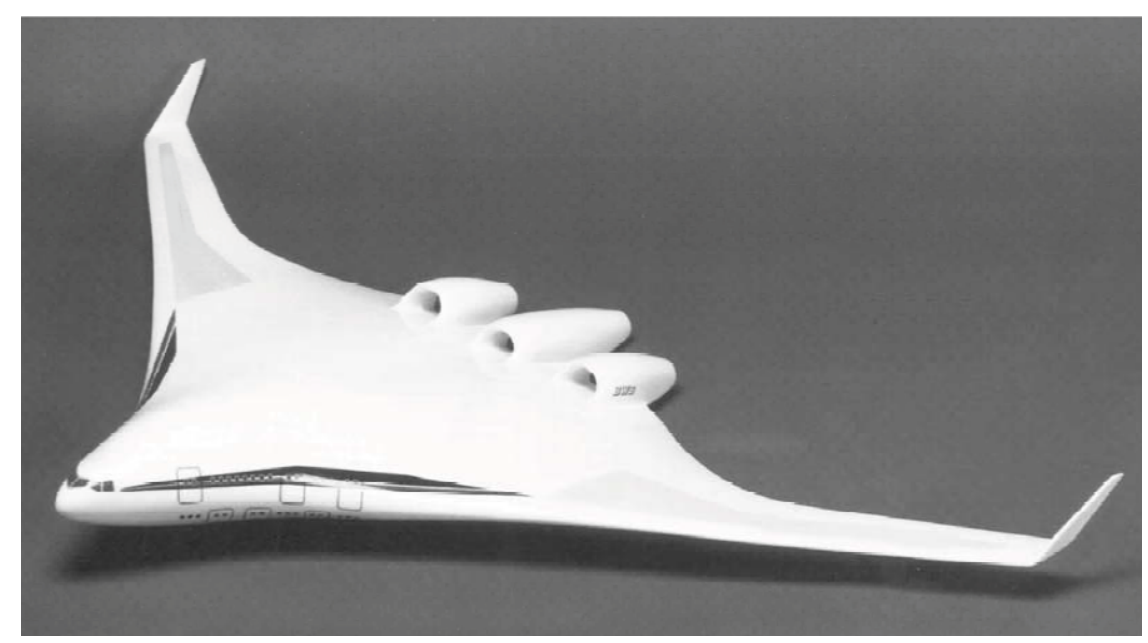

Figure 1.6: NASA/BOEING BWB concept 45]

Greitzer et al[46] explains origin of benefits of boundary layer ingestion by comparing two physical concept of propulsive systems one with BLI and other without BLI. Their characterization builds a relationship between the momentum deficit around airframe thus airframe drag with the thrust required for sustaining cruise condition supplied by propulsive systems. Furthermore, they clearly proves with mathematical expression that if aircraft boundary layer is ingested by the engine it requires less energy input to sustain cruise condition compared to the propulsive system without BLI. Other examples show that $20 \%$ or even greater range increase can be achievable with BLI propulsive systems [53, 58]. However this can only be possible with supplying sufficiently uniform flow to the engine through intake. Furthermore, BLI very likely lead to low intake pressure recovery values so that BLI systems can lead to significant amount of thrust which will be discussed later. Therefore response of the engine to the characteristics of the flow profile that formed at the engine face must be wellunderstood. Greitzer el al. stated that if inefficiencies, which are generally growing with boundary layer ingestion, like total pressure loss inside duct are included non- 
BLI system can be preferable depending on the magnitude of the losses. Another study 32 conducted at NASA Glenn Research Center investigates the effect of BLI on the turbojet engine system including duct losses. Their results show that benefit of BLI is almost zero or negative depending on the losses which are seen in real applications. Furthermore, they offer a new aircraft concept named N3-X shown in figure 1.7.

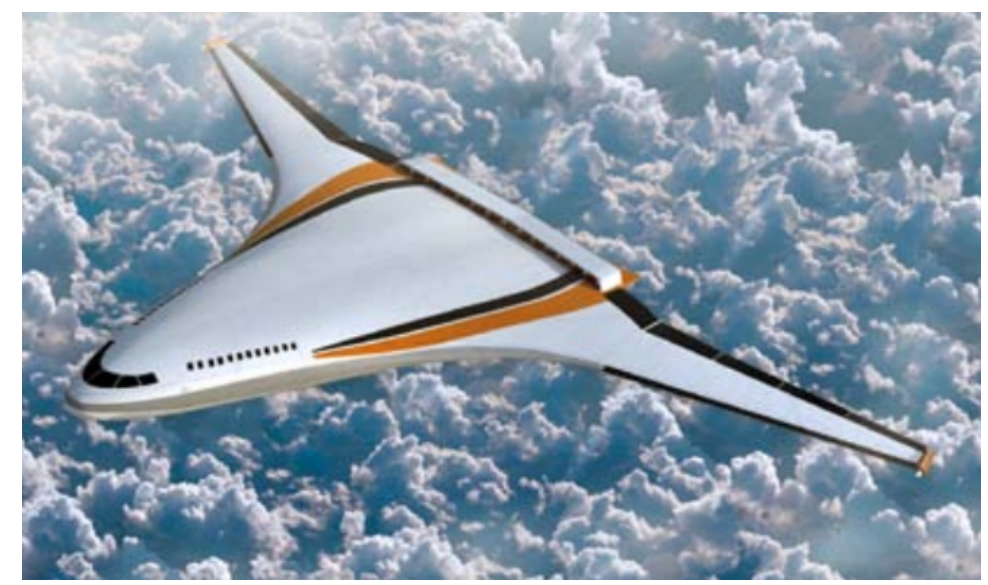

Figure 1.7: N3-X vehicle 32

The most interesting part of this concept is on the propulsion system. In this concept turbofan or turboshaft engines placed at the wing tips where undisturbed flow present. These engines located at the wing tips are working as an electric generators creating energy for electrically driven low pressure fan modules located across the rear fuselage in order to ingest boundary layer formed on the airframe.

Although BLI propulsive systems offer some theoretical improvements on the fuel consumption, for real applications things seems not that straight forward and duct losses increasing with BLI can easily result in decrease in overall system efficiency.

\subsection{Distortion}

Total pressure distortion, which is the indicator of the flow-non uniformity reaching AIP is one of the most important parameter effecting intake/engine compatibility. Compatibility problems between the engine and intake can be characterized with total pressure distortion[18]. If this characterization can be done for one or several forms of 
distortion, engineering procedure can be developed which leads to the intake designers during design process. Before discussion on distortion and its effects on compressor stability, it is appropriate to clarify definition of the AIP. Since it is not applicable to measure any flow quantity at the engine face when engine is operating, inlet designers constituted Aerodynamic Interface Plane(AIP) concept as a plane which is hypothetically placed at just upstream of the engine face where equivalent flow field with the engine face is obtainable[7].
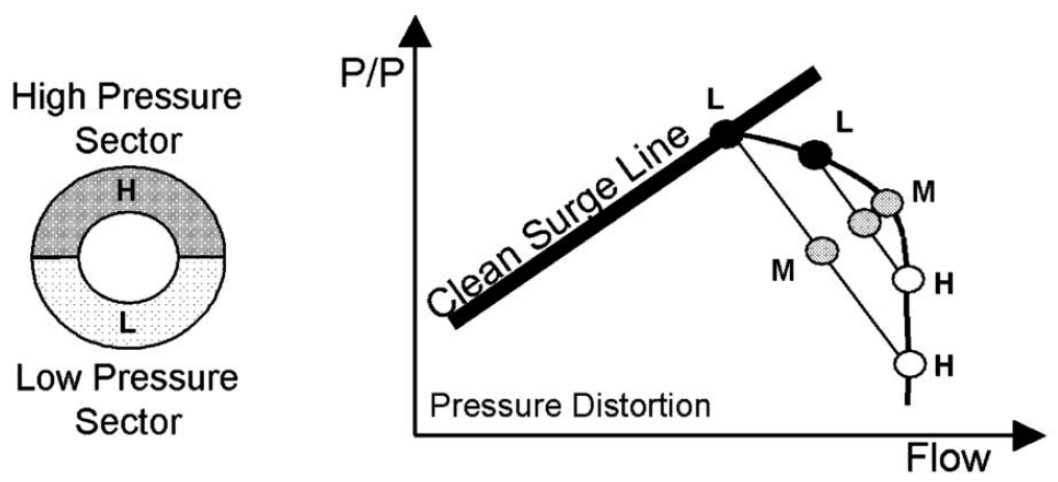

Figure 1.8: Effect of distorted (spoiled) region on compressor stability [35]

The performance of the rotor blades depend on the velocity triangles formed by the velocity components of the upcoming flow to the engine face and the rotor speed. Since total pressure distortion represents the non-uniformity of the flow components reaching to the engine face, there is a direct interaction between the compressor performance and flow distortion formed at the engine face. If flow distortion is severe, there is a significant change in velocity vector orientation at certain extent of the engine face and it can easily lead to compressor blade to stall. Furthermore, in some serious cases compressor surge which is combined with high level of structural vibrations, noise and severe structural damage on the compressor blades can occur due to flow distortion if extent of the distorted region is sufficient. General effect of the distortion is changing the compressor stability characteristics such that compressor surge line move towards the lower pressure ratio or higher mass flow values[39]. This can be characterized with parallel compressor theory[41]. In the parallel compressor theory a single compressor modeled as several circumferential compressor segments with equal area and these 
segments regarded as an identical, individual compressors working in parallel manner. Each segments have their own individual inflow condition with single and common exit flow condition. If the operating point of the distorted region reaches to the stability limit of the original compressor, distorted region stalls and if the circumferential extent of this region is sufficient surge will occur even when the mean operating point far from the original surge line[35]. Therefore distorted region shifts the whole compressor surge line closer to the operating point [56]. This is illustrated at the figure 1.8

Total pressure distortion formed at the AIP can be result of flow separation, boundary layer ingestion, ingestion of aircraft vortices developed on the airframe, lip separation or many other phenomenon that causes flow irregularity inside the intake duct. Distortion can be steady or unsteady, circumferential or radial. In real cases, always radial distortion present at the engine face due to boundary layer developed on the intake walls. Generally radial distortion is neglected and engine/intake compatibility is characterized with circumferential distortion. In order to define quantitative measure of distortion equation 1.1 is used.

$$
D C(\theta)=\left(P_{f}-P_{\theta}\right) / q_{f}
$$

In this equation $P_{f}$ and $q_{f}$ indicates the mean total pressure and the mean dynamic pressure at the engine face respectively whereas $P_{\theta}$ is the mean total pressure of the lowest value obtained at the engine face in a certain circumferential extent limited by the angle $\theta$. The $\theta$ must be selected carefully in order to represent intake/engine compatibility satisfactorily to build adequate engineering procedure. Generally $60^{0}$ is considered as the minimum satisfactory value [56]. Therefore being $D C(60)$ is most common, $D C(90)$ and $D C(120)$ descriptors are also used in order to measure the condition of engine/intake compatibility. Figure 1.9 shows an example of $60^{0}$ circumferential extent at which lowest mean total pressure value is obtained on the engine face of an investigated duct. 


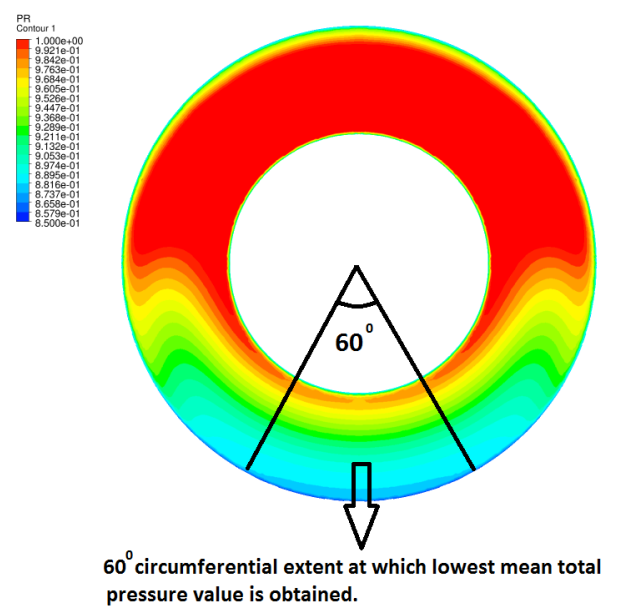

Figure 1.9: Pressure recovery contours at engine face with $60^{0}$ sector at which lowest mean total pressure is obtained.

If the distortion is steady state time averaged values of the parameters in the equation (1.1) has to be used. If dynamic distortion wants to be measured spatial average values must be taken at an instant in time. In the present work steady-state, circumferential distortion is investigated.

In order to calculate $\mathrm{DC}(60)$ values from computational results, area weighted average values are calculated on probe locations or equivalent slices each covering equal area. Since symmetry boundary condition was used for the computations collected for measuring effect of vortex generators on investigated intake duct half of the engine face are divided into 24 equal circumferential segments each covering 7.5 degree. For flow calculations these segments are named different names from Pal1 to Pal24 as shown in the figure 1.10. Area weighted average total pressure values for all these segments are collected and stored with simple journal file. Furthermore, it is assumed that circumferential segments which are not present in the flow domain due to symmetry boundary condition have identical properties with their symmetrical pairs. Finally, post processing is performed such that 60 degree circumferential extent which has lowest mean total pressure value is determined with all possible coupling options including circumferential segments which are not present in the flow domain. 


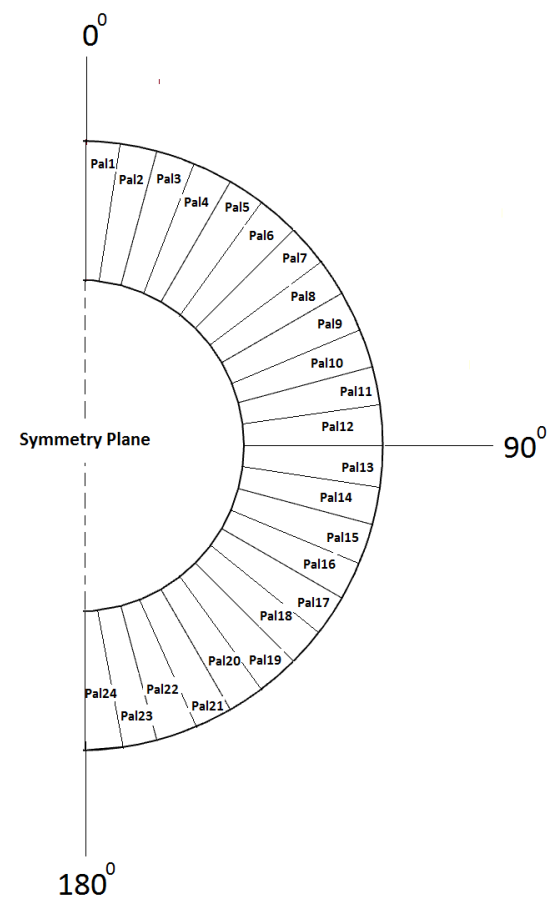

Figure 1.10: Engine face divided by 24 equal area segments for $\mathrm{DC}(60$ calculations $)$

\subsection{Pressure Recovery}

Intakes operating at high speed flow conditions work as compressor in order to provide adequate reduction in the velocity of the flow reaching to the engine face. This reduction in the velocity provided by the area increase in the streamwise direction such that static pressure increase actualize in most suitable way. If static pressure increase provided isentropically by the intake duct, there is no total pressure decrease inside the intake which leads to highest possible thrust values with least fuel consumption. However, there is always loss in total pressure in even straight ducts emitting undisturbed uniform flows, due to the formation of entropy reach flow on the intake walls.

Pressure recovery which is an indicator of the efficiency of an intake measures the ability of an air intake to convert free stream energy into the usable energy for the engine components. Flow is being sucked by the engine in low speed operating conditions. Therefore in low speed applications, static pressure exposed to overall reduction opposite to the high speed operating conditions. That is why it is practical to use total 
pressure in the definition of the pressure recovery. Pressure recovery of an air intake defined as;

$$
P R=P_{f} / P_{t \infty}
$$

In the equation $1.2 P_{f}$ and $P_{t \infty}$ represents mean total pressure values at the engine face and free stream respectively.

Although effect of pressure recovery on engine performance depends on the engine itself, reduction in pressure recovery directly results decrease in engine thrust and this loss can be characterized by the equation 1.3 where $\mathrm{X}$ represent thrust and $\mathrm{K}$ is a factor greater than 1 but depending on engine type 56$]$.

$$
\triangle X / X=K \times \triangle P / P_{t \infty}
$$

Actually for any type of inlet total pressure losses occur in three ways [56]; friction on the walls, turbulent mixing associated with flow separation and shock waves. Welldesigned and typically podded engine offers pressure recovery values as high as 0.995 , for a S-duct this value can easily decrease to $0.95[39$, and it gets even more smaller when the boundary layer ingestion comes into the stage. 


\section{CHAPTER 2}

\section{LITERATURE SURVEY}

In this chapter flow control methods especially applicable to the boundary layer ingesting serpentine inlets are mentioned with experiences found in the literature.

\section{$2.1 \quad$ Flow Control}

Flow control methods have significant influence on all major areas of aeronautical engineering. Characteristics of external or internal flows, combustion instabilities and management of transition from laminar to turbulent flow are the best-known examples where benefit from flow control methods with small energy usage can be gained[30]. As already mentioned before, serpentine inlets with large amounts of boundary layer ingestion are much more prone to the total pressure loss and total pressure distortion compared to the any other common inlet configurations. Therefore, in order to benefit from boundary layer ingesting serpentine inlets it is common to use several flow control methods which are covered under two main topics: active flow control and passive flow control. Typically this classification is based on the external energy requirement of flow control method[30]. Active flow control corresponds to the methods in which external energy is needed to operate flow control devices such as ejectors used for suction or blowing. At the same time, passive flow control corresponds to the other flow control methods in which no external energy is needed for operating flow control devices such as vortex generators. In some cases it is possible to see hybrid usage of these two methods.

Both active and passive flow control methods has their own advantages and disadvan- 
tages. Generally, installing and maintaining passive flow control devices are relatively straightforward compared to active flow control devices. However, since active flow control techniques are much more adjustable to the peripheral changes, these methods provide additional performance improvements over the whole flight envelope. However, at the same time in some scenarios it is also possible to adapt passive flow control devices for the variable flow conditions. Such as changing vortex generator heights one flight condition to the another[30]. Boundary layer suction, boundary layer energization with flow injection and vortex generators are the main flow control methods used in order to manage difficulties seen in the boundary layer ingesting serpentine inlets. Although with some particular designs suction or fluid injection can be supplied without external energy usage as in the worked collected by Watterson and Raghunathan[62], examples of such flow control methods generally required external energy. At the same time vortex generators which are small protuberances are used as an pure passive flow control devices.

\subsubsection{Suction}

Idea of suction type flow control depends on removing low energetic fluid flow developed in the boundary layer. With this method, reduction in the total thickness of boundary layer and modified shape of boundary layer profile with less velocity deficit can be obtained.

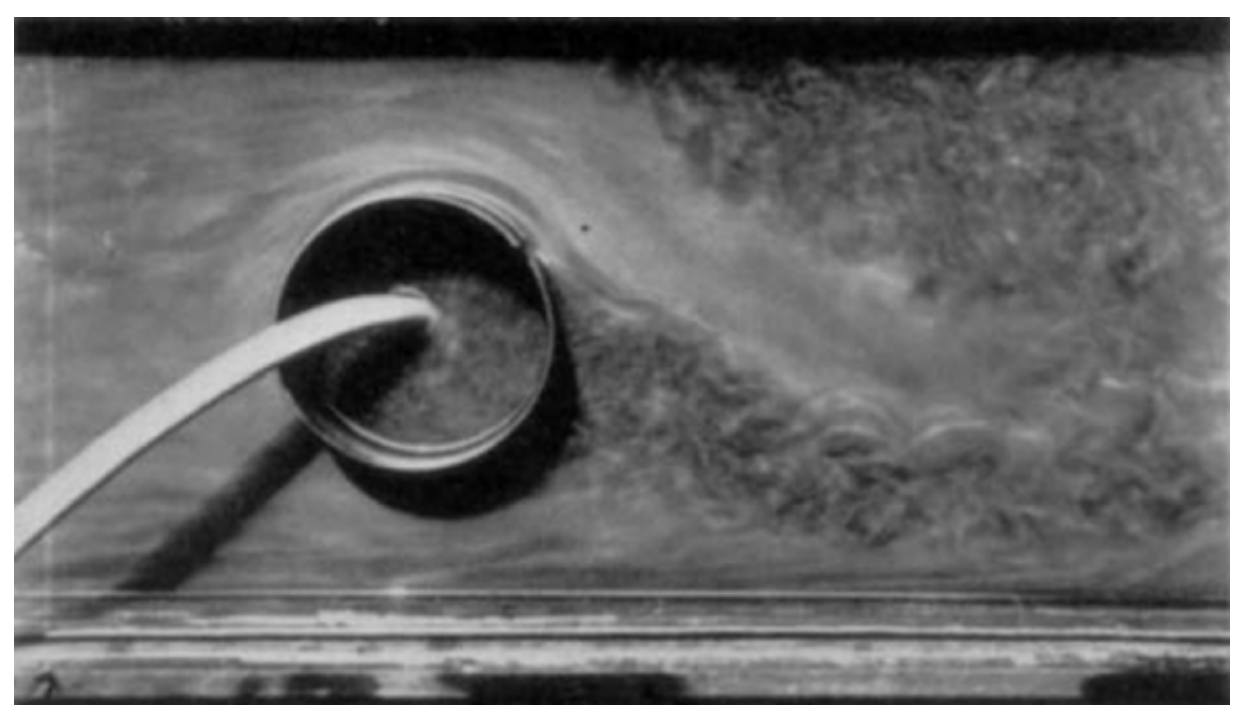

Figure 2.1: Flow past a circular cylinder with suction on one side [54] 
The first study for delaying separation by the effect of suction conducted by L.Prandtl. He used steady suction method for removing boundary layer on the walls of cylinders. He published a very dramatic flow visualization photograph which shows the ability of suction to prevent separation from one side of a circular cylinder 54]. The related photograph is shown in figure 2.1 which demonstrates adhered flow to the surface on one side of cylinder by the effect of suction. After Prandtl's findings boundary layer suction applied to the airplane wings in order to delay stall angle. Since effect of boundary layer profile on the serpentine inlets are similar to the those seen in the other aerodynamical problems, boundary layer suction is widely used by the intake designers. Boundary layer suction can be applied with both passive and active flow control methods. By the means of passive control method, boundary layer suction is provided with the some pressure difference between the flow around the airframe with low static pressure and boundary layer flow. At the same time boundary layer suction can be performed with the help of simple ejectors. This type of ejectors generally requires high energetic flow from early stages of the compressor to create a pressure difference. Vacuum created by the pressure difference draws the low energetic flow into another duct or array of suction holes rather than the engine.

Bleed is one of the useful methods for boundary layer suction. Actually in the jargon of intake aerodynamics, the bleed term indicates a separate duct which leads the boundary layer away[56]. It is possible to find two type of bleed which called as ram(pitot) and flush bleed. Ram bleed is aligned with the incoming flow whereas the inlet face of flush bleed is just on a level with the aircraft surface. In order to flush bleed to operate, they are generally placed at a region where substantial amount of pressure rise is achieved so that pressure difference leads the flow into the bleed duct. For the ram type bleed, flow enters into the bleed duct by the dynamic pressure of the incoming flow. It is also possible to sucked significant amount of boundary layer with the number of holes located at a defined wall region called as perforated surface [22, 38]. These three bleed systems designs are illustrated at figure 2.2 .

Since bleed system reduces negative effects of shock-boundary layer interactions in supersonic inlets where compression achieved with pre-designed shock structure, benefits of bleed systems mainly emphasized for the supersonic inlets in the literature. Properly designed bleed system can provide higher total pressure recovery and less distortion 


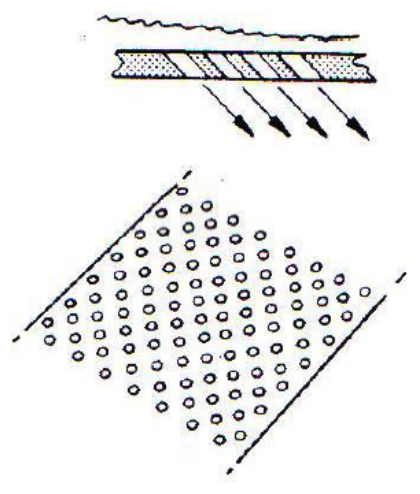

(a) Perforated Wall

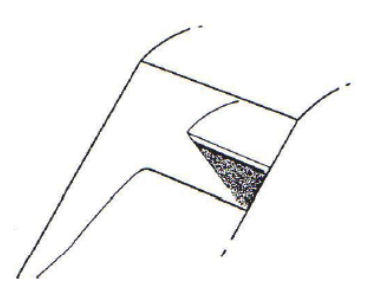

(b) Flush Bleed

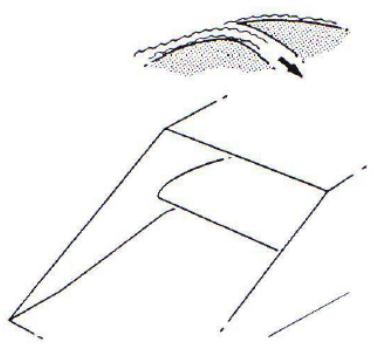

(c) Ram Bleed

Figure 2.2: Different Bleed System Designs 27]

occurred at the engine face by preventing separation originating from negative effects of boundary layer shock interactions 23,12 . Furthermore, even with hypersonic inlets bleed methods can be effectively used. Work collected by Dirk et al[55] show that with very limited bleed mass flow corresponding $\% 60$ of the mass flow in the boundary layer signifant amount of reduction in separation is achievable. However, bleed ducts increases total weight of the air vehicle and drag. Furthermore, since bleed mass flow rates can be significantly large, oversize inlet throat designs are needed for many situations. Therefore it would be very beneficial if flow control technology which adds less drag and weight to the overall aircraft is employed instead of bleed method.

\subsubsection{Blowing}

Blowing as a flow control method indicates injection of additional energy to the fluid particles in the boundary layer in order to prevent separation[54]. Furthermore it is an effective way to use blowing for reshaping flow structure inside the intake duct such that flow ejectors placed with jet pitch angle and jet skewed angle with respect to incoming flow[8]. Several studies investigated effect of active flow control on boundary layer ingesting serpentine diffusers, with ejectors placed normal to the oncoming flow with a $30^{0}$ degree upward incidence from the local surface in order to destroy or weaken the counter rotating vortices originating from the centrifugal forces inside the inlet [45, 26] and it is shown that this arrangement is effective.

Blowing devices in other words ejectors used for flow control inside intake ducts requires 
high energetic flow to operate. Required energetic flow generally corresponds to $1 \%$ to $2 \%$ of the total mass flow rate and supplied from the early stages of the compressor. Although this indicates consumption of work done by compressor it is possible to gain significant increase in stability margin when blowing efficiently applied. Study conducted by Rabe et al[48 show that with only $1 \%$ of the inlet mass flow rate $55 \%$ increase in stability margin is obtainable. Furthermore, some investigators use suction and blowing simultaneously[26, 31, 24] in order to prevent advantageous of both flow control methods. This simultaneous action generally supplied by high pressure jets which are basicly driven by venturi effect such that suction of the low energetic flow is carried through low pressure region obtained by high energetic flow and both high energetic flow and sucked flow can be inject for flow control as shown figure 2.3 .

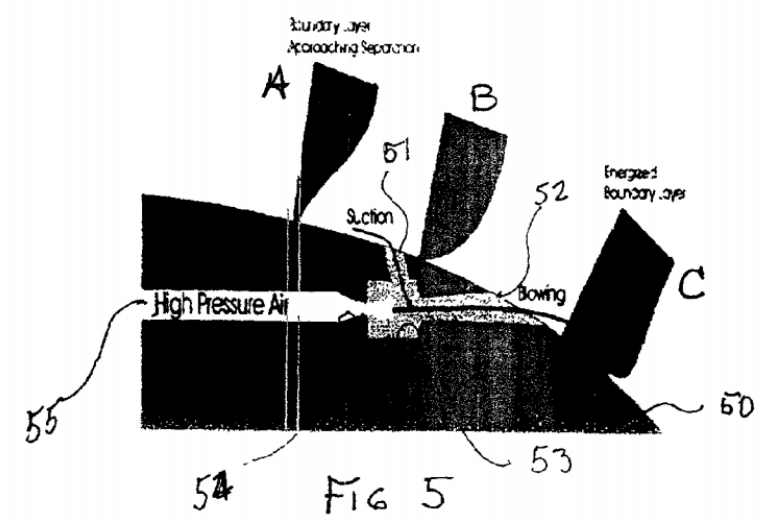

Figure 2.3: Blowing and suction via single ejector[20]

\subsubsection{Vortex Generators}

In order to increase aerodynamic efficiency for various aircraft components, it is common to use set of vortex generator(VG) arrays regardless of flow regime. VGs can be used for tripping laminar flow or re-energizing low energetic boundary layer flow near the wall by creating stream wise vortices which enables mixing low momentum flow in the boundary layer with the high energetic flow at the main stream so that flow separation can be prevented. However for a serpentine inlet redirecting flow inside the duct can provide further benefits compared to the mixing only. Reichert and Wendt [50] emphasize the possible benefits of redirecting the flow in S-ducts. Their work shows a clear evidence about further benefits of redirecting flow compared to the 
mixing only, they clearly states their assessment about the possible greater aerodynamic performance improvement for a three dimensional flow by the redirecting flow instead of relying only the mixing provided by the VGs. This redirection originated by VGs neutralize the natural vorticies arrived from curvature of the serpentine inlet.

For redirecting the incoming flow, co-rotating vortex generators can be used. It may be possible with the co-rotating vortex generators to condition the total pressure at the engine face more uniformly by creating a new secondary flow field which destroys the counter rotating vortices originate from curvature of the serpentine inlet. Counter and co rotating VG arrangements are shown in the figure 2.4 .
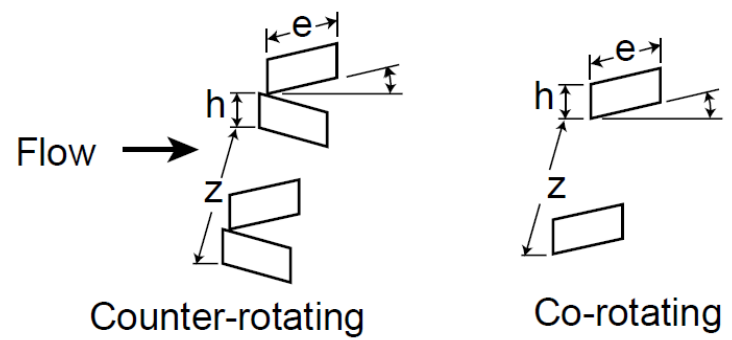

Figure 2.4: Counter and co- rotating vortex generator configurations 36]

At the same time, counter rotating arrangements are more suitable for increasing mixing effect of vortex generators. Although counter rotating VGs are successful in suppressing separation, natural vorticies occurring in serpentine inlet will remain and these natural vorticies cause high total pressure loss and distortion at the engine face. Comprehensive review about the vortex generators conducted by the Lin[36] emphasizes the greater effectiveness of co-rotating vortex generators compared to the counterrotating vortex generator configurations for 3-D flows such as those in the serpentine inlets. Therefore it can be said that results obtained by Reichert and Wendt[50] are compatible with findings mentioned in the review conducted by Lin[36].

Conventional vortex generator heights generally are on the order of boundary layer thickness, at the same time vortex generators which has height between $10 \%$ and the $50 \%$ of the boundary layer thickness are categorized with different names such as low profile vortex generators, submerged or micro vortex generators[36]. Since high vortex generator heights can increase the parasatic drag which dissipates aerodynamic efficiency obtained by the VGs, low profile VGs can serve more efficiently compared 
to the conventional VGs in certain conditions. Furthermore, especially for supersonic flows, since low profile VGs are submerged into the boundary layer, they have much less interaction with the high speed flow compared to the conventional VGs which reduces possible wave drag increase. Low profile vortex generators are much more suitable for preventing adverse effects of shock/boundary layer interactions in transonic and supersonic applications[37]. Low profile VGs are especially more efficient in the situations where seperation point is more or less the same and the generators can be located comparatively closer to the upstream of the separation point [36].

Vortex generator height, length, vortex generator spacing and inclination angle can be used as an optimization parameter as well as distance between vortex generators and the separation point. Generally these parameters are non-dimensionalized with the boundary layer thickness or the inlet entrance height. Although the other geometric parameters can be used for this purpose, boundary layer thickness seems most reasonable among them since it directly relates the geometric properties of vortex generator with the entropy reach flow which degrades S-duct performance. In the optimization study[29], vortex generator height and its distance from separation point come forward as a two dominant design parameter effecting distortion management.

There are several types of vortex generator such as vane, wishbone, doublet and ramp. Although each of these has different characteristics, their function is quite same. Typical vane type triangular or rectangular vortex generators which are usually placed with an inclination angle with the incoming flow act as a small lifting surfaces and they create an axial vortex moving to the downstream. Wishborne type vortex generators can be used for increasing effect of mixing, because they create strong pair of counter rotating vorticies 65]. Influence of a single wishbone vortex generator is similar with the closely spaced pair of counter rotating vane type vortex generator. Ramp and doublet VGs act as a pair of vane type VGs placed such that trailing edges of the VGs are closer compared to the leading edges 60] as shown in the figure 2.5. Second ramp, which is closely placed to the first ramp, seen in the doublet VG configurations increase the vortex strength without requiring higher vortex generator height [36]. 


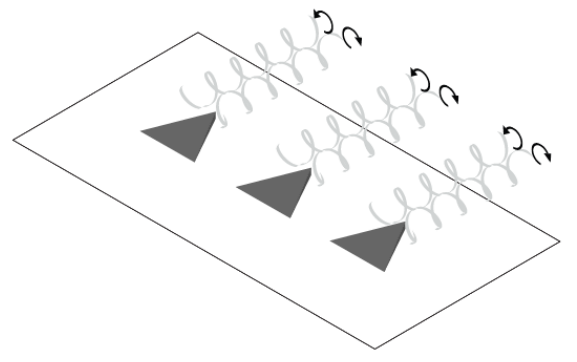

(a) Ramp VGs

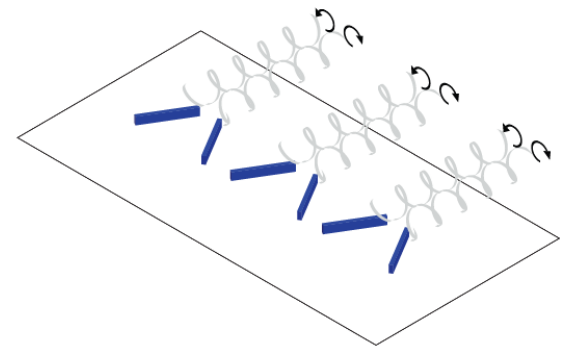

(b) Vange Vgs

Figure 2.5: Demonstration of counter rotating vorticies created by the ramp and vane type VGs 60]

Vortex generators as being small, robust and easy implement devices are used in many aerodynamic problems including serpentine inlets with and without boundary layer ingestion.

Tournier[61] investigated effects of VG's on the transonic S-duct inlet with the boundary layer ingestion. Inlet used in his experiments has a designed throat Mach number 0.6 and they simulate incoming boundary layer with the screen placed upstream of the inlet throat such that incoming boundary layer thickness is $20 \%$ of the inlet height at the design condition. Their results show that co-rotating VG arrangements provide higher pressure recovery and they are twice as effective compared to the counterrotating VG arrangements for reducing distortion at the engine face.

In the experimental study conducted by Reichert and Wendt [50], 20 different vortex generator configurations were tested to investigate their effects on curved diffuser performance. Arrays of VGs tested in this study include both co and counter rotating VG arrangements. Tests were performed at the duct inlet Mach number of 0.6 and the ingested boundary layer thickness was $4 \%$ of the duct diameter. Their best configuration was decreased distortion by more than $50 \%$ and increased pressure recovery by $5 \%$.

Theoretical and experimental work[6] show that $80 \%$ reduction in the engine inlet distortion can be achieved with vortex generators. In this study design of vortex generator set formed with CFD methods with the idea of managing secondary flows rather than suppressing separation inside serpentine inlet. In the end of this study, 
excellent agreement between the CFD results obtained via RNS3D which is an in house code developed by NASA/MOD joint aerodynamic program and the experimental results conducted in DRA/Bedford wind tunnel.

Another experimental study [4] investigates the effects of vortex generators on diffusing S-duct with large amount of boundary layer ingestion. Ingested boundary layer thickness by the S-duct has a height $27 \%$ of the inlet entrance which leads to poor performance for duct without flow control such that its $\mathrm{DC}(60)$ and PR values equal to 62 and 90.5 respectively.In this study array of VGs were able to decrease distortion to the acceptable levels such as $\mathrm{DC}(60)$ reduced to 18.5. However at the same time, vortex generators have only limited effect on the total pressure recovery. Furthermore, low profile VG arrangements investigated in this study were not effective for reducing circumferential distortion compared to the VG's with heights on the order of boundary layer thickness. Furthermore, it was also stated that the ineffectiveness of the low profile VGs may come from the limited number of installed VGs.

Another study [3], investigates the use of Design of Experimental methods for developing optimum vortex generator arrangements in order to increase performance of a boundary layer ingesting offset inlet at transonic flow condition. In this study numerical simulations are obtained with OVERFLOW which is a RANS flow solver developed by NASA. Two set of DOE optimization were carried out with using incidence angle and vg height as design factors for VG sets in co-rotating arrangement. VG heights were non-dimensionalized with ingested boundary layer thickness which corresponds to $30 \%$ of the inlet entrance height. In the end of study $\mathrm{DC}(60)$ was reduced 0.64 to 3.5 while keeping pressure recovery unchanged.

In the present work, effects of vortex generators placed in order to restructure the flow field inside the large amount of boundary layer ingesting semi submerged intake is computationally investigated. 


\section{CHAPTER 3}

\section{VALIDATION STUDY AND TURBULENCE MODEL SELECTION}

Flow inside serpentine inlets is exposed to high pressure gradients in both circumferential and stream wise directions. These pressure gradients cause flow separation and secondary flows, thus computational investigation of flow characteristics inside serpentine diffusers are challenging. In this chapter ability of the commercial CFD code Fluent14.0 in analyzing fluid flow and capturing the intake performance parameters of an serpentine inlet are investigated. In order to achieve this goal M2129 inlet geometry which is based upon AGARD Fluid Dynamics Panel Group 13 Numerical Sub group Test-Case 3[1] was chosen. There are two set of experimental data available in the literature for M2129 intake. One of the experimental data is conducted for the M2129 intake with cowl lip and the other for same intake but without cowl lip. Experimental data available for M2129 intake without cowl lip also includes vortex generator effects on the flow field inside this intake. In the current study, each case investigated and comparisons are made between the computational and experimental results available in the literature.

\section{$3.1 \quad$ M2129 Intake}

Flow inside RAE M2129 intake is computationally investigated with the commercial CFD code Fluent 14.0 for the validation study and turbulence model selection. This intake geometry introduced by the AGARD in 1991[1]. After its recognition it has been a subject of many experimental and computational works. Mohler[44, Menzies[43], 
Anderson [5] and Junsok et al. 67] are only some of the researchers who conducted studies with this intake.

This special intake has circular diffuser section with constant cross section region at upstream of the diffuser throat. After constant cross section region serpentine diffuser starts and just downstream of the diffuser another constant cross sectional region connects the intake and the engine face as seen in the figure 3.1 .

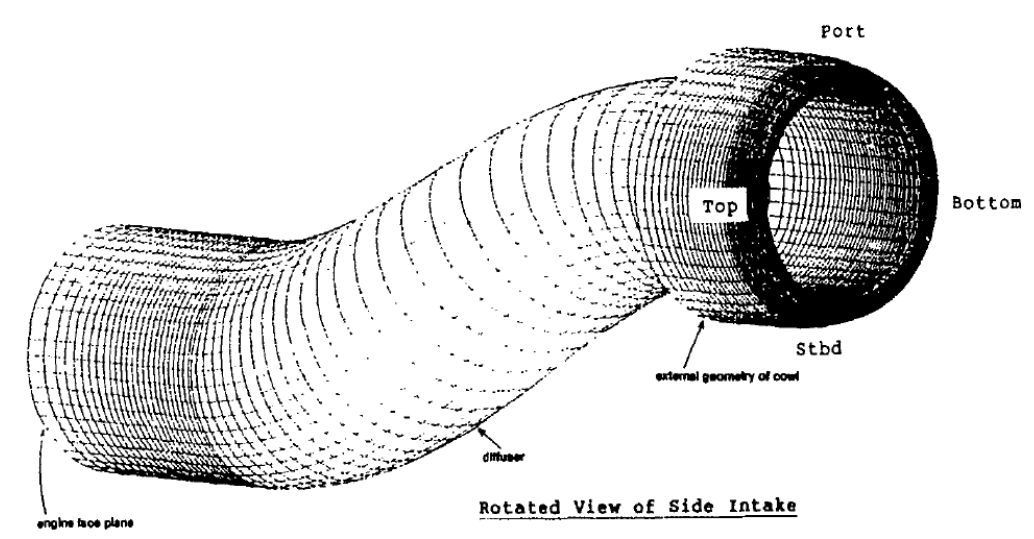

Figure 3.1: M2129 intake geometry[1]

The duct has circular cross section through its length and both constant cross sectional regions placed at both upstream of inlet throat and downstream of diffuser are one engine diameter long. The intake cowl has an ellipse shape with $1 / 4$ ratio. Diffuser part of this intake has an area ratio 1.4. Centerline curvature and radius distribution of the diffuser part are defined with the following equations;

$$
\begin{gathered}
Z_{c l}=-\Delta Z \times\left[1-\cos \left(\pi \times \frac{X_{c l}}{L}\right)\right] \\
\frac{R-R_{i}}{R_{e f}-R_{i}}=3 \times\left(1-\frac{X_{c l}}{L}\right)^{4}-4 \times\left(1-\frac{X_{c l}}{L}\right)^{3}+1
\end{gathered}
$$

With the geometric parameters given in table 3.1 .

The experiment which validation study based on performed by AGARD Fluid Dynamics Panel Working Group 13[1] is divided into two parts. First part is the experimental data collected from the experimental investigation of duct with the cowl lip and other 
Table3.1: Geometric parameters of M2129 intake

\begin{tabular}{cccc}
\hline \hline$R_{1}$ Throat Radius $(\mathrm{cm})$ & $R_{e f} / R_{1}$ & $L / R_{1}$ & $\triangle Z / R_{1}$ \\
\hline 6.44 & 1.183 & 7.1 & 2.13
\end{tabular}

is a duct without cowl-lip. In the first case simulated flow scenarios are based on capture flow ratio and free stream Mach number whereas for the second part simulations based on throat Mach number. Stagnation values for pressure and temperature are the essential conditions for both cases [67]. In this work, flow simulations for these two parts were investigated separately.

\subsection{Duct With Cowl-Lip}

In the experiment conducted for intake with cowl lip, data is available for two different flow case one with high capture flow ratio thus with high mass flow rate and the other with lower capture flow ratio thus with low mass flow rate. Because of the nature of the flow in the s-ducts, experimental case with high mass flow rate cause bigger separation region whereas low mass flow case results in smaller separation region in the S-duct. Flow conditions of high and low mass flow rate case stated by the AGARD given in table 3.2 .

Table3.2: Experimental flow conditions for HMFR case and LMFR case

\begin{tabular}{|cc|cc|}
\hline \multicolumn{2}{|c|}{ HMFR CASE } & \multicolumn{2}{c|}{ LMFR CASE } \\
\hline \hline Total Pressure & $29.889 \mathrm{in} \mathrm{Hg}$ & Total Pressure & $29.865 \mathrm{in} \mathrm{Hg}$ \\
\hline Total Temperature & $293 \mathrm{~K}$ & Total Temperature & $293 \mathrm{~K}$ \\
\hline Flight Mach Number & 0.21 & Flight Mach Number & 0.21 \\
\hline Capture Flow Ratio & 2.173 & Capture Flow Ratio & 1.457 \\
\hline
\end{tabular}

Capture flow ratio which defines magnitude of engine mass flow demand is used for determining boundary condition at the engine face. It is defined as ratio of areas formed by the leading edge of intake lips(capture area) to the area formed by the free stream lines coming to the intake. Following formula is used for calculation of capture 
flow ratio.

$$
C F R=\frac{A_{\infty}}{A_{c}}
$$

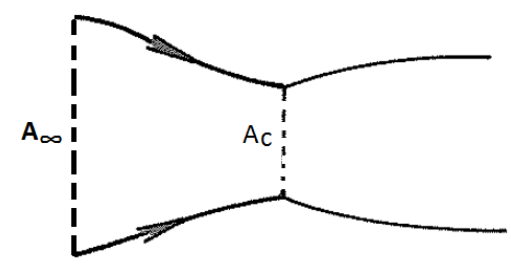

Figure 3.2: Capture area and free stream area enclosed by dividing stream Lines

\subsubsection{Numerical Model and Boundary Conditions}

For correctly analyzing the flow in S-ducts, it is crucial to select most suitable turbulence model and numerical approach. Although it is general methodology to use density based formulations for analyzing compressible flow in S-Ducts, there is an alternative way which is a pressure based coupled solver which significantly improves the convergence without compromising precision of solution. Pressure based coupled solver proved its capability to detect flow characteristics and performance parameters like PR and DC of a serpentine diffuser working in compressible regime in the earlier work conducted by Kumar et al[34. In the current work RANS solutions are collected with Pressure Based Coupled Solver with Least Square Cell Based method as proposed by Kumar et al[34]. For discritization 2nd order upwind schemes are used for 2nd order solution accuracy. Ideal gas assumption was made and Sutherland formula is used for viscosity modeling. 


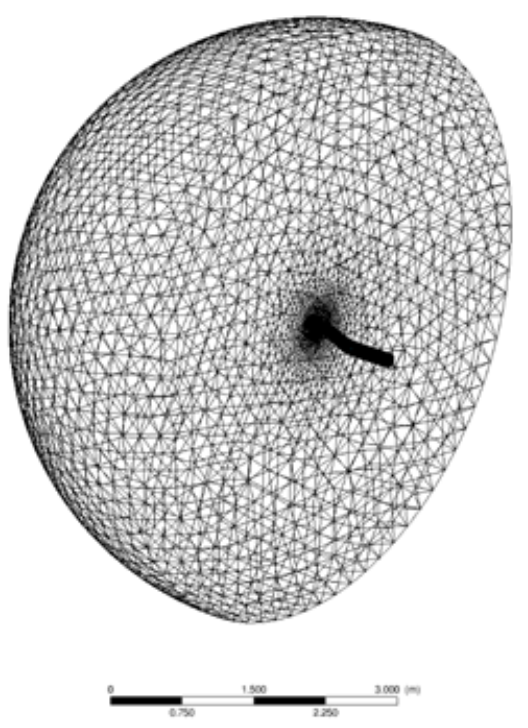

Figure 3.3: Computational flow domain

In order to sustain defined capture flow ratios in the set of experimental data a constant static pressure value is applied to the pressure outlet boundary condition. The outlet is placed sufficiently downstream to the engine face as in the experimental study in order to break up the possibility of reflection of disturbances at the outlet which can affect the upstream flow. Moreover constant static pressure boundary condition is applied to the engine face experimentally validated by Slater[57] and used by other researchers who computationally investigated serpentine inlets including M2129 intake [44, 43, 5, 67]. The value of the static pressure applied to the pressure outlet is adjusted in order to find closest value for capture flow ratios defined in experimental data. All other boundaries are defined as pressure far field whereas intake walls, lips and hub defined as no-slip wall. Flow domain shown in the figure 3.3 is a semi-sphere with a radius equal to 20 times the intake throat radius. Performance of three RANS turbulence models are evaluated and comparisons of the results are done with the available experimental data. Turbulence models used in the validation study are $\kappa-\omega$ SST(KWSST), Realizable $\kappa-\varepsilon(\mathrm{RKE})$ and Spalart Allmaras(SA) which are most widely used turbulence models in the aerospace industry.

Mesh used for the validation study is unstructured and near wall resolution is applied such that viscosity dominant section in the boundary layer resolved with high accuracy with the turbulence models used in this work which are KWSST, RKE and S-A. 
Boundary layer is composed of 20 layers and the $\mathrm{y}+$ value is close to the +1 across the intake walls. In order to use RKE with this mesh an enhanced wall treatment is used. Moreover curvature correction method is used for all three turbulence models. CFL number and number of iterations were held constant as 15 and 2000 respectively through the all analysis with all turbulence models and for both flow conditions.

\subsubsection{Mesh Sensitivity Analysis}

Mesh sensitivity analysis must be conducted before any type of computational analysis in order to find optimum grid size which minimizes computational cost and errors originating from excessive or inadequate grid sizes. Therefore, for computational analysis of flow inside M2129 intake three unstructured meshes with total number of 1219288 , 3479633 and 5927000 elements were created. The comparison of the results obtained from these three meshes with same boundary conditions and same turbulence model are given in the table 3.3 .

Table3.3: Results Of the mesh sensitivity analysis

\begin{tabular}{|c|c|c|c|}
\cline { 2 - 4 } \multicolumn{1}{c|}{} & $\begin{array}{c}\text { Coarse Mesh } \\
\text { \# of cells } \\
\mathbf{1 2 1 9 2 8 8}\end{array}$ & $\begin{array}{c}\text { Medium Mesh } \\
\text { \# of cells }= \\
\mathbf{3 4 7 9 6 3 3}\end{array}$ & $\begin{array}{c}\text { Fine Mesh } \\
\text { \# of cells }= \\
\mathbf{5 9 2 7 0 0 0}\end{array}$ \\
\hline$C F R$ & 1.479 & 1.491 & 1.493 \\
\hline$M_{A I P}$ & 0.313 & 0.315 & 0.314 \\
\hline$M_{t h}$ & 0.424 & 0.428 & 0.427 \\
\hline$P R$ & 0.983 & 0.989 & 0.989 \\
\hline$D C(60)$ & 0.260 & 0.245 & 0.246 \\
\hline
\end{tabular}

As it can be seen from the table 3.3, medium mesh gives almost identical results with the fine mesh therefore it is decided that for the purpose of this work it is reasonable to continue to the analyses with the medium mesh. Unstructured meshes around M2129 intake geometry created for mesh dependency analysis are shown in the figure 3.4 


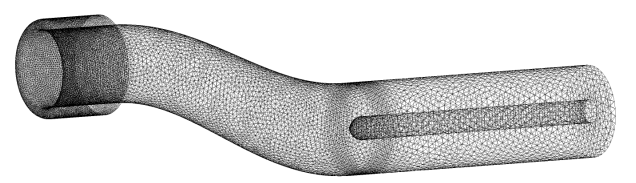

- - - -

(a) Coarse mesh- M2129 intake with cowllip

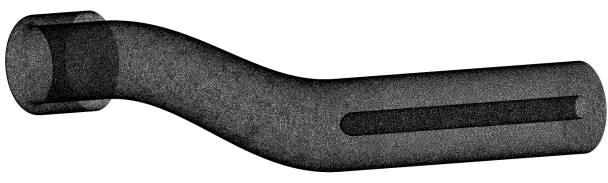

$$
\text { - - - - com }
$$

(c) Fine mesh- M2129 intake with cowl-lip (b) Medium mesh- M2129 intake with cowl-lip

Figure 3.4: Surface meshes around M2129 intake with cowl-lip

\subsubsection{Convergence Histories}

In order to reach confidence about convergence characteristics of the solution method, turbulence models and selected grid, continuity residuals and area weighted total pressure variation with each iteration was stored. Convergence histories of continuity and total pressure are given in the below figures. 


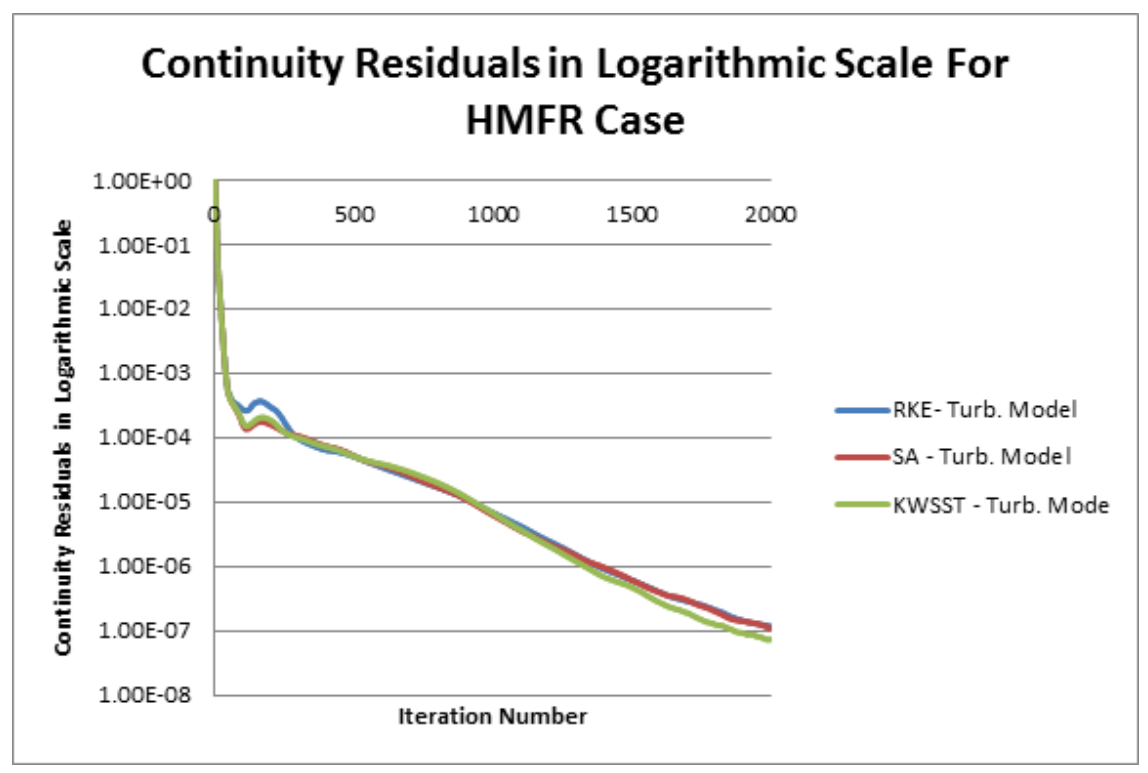

Figure 3.5: Continuity residual in logarithmic scale for HMFR case

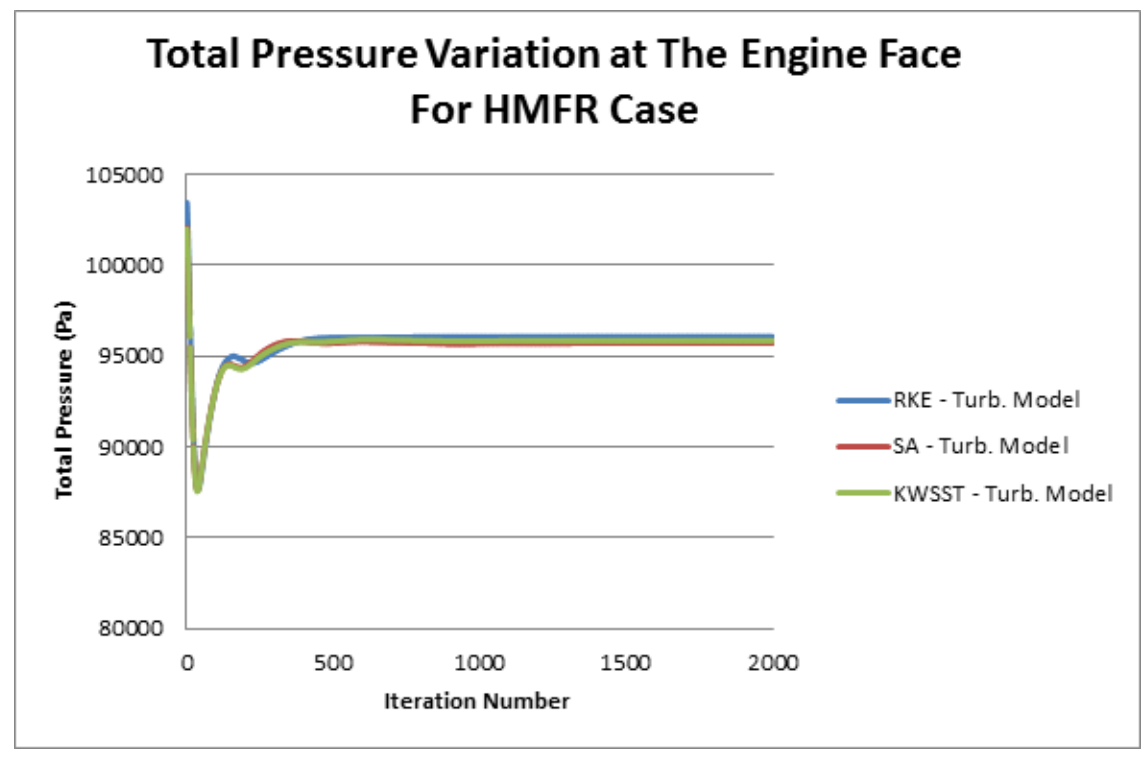

Figure 3.6: Area weighted total pressure variation at the engine face for HMFR case 


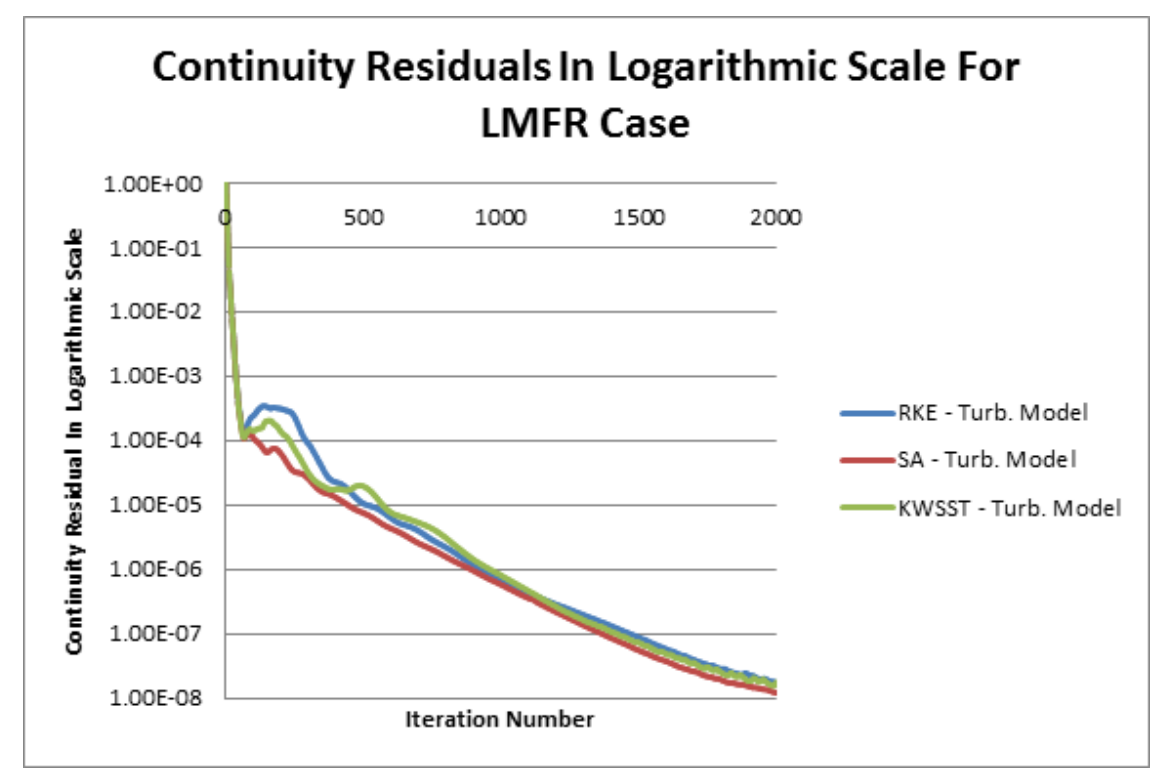

Figure 3.7: Continuity residual in logarithmic scale for LMFR case

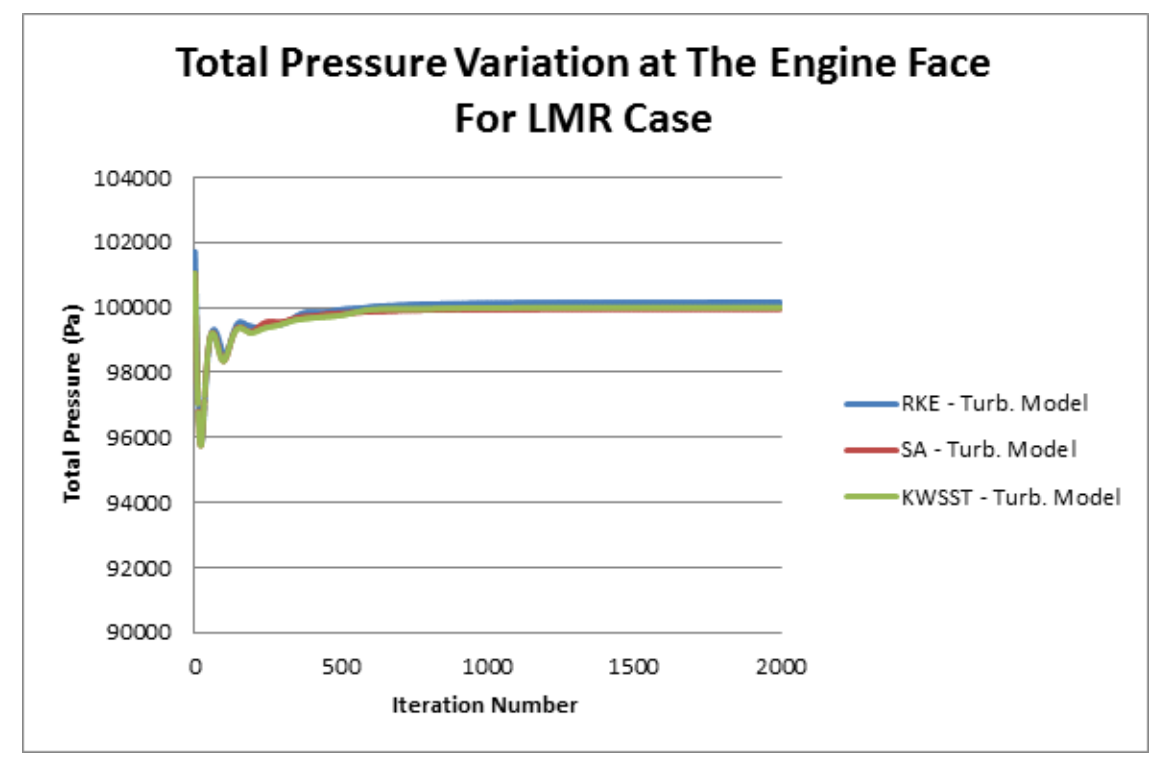

Figure 3.8: Area weighted total pressure variation at the engine face for LMFR case

Total iteration number was selected as 2000 for all cases and turbulence models. However as can be seen from the above figures this number is a bit much than necessary because the convergence is already achieved around 1000 iteration for all turbulence models and both cases. From the above figures it is observed that there is no convergence problem and the characters of the convergence are identical for all turbulence models for each case. Therefore, in terms of convergence rates there is no superior turbulence model among KWSST, RKE and SA. 


\subsubsection{Comparison of Computational and Experimental Results}

With the high confidence on the convergence of the solutions and grid independency, primary concern turned into selection of the most suitable turbulence model for flow in S-ducts among the KWSST, RKE and SA. Towards the available experimental data, quantitative comparisons were made for intake performance criterion; $\mathrm{DC}(60)$ and PR. In addition to these criterion comparisons were also carried out for static pressure distribution along the port and starboard side of the intake walls shown at figure 3.1 and Mach number values at the intake throat and engine face. Since experimental data is available for two cases one with high mass flow and other with low mass flow rate, this part is divided into two sections. Firstly comparison of the experimental and the computational results will be made for low mass flow rate case and secondly comparison will be made for the high mass flow rate case. Unfortunately, no qualitative comparison could be made through the available data given in AGARD study[1].

\subsubsection{Low Mass Flow Rate Case}

Computational results obtained with KWSST, RKE and SA turbulence models and the available experimental data is given at table 3.4 . Actually all results obtained by the computations corresponds slightly higher capture flow ratio values compared to the experiment. However this variation is considered to be negligible.

Table3.4: Comparsion of the computational results with experiment - LMFR case

\begin{tabular}{|l|c|c|c|c|}
\cline { 2 - 5 } \multicolumn{1}{c|}{} & $\begin{array}{c}\text { SA } \\
\text { Turb. Model }\end{array}$ & $\begin{array}{c}\text { KWSST } \\
\text { Turb. Model }\end{array}$ & $\begin{array}{c}\text { RKE } \\
\text { Turb. Model }\end{array}$ & EXPERIMENT \\
\hline CFR & 1.491 & 1.491 & 1.495 & 1.457 \\
\hline Mth & 0.428 & 0.428 & 0.429 & 0.412 \\
\hline Mef & 0.315 & 0.315 & 0.314 & 0.304 \\
\hline PR & 0.9883 & 0.9888 & 0.9903 & 0.9897 \\
\hline DC(60) & 0.271 & 0.245 & 0.176 & 0.226 \\
\hline
\end{tabular}

As it can be seen from table 3.4 all turbulence models gives very similar Mach number values at the engine face and throat and these values are compatible with the experiment. This small difference may be originate from the higher capture flow ratio.

Among the computations obtained by three turbulence models first apparent difference 
stand out in PR values. Highest and the most accurate PR value is obtained by the RKE turbulence model whereas smallest PR value arise with SA turbulence model. All three turbulence model result in slightly different pressure recovery values with some error. However these errors are so small that the difference between the experimentally and computationally obtained PR values is around $0.1 \%$.

When the comparison is made for crucial performance criteria of an intake $\mathrm{DC}(60)$, some difference between the computations and experiment is noticed. RKE turbulence model leads to optimistic $\mathrm{DC}(60)$ value whereas the other turbulence models calculate higher $\mathrm{DC}(60)$ values compared to the experiment. Among the three turbulence models KWSST predicted most accurate distortion coefficient whereas SA yields largest error in terms of distortion coefficient.

Furthermore, static pressure along the intake walls can provide information about suitability of the turbulence models. Because, flow in S-ducts are subject to sudden accelerations or decelerations due to stream line curvature and diffusion which cause flow non-uniformities. Therefore, capturing the magnitude and the location of the flow acceleration and deceleration has high importance.

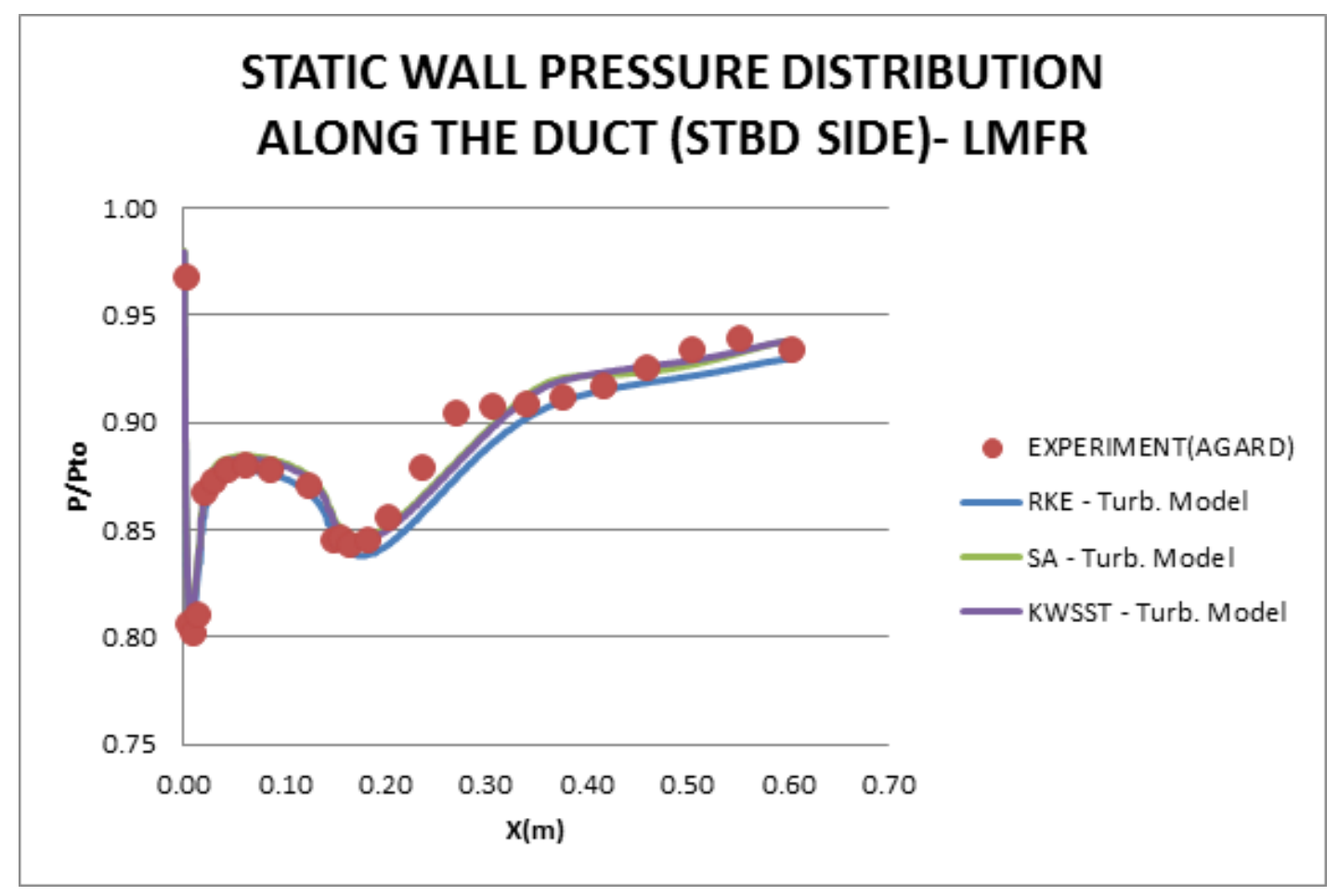

Figure 3.9: Static pressure distribution along the STBD side of the intake walls LMFR 
The comparison of the static pressure distribution along the starboard(stbd) side of the intake wall is shown at Figure 3.9. As it can be depicted from this figure, computations obtained with KWSST and SA turbulence models give very similar static pressure distribution on large part of the intake wall. However a small but in some degree important discrepancy is observed between the RKE and the other turbulence models in terms of static pressure distribution along the stbd side of the intake wall. All turbulence models predict static pressure on the lips very close to the experimental data. However after the lips some difference stands out for computations and the experimental data. After the lips computation obtained with RKE turbulence model gives smaller static pressure whereas other two turbulence models result in higher static pressure up to the first bend of the intake. At the first bend of the intake KWSST and SA turbulence models catch the experimental values, however at the same time RKE turbulence model continue to predict smaller static pressure values compared to the experiment. Just after the first bend experimental data shows sudden increase in static pressure. Although this sudden increase captured by all three turbulence models their magnitudes are much lower than the experimental values and all predictions lies under the experimental values up to the location closer to the second bend. At the second bend static pressure predicted by RKE turbulence model in small extent closer to the experimental data. However after the second bend static pressure increases such that KWSST and SA turbulence models become much closer to the experiment. Actually in general static pressure predictions at the stbd side of the intake with RKE turbulence model lies under the experimental values. At the same time KWSST and SA turbulence models gives very similar results. However at the locations near the first bend and second bend KWSST predictions are closer to the experimental values compared to the all other turbulence models. 


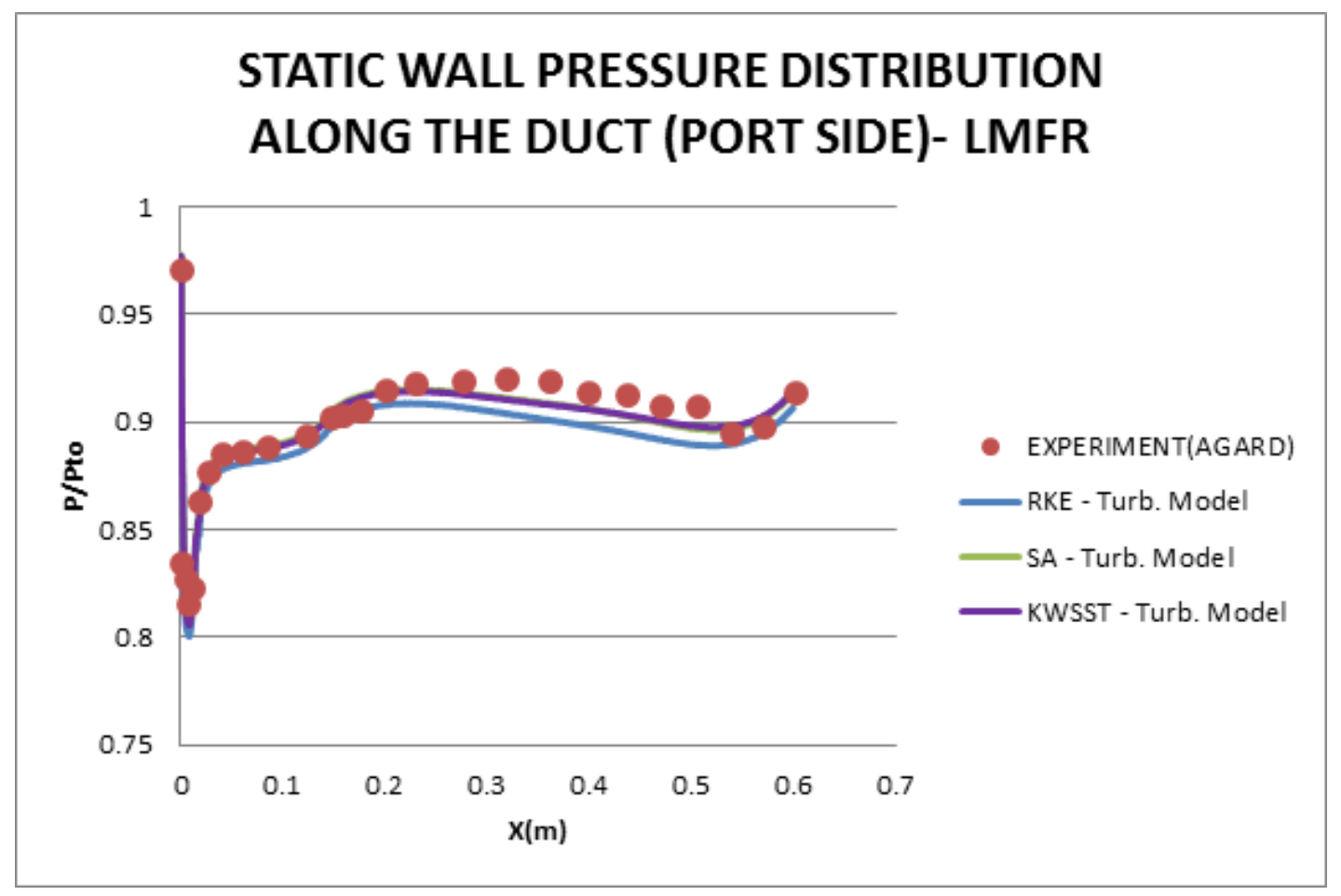

Figure 3.10: Static pressure distribution along the PORT side of the intake walls LMFR

Similar comparison is made for the port side of the intake walls and results are shown in the figure 3.10. It is seen that characteristic of the static pressure distribution is consistent with the stbd side of the intake. Static pressure predictions along the lips are very similar for all three turbulence models and results are compatible with the experimental values. However just after the lip section RKE turbulence model fails in predicting static pressure and it gives smaller results compared to the experiment. At the same time predictions obtained with KWSST and SA turbulence models successfully catch the experimental results up to end of the first bend. After this point all three turbulence model collapse below values compared to the experiment. However even at this portion of the intake wall KWSST and SA turbulence model shows closer results to the experiment compared to the RKE turbulence model.

In general for the LMFR case all three turbulence models are capable to predict the static pressure distribution along the intake wall with some error margin. Characteristics of the flow deceleration and acceleration are successfully captured by all three turbulence models. However in general, KWSST seems most suitable model for cap- 
turing the static pressure distribution on the intake walls.

Computed Mach number contours obtained at the symmetry plane shows parallel characteristics with the quantitative results. From the comparison of the figure 3.11 , figure 3.12 and figure 3.13 it is clear that SA turbulence model result indicates higher separated flow region whereas RKE result smaller one which respectively causes the highest and smallest distortion values obtained at LMFR case. Except the size of the separated regions and the extent of the highest velocity region captured with RKE turbulence model, flow characteristics similarly captured with all turbulence models.

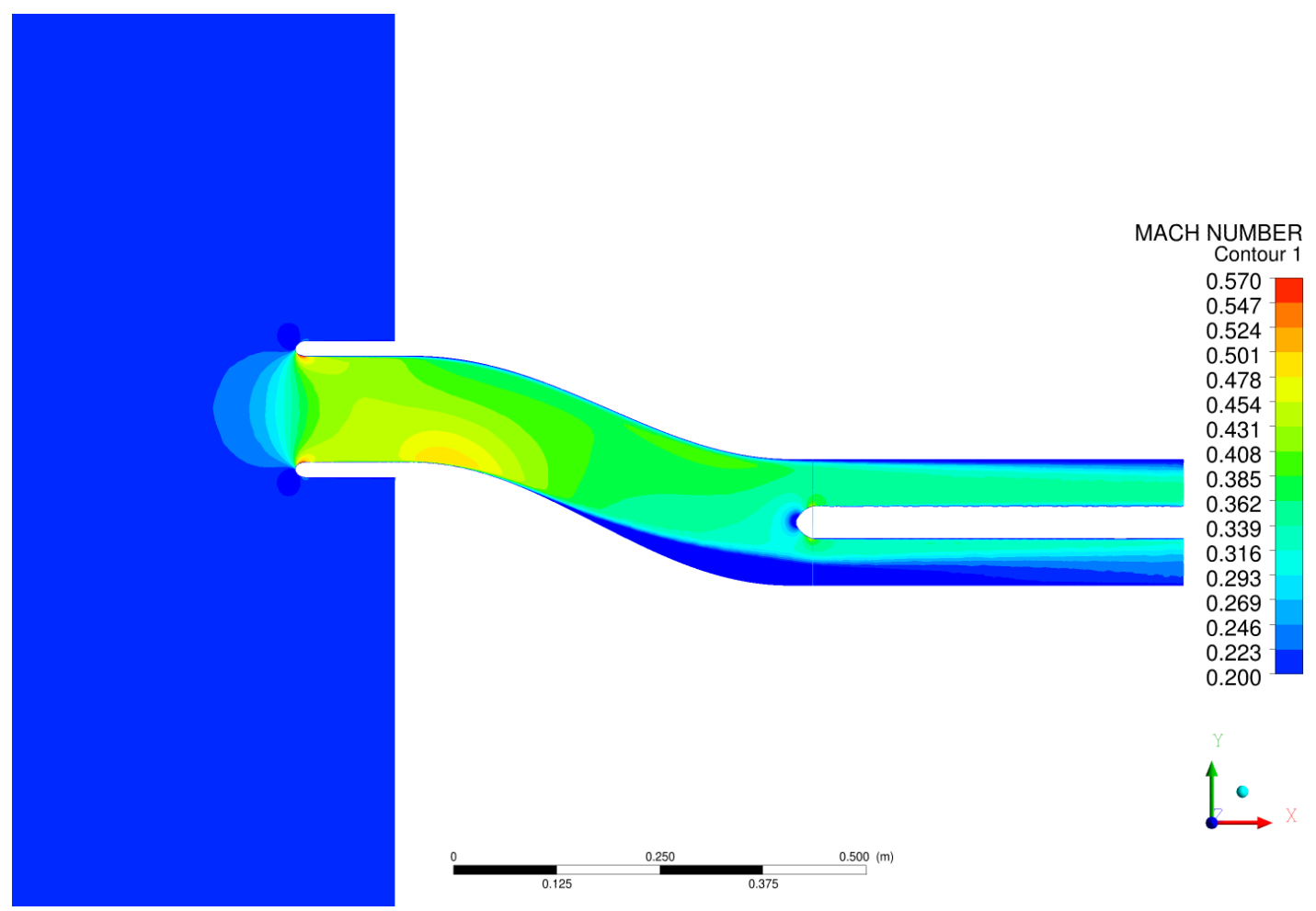

Figure 3.11: Computed Mach number contours with KWSST turbulence model LMFR 


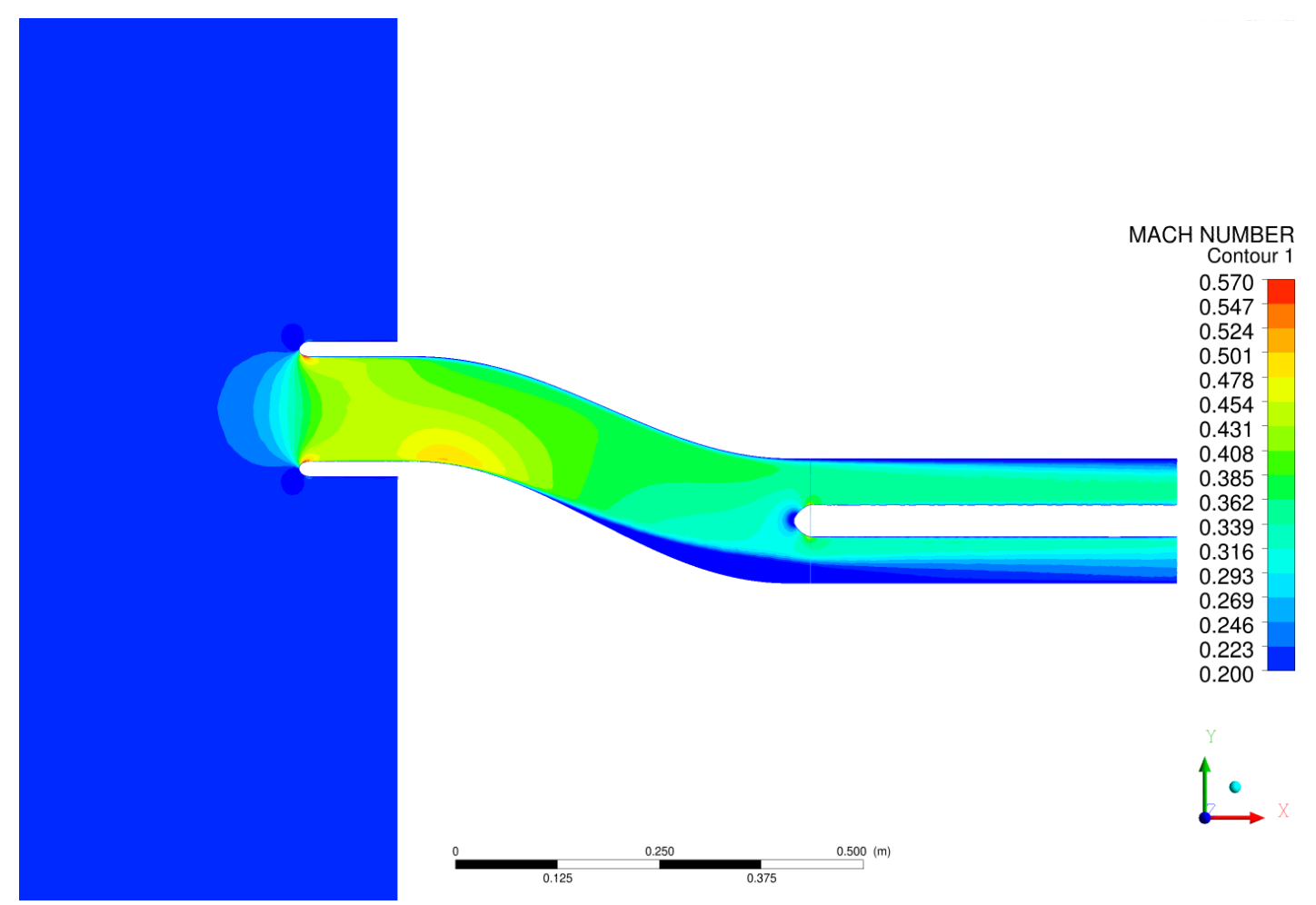

Figure 3.12: Computed Mach number contours with RKE turbulence model - LMFR

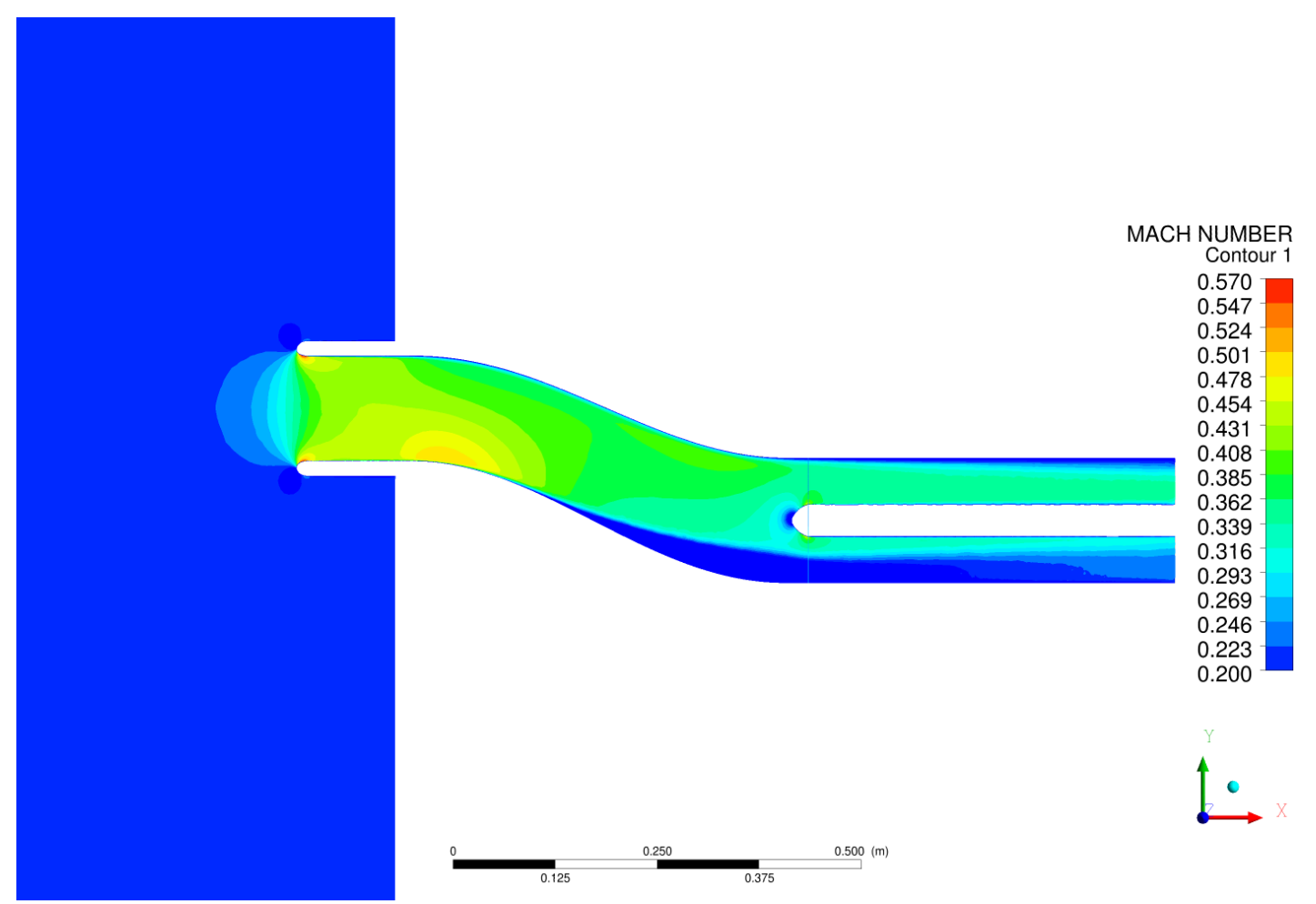

Figure 3.13: Computed Mach number contours with SA turbulence model - LMFR 
Effects of turbulence model selection on the total pressure contours at the engine face can provide further information. As given at the figure 3.14 there is an obvious effect of turbulence model selection on the engine face pressure distribution. Although all turbulence models used in this work predict horizontal extent of the low total pressure regions similarly their heights are different as well as their magnitude. As parallel to the values given at the table 3.4. SA turbulence model gives largest total pressure deficit whereas lowest total pressure deficit obtained by RKE turbulence model. Furthermore computed tangential velocity vectors at the engine face shows different characteristics for each turbulence model. Velocity vectors obtained with KWSST and SA turbulence models indicates clear and relatively strong vortex region whereas this region is not predicted so strong and obvious with RKE turbulence model which causes the optimistic PR and DC(60) predictions as summarized in the table 3.4 . 

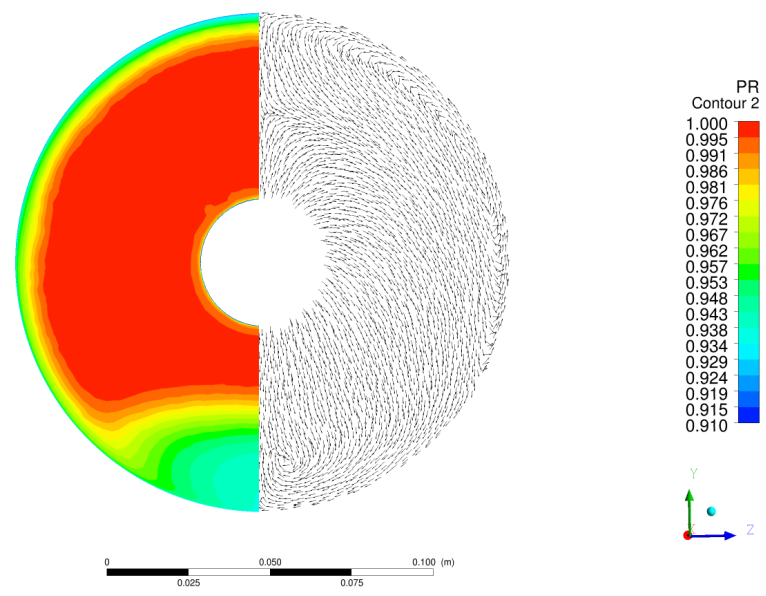

(a) KWSST - LMFR

ANSYS
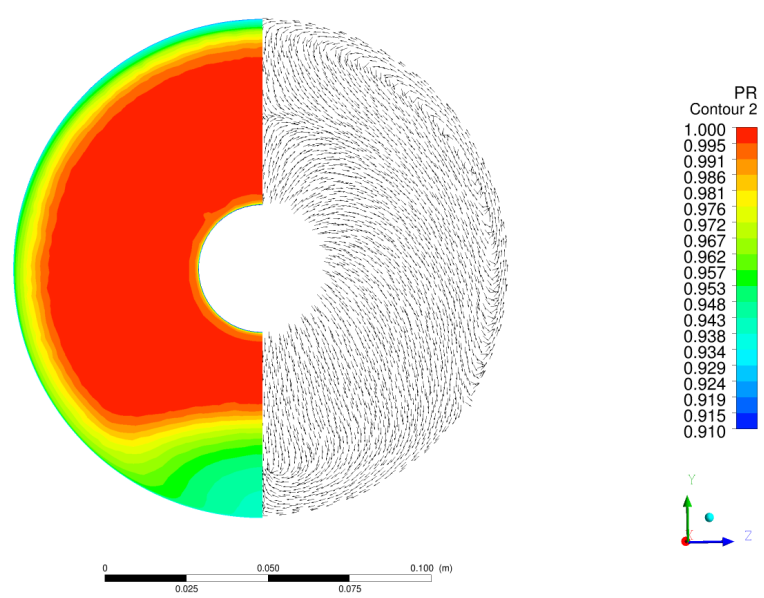

(b) RKE - LMFR

ANISYS
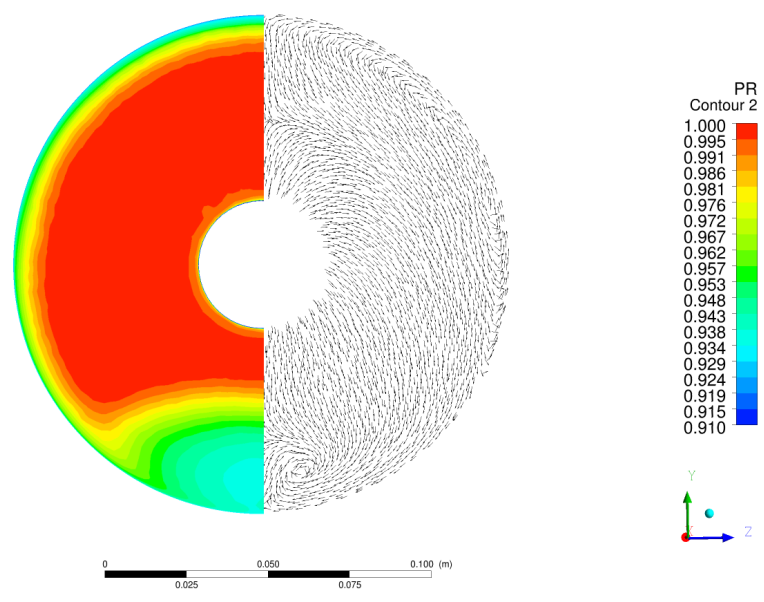

(c) SA - LMFR

Figure 3.14: Turbulence model effect on engine face total pressure recovery contours and tangential velocity vectors 


\subsubsection{HMFR Case}

Computational and experimental results for HMFR case are shown at the table 3.5 . As can be seen from this table modeled capture flow ratios are again shows small difference compared to the experimental value. However this difference is so small that it has no significant effect on the flow characteristics in the S-duct. Furthermore when comparisons are made for the Mach number values at the throat and the engine face in some extent significant difference attract the attention. Especially predicted throat Mach number values are higher than the experimental values whereas predicted engine face Mach number values are close each other and the experimental one.

Table3.5: Comparsion of the computational results with experiment - HMFR case

\begin{tabular}{|l|c|c|c|c|}
\cline { 2 - 5 } \multicolumn{1}{c|}{} & $\begin{array}{c}\text { SA } \\
\text { Turb. Model }\end{array}$ & $\begin{array}{c}\text { KWSST } \\
\text { Turb. Model }\end{array}$ & $\begin{array}{c}\text { RKE } \\
\text { Turb. Model }\end{array}$ & EXPERIMENT \\
\hline CFR & 2.153 & 2.158 & 2.167 & 2.173 \\
\hline Mth & 0.827 & 0.837 & 0.860 & 0.794 \\
\hline Mef & 0.544 & 0.542 & 0.539 & 0.530 \\
\hline PR & 0.9456 & 0.9469 & 0.9491 & 0.92798 \\
\hline DC(60) & 0.580 & 0.549 & 0.531 & 0.398 \\
\hline
\end{tabular}

Computationally obtained pressure recovery values show slightly optimistic characteristic compared to the experiment. This may be due to the lack of capability of turbulence models in terms of predicting losses in S-duct flows. However the variation between the computationally and experimentally obtained PR values are at most $2 \%$. Therefore, all turbulence models have good agreement with experiment in terms of predicting pressure recovery while SA gives most accurate one.

However there is a significant difference between the $\mathrm{DC}(60)$ values obtained computationally and experimentally. All turbulence models used in this work over predict the distortion coefficient. Although this may come from the inadequacy of the steadystate CFD methods where separation regions are large, this can also be originating from the experimental handicaps. There is a possibility of using pressure rake during the experiments which cannot resolve the high gradients of total pressure at the engine. Furthermore Kumar et al[34] shows the possibility that even rakes placed at the engine face may reduce the distortion coefficient in a significant manner. 
Through the available experimental data, comparison is made for static pressure distribution along the stbd and the port side of the intake walls as in the case of LMFR. Static pressure distribution on the stbd side of the intake wall is shown at the figure 3.15. From this figure, it is seen that predictions of the static pressure distribution on the stbd side of the intake walls are not that much closer to the experimental values as in the LMFR case. Actually just after the lip section all computationally obtained static pressure values with three turbulence models depart from the experimental results. Computations exhibit higher flow deceleration rate just after the lip section and lower flow acceleration around first bend of the intake. Just after the first bend computational and experimental values overlap to each other. However computational results again shows higher flow deceleration thus higher increase rate of static pressure around the second bend. Towards the engine face computational and experimental static pressure values again get closer to the each other.

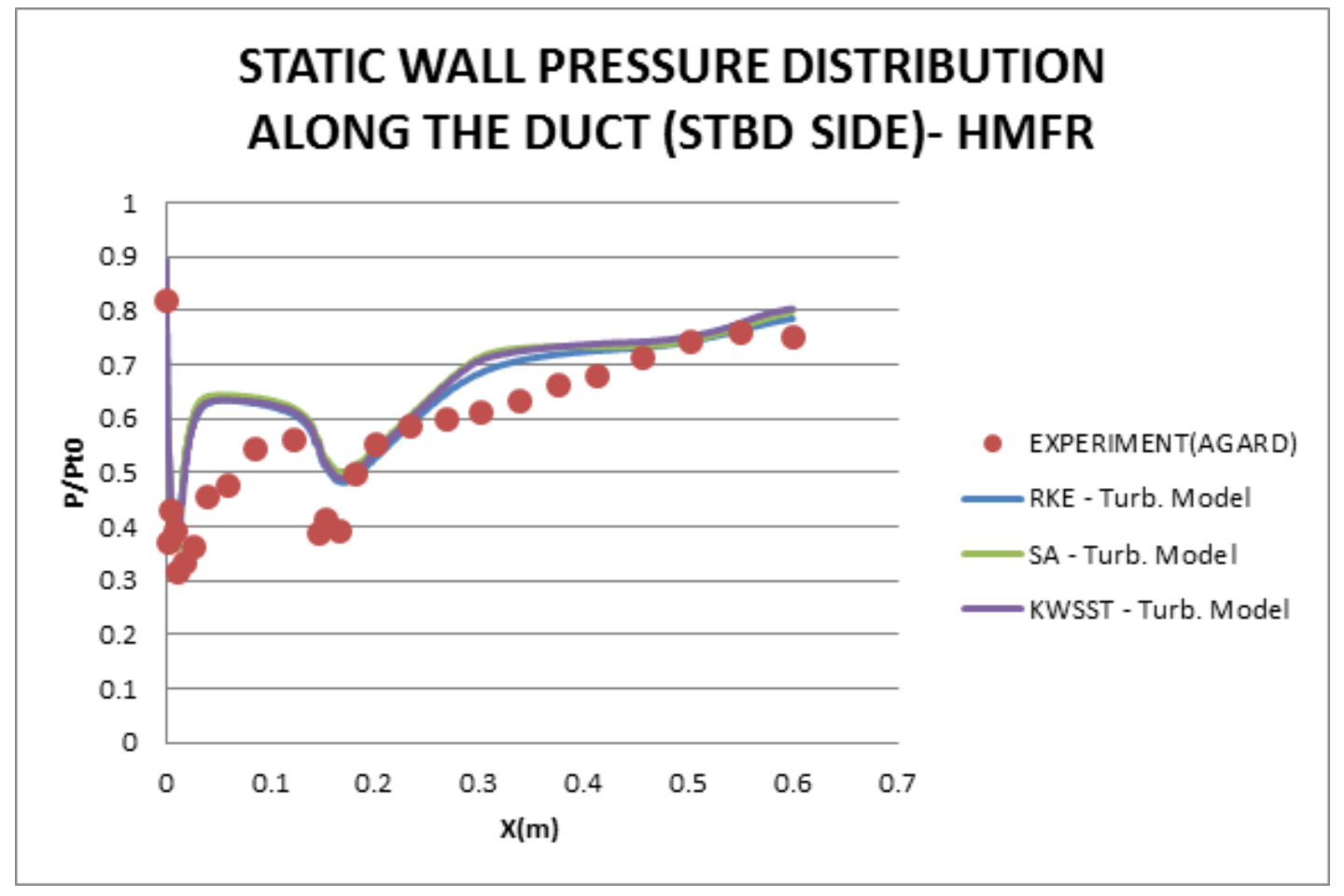

Figure 3.15: Static pressure distribution along the STBD side of the intake walls HMFR

If similar comparison is made for the port side of the intake walls where expected pressure changes are not so sudden and excessive compared to the stbd side again some difference stands out between the experimental and computational static pressure 
distribution as can be depicted from figure 3.16. As in the stbd side up to the end of the lip section computational and experimental values are in excellent agreement. However just after the lip section deceleration rate of the flow thus increase in the static pressure predicted much higher compared to the experiment. Around first bend computational and experimental results become closer to the each other and after this point, characteristics of the flow at the port side of the flow successfully captured with some error margin. Through the engine face experimentally and computationally obtained static pressure values gets even closer.

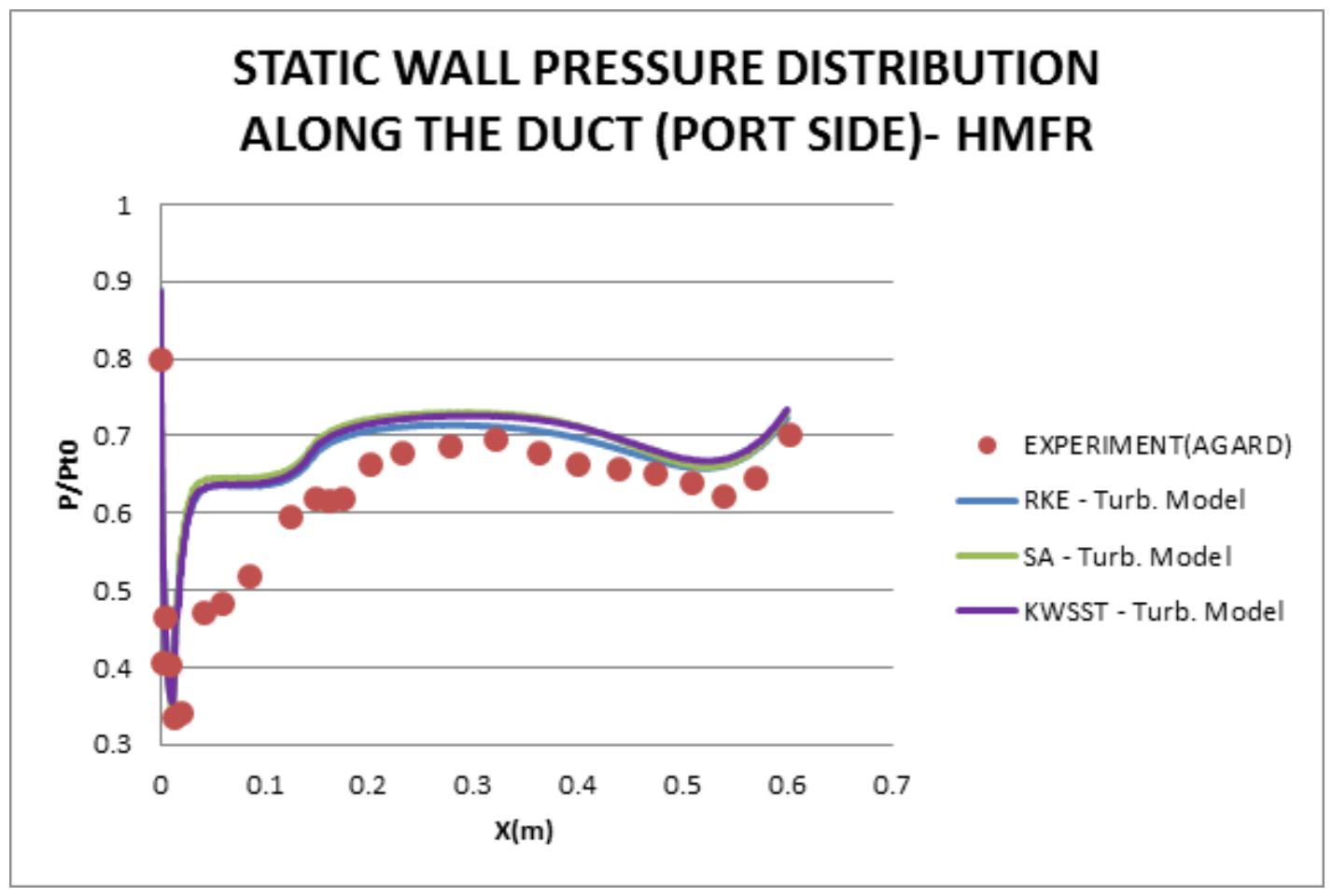

Figure 3.16: Static pressure distribution along the PORT side of the intake walls HMFR

For the HMFR case, although all turbulence models gives similar results to each other they all fail in successfully capturing flow deceleration and acceleration rates in the Sduct. Moreover selection of the most suitable turbulence model in terms of their ability in predicting static pressure distribution is not so feasible with the comparison of the results obtained for HMFR since all turbulence models create similar but outlying static pressure values with respect to the experimental ones.

Furthermore the characteristic of the flow inside M2129 intake is visualized with the 
Mach number contours obtained at the symmetry plane for each turbulence model as shown in the figure 3.17, figure 3.18 and figure 3.19 . For all results it is observed that there are some packets of small supersonic regions located at the first bend and on the lips. This is parallel to the reported experimental results in the AGARD study[1]. The strongest supersonic flow region forms at the first bend captured with the RKE turbulence model whereas predictions obtained with other two turbulence model shows weaker supersonic region at the first bend of the intake duct. From the Mach number contours it is possible to see the effect of hub on the flow characteristics. Hub seems to work such that it does not allow to enlarge distorted region through the upper side of the engine face. Therefore, it seems crucial to model hub geometry for analyzing flow inside the intake ducts especially for the cases where distorted region are relatively large.

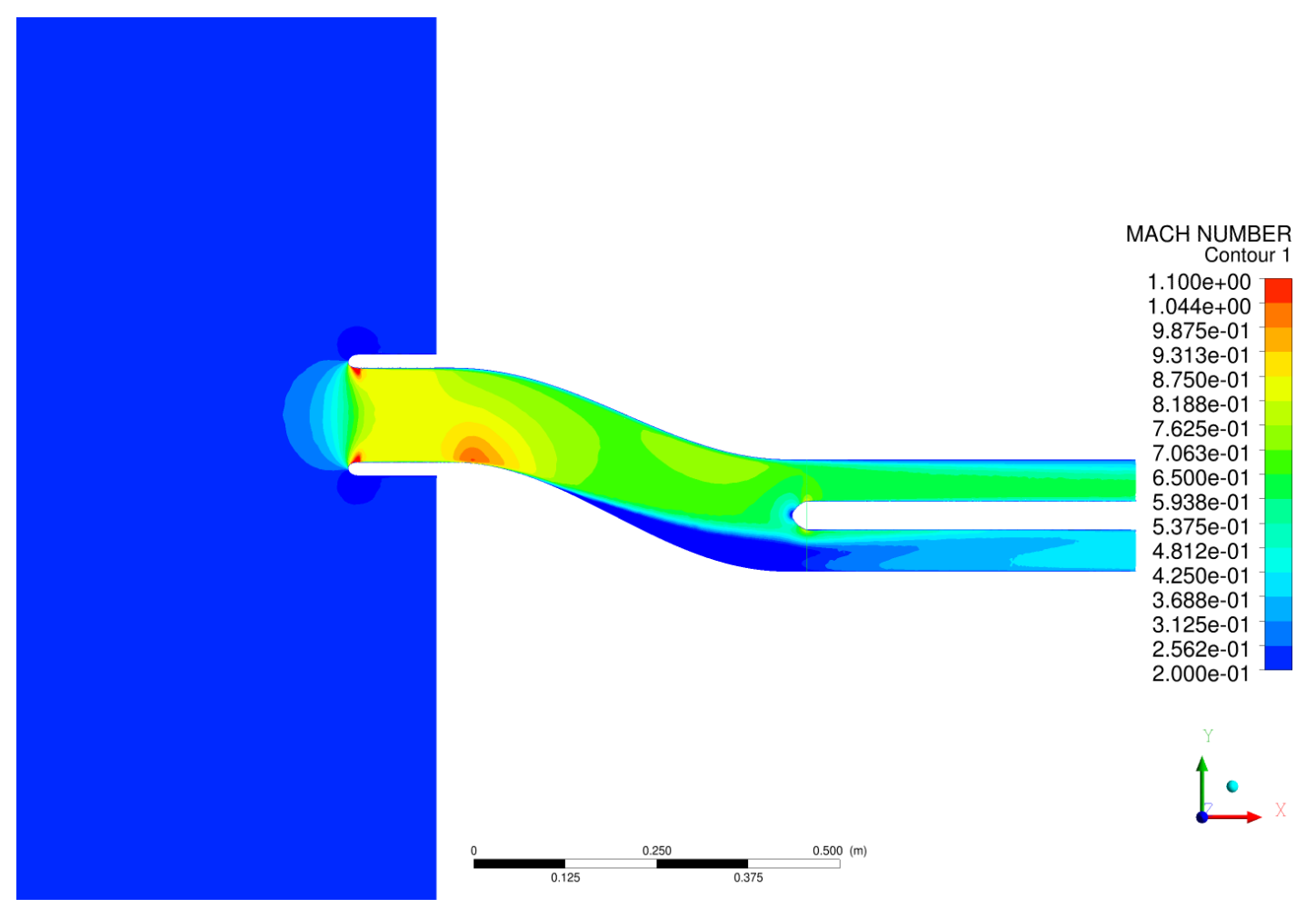

Figure 3.17: Computed Mach number contours with KWSST turbulence model HMFR 


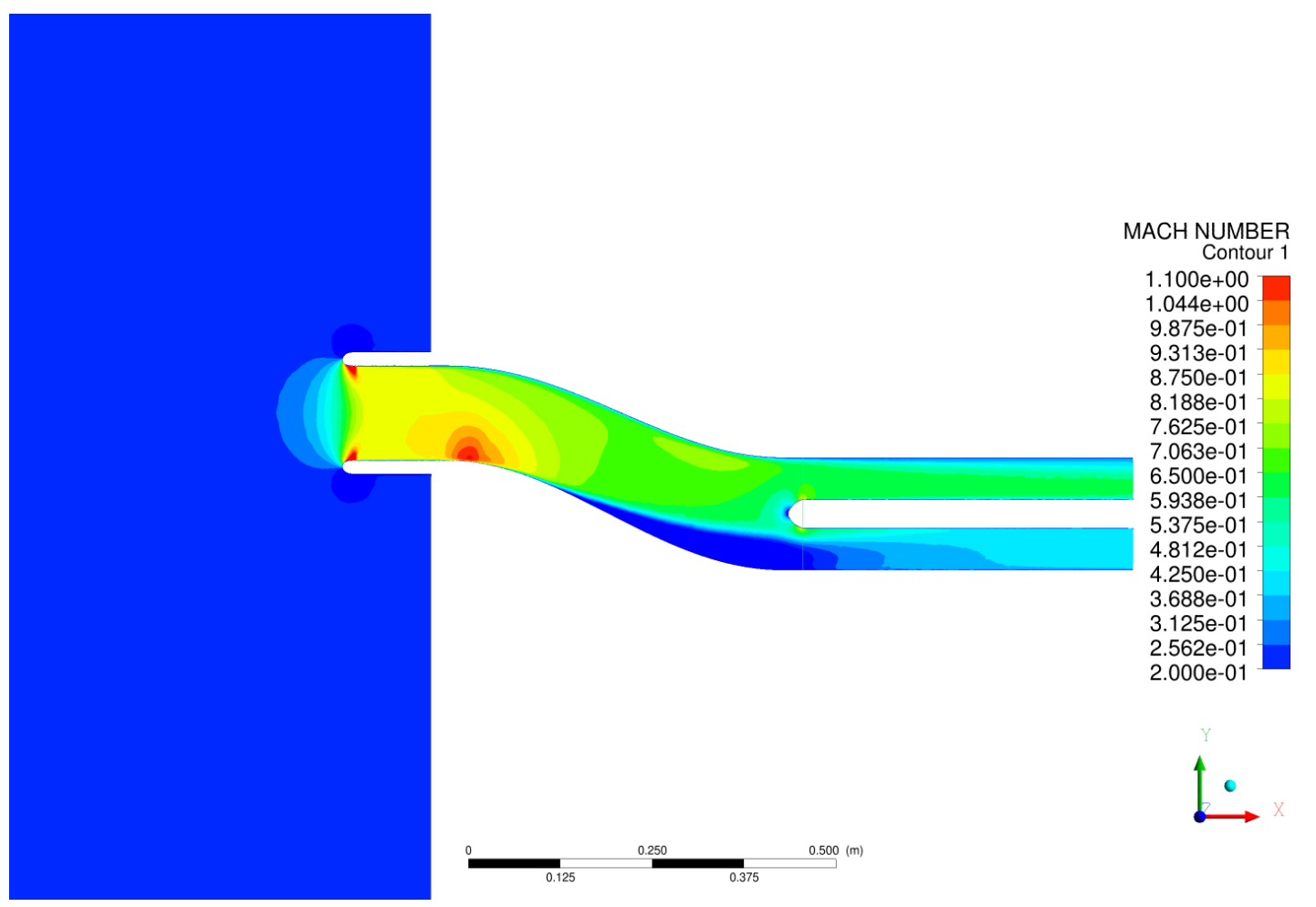

Figure 3.18: Computed Mach number contours with RKE turbulence model - HMFR

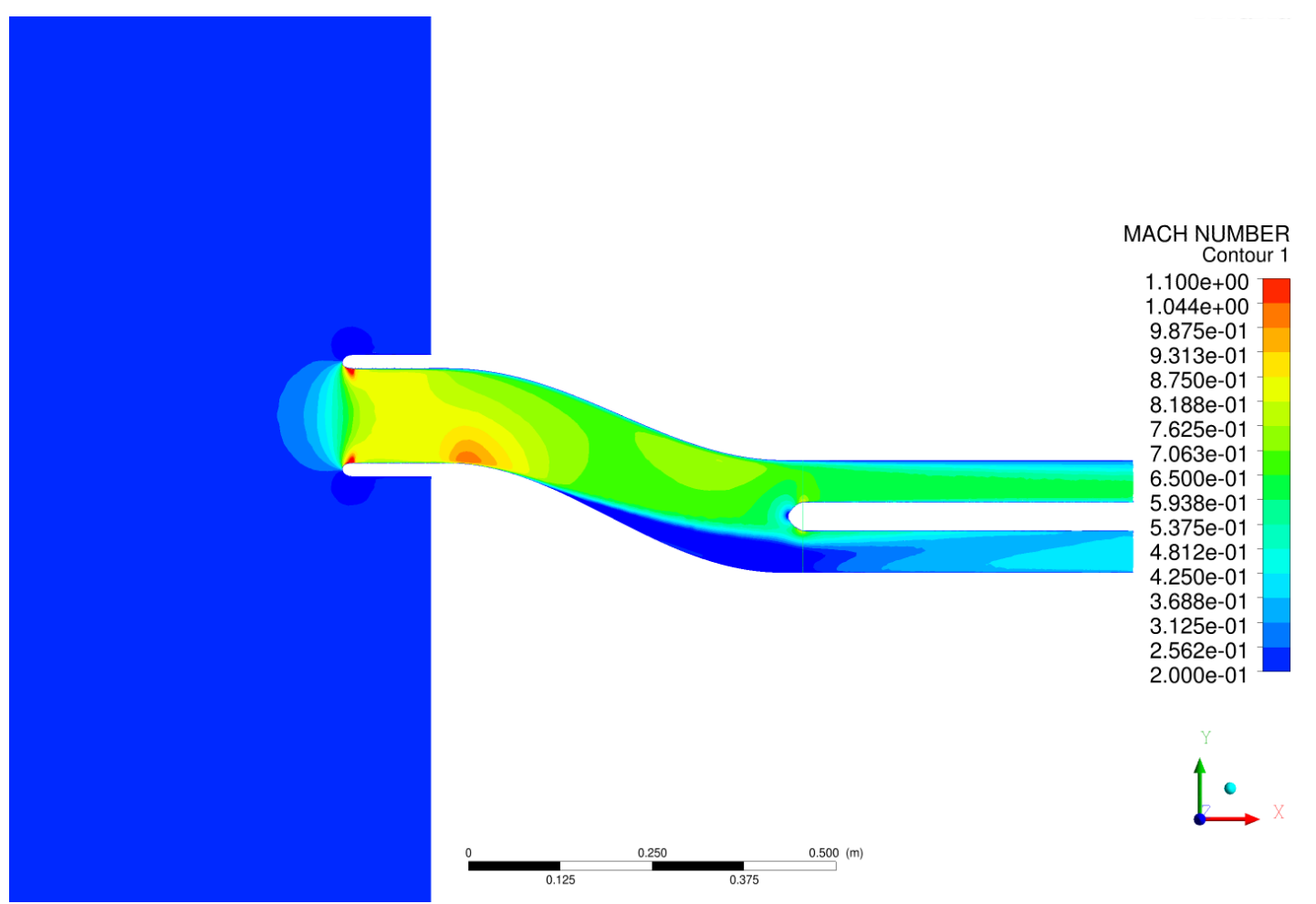

Figure 3.19: Computed Mach number contours with SA turbulence model - HMFR 
As in the LMFR case, effects of turbulence models on the engine face total pressure distribution are also investigated. Comparison of the obtained total pressure contours with turbulence models used in this work is shown at the figure 3.20

It can be observed from figure 3.20 that, the shape of the computed low total pressure regions are clearly affected by the presence of the bullet. This effect is not that visible at the predicted total pressure contours for LMFR case since height of the low total pressure region did not reach to the bullet. Furthermore, size of the lowest total pressure region changes significantly with the turbulence model such that computations obtained with SA gives largest region of the lowest total pressure whereas this region becomes very small at the computations obtained by RKE turbulence model. Therefore, it can be seen that as in the LMFR case total pressure contours at the engine face are parallel to the results presented at the table 3.5 . 

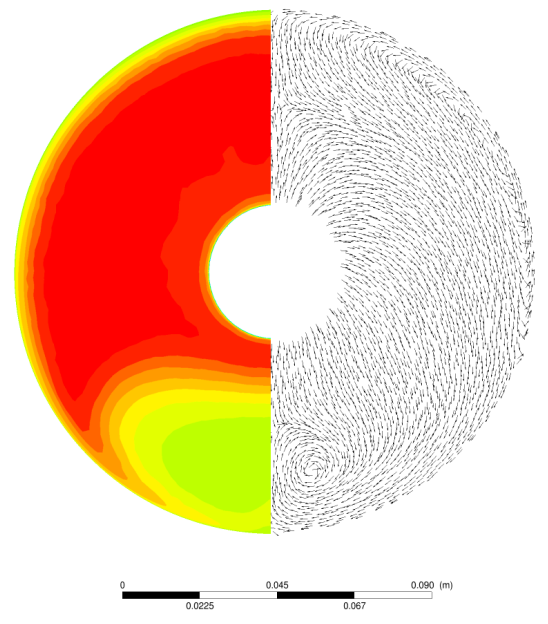

(a) KWSST - HMFR
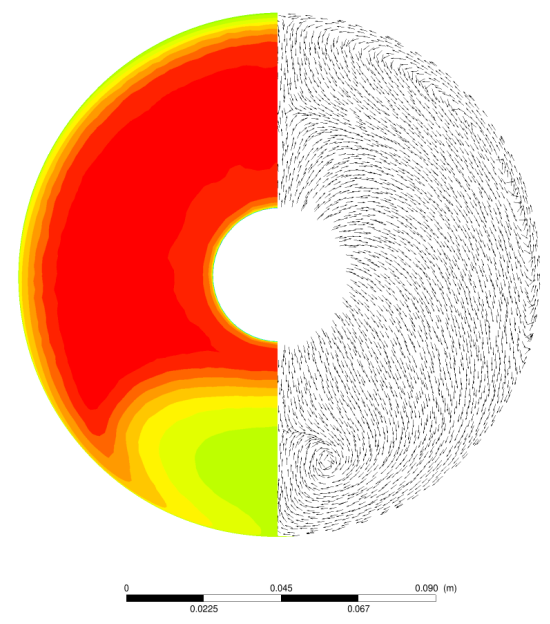

(b) RKE - HMFR

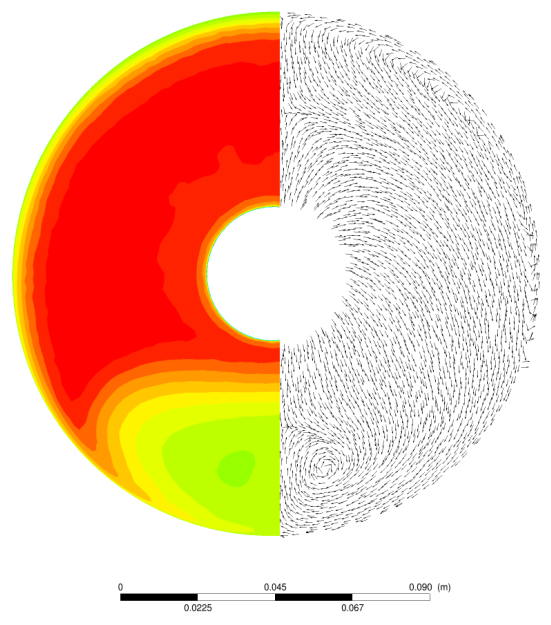

(c) SA - HMFR

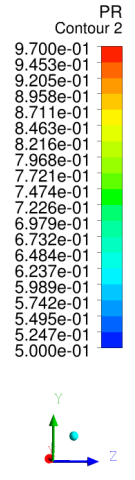

ANSIS

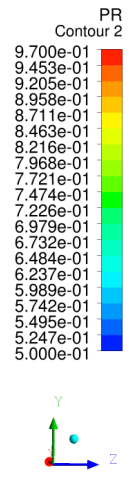

ANSYS

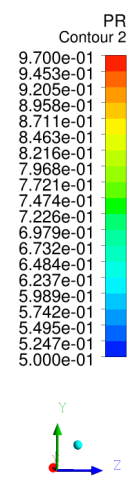

Figure 3.20: Turbulence model effect on engine face total pressure recovery contours and tangential velocity vectors 


\subsubsection{Comparison of the Computational Results with Previous Work}

Experimental results shared by AGARD[1] were also used by another computational study carried out by Menzies 43. PMB which is a three dimensional flow code developed in Glasgow University is used in his computational studies with the three different turbulence models which are SST, SA and KW. The mesh type and the presence of the bullet are the main differences between the current and the previous work conducted by Menzies. The unstructured mesh on the M2129 intake geometry with the bullet on the engine face was produced in the current work while previous work uses structured mesh on the M2129 intake geometry without bullet.

Table3.6: Comparison of the results obtained by current and previous work with the experimental results

\begin{tabular}{|l|c|c|c|c|}
\hline \multirow{2}{*}{\multicolumn{1}{|c|}{ CASE }} & \multicolumn{2}{c|}{ HMFR CASE } & \multicolumn{2}{c|}{ LMFR CASE } \\
\cline { 2 - 5 } & DC & PR & DC & PR \\
\hline Experiment & 0.398 & 0.92798 & 0.226 & 0.9897 \\
\hline Current Study KWSST & 0.549 & 0.9469 & 0.245 & 0.9888 \\
\hline Current Study RKE & 0.531 & 0.9491 & 0.176 & 0.9903 \\
\hline Current Study SA & 0.580 & 0.9456 & 0.271 & 0.9883 \\
\hline Previous Study KW & 0.658 & 0.94359 & 0.229 & 0.99992 \\
\hline Previous Study SST & 0.688 & 0.94117 & 0.377 & 0.99994 \\
\hline Previous Study SA & 0.651 & 0.94366 & 0.340 & 0.99990 \\
\hline
\end{tabular}

Experimental and computational results computed in the current and previous computational work are given at table 3.6 . Two general conclusions can be depicted from this table. First for both computational studies turbulence model effect is more obvious for the LMFR case especially in prediction of distortion coefficient and second, when separation is dominant as in the case of HMFR, the difference between the computationally and experimentally obtained PR and DC values become much more significant.

General characteristics of the results are similar when comparison is made between the experimental and the computational studies. However, especially for the HMFR case, PMB solver predicts much higher engine face distortion even compared to predictions obtained in the current work. This difference may originate from the absence of the bullet geometry in the previous work. Total pressure contours at the engine face and 
Mach number contours at the symmetry plane obtained and shared in the current work shows obvious effect of the bullet modeled at the engine face. Furthermore when comparison is made for the pressure recovery values obtained for the HMFR case, it is seen that although both computational results indicate more optimistic predictions compared to the experiment, PMB solver is more successful in computing PR values for HMFR case.

As mentioned earlier, computational results obtained for LMFR case shows greater agreement with the experimental data. This is true for both computational studies. Especially previous computational result obtained with KW turbulence model show excellent agreement with the experimental result in terms of distortion coefficient. However other turbulence models used with the PMB code are again results in much larger distortion coefficients as in the case of HMFR. In contrast to earlier work results obtained with different turbulence models in the current work shows only limited differences. In the current work KWSST and SA turbulence models result in higher whereas RKE results in smaller distortion coefficient compared to the experiment. Moreover, opposite to the HMFR case, predictions of the PR value with current work are closer to the experimental value. However the difference between experiment and other two computational studies are not significant in terms of pressure recovery values.

Furthermore when comparison is made between the Mach number contours at the symmetry plane computed in the previous and current study some obvious differences stand out especially for the HMFR case. For this case, PMB solver predictions obtained with SA and KW models somehow shows large supersonic regions and shock wave structure at the entrance of the intake duct. However at the same time PMB solutions with SST turbulence model shows only small packet of supersonic regions located at the first bend and lip region which is the actual case reported at the AGARD study[1]. In the current study there is only small packet of supersonic regions inside the intake duct observed for any simulation obtained with any turbulence model as explained earlier. Menzies Ryan D. D. insist on SST turbulence model for his further simulations because of the large supersonic regions obtained with SA and KW turbulence models which should not be present according to AGARD study[1]. 


\subsection{M2129 Intake without Cowl-Lip}

Since it requires less number of grid and therefore less computational time, it was more commonly preferred to investigate flow characteristics inside M2129 intake without cowl lip by the previous researchers. Furthermore, experimental data which includes effect of vortex generators is conducted with the M2129 intake without cowl lip[67]. Experimental measurements were collected in the DRA/Bedford $13 \times 9 \mathrm{ft}$ wind tunnel by Anderson and Gibb [6]. One of the main objectives of the work conducted by Anderson and Gibb is to show that vortex generator installations can increase the intake performance over the wide range of flow conditions. In order to achieve this goal series of data collected for various throat Mach number values ranging between 0.2 and 0.8. Furthermore, $\mathrm{DC}(60)$ and $\mathrm{PR}$ values are specified for each throat Mach number.

In the current study, computational results are compared with the available experimental data [6] in order to measure relative success of the turbulence models in capturing flow characteristics inside serpentine inlets with and without vortex generators. As in the case of duct with cowl lip, SA, RKE and KWSST turbulence models are used.

\subsubsection{Computational Domain and Duct Geometry}

Diffuser geometry is identical to the geometry explained with the equations 3.1 and 3.2. In addition to the M2129 geometry itself a $25.76 \mathrm{~cm}$ and a $12.88 \mathrm{~cm}$ long constant area section was connected to upstream and downstream of the duct respectively.

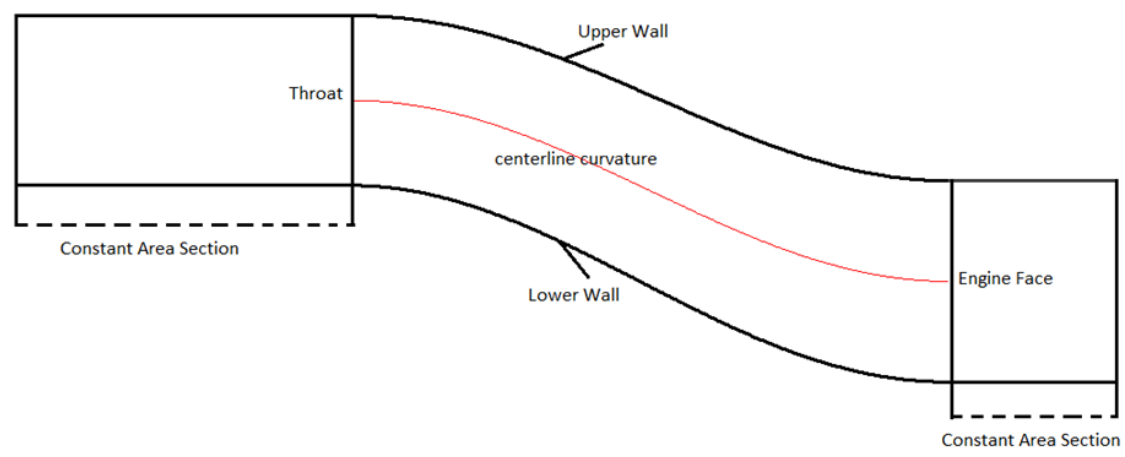

Figure 3.21: M2129 inlet geometry used for the CFD analyses 
The upstream extension is placed to develop boundary layer and the downstream extension is mounted in order to push back the computational domain with respect to engine face. These extensions were also used in the earlier studies [44] and [28]. Duct geometry modeled as flow domain is shown in the figure 3.21 .

\subsubsection{Mesh Dependency Analysis and Flow Simulations}

For mesh dependency analysis three unstructured meshes consist of 308808, 1193339 and 4636327 number of elements are created and these meshes are called coarse, medium and fine mesh respectively.

Mesh dependency analysis is conducted with KWSST turbulence model with exactly same boundary condition and for comparison of the results obtained with three meshes, throat Mach number, $\mathrm{DC}(60)$ and $\mathrm{PR}$ values are computed. Results of the investigation are summarized in the 3.7 .

Table3.7: Results of the mesh sensivity analysis - duct without cowl lip

\begin{tabular}{|c|c|c|c|}
\cline { 2 - 4 } \multicolumn{1}{c|}{} & $\begin{array}{c}\text { Coarse Mesh } \\
\text { \# of elements } \\
=\mathbf{3 0 8 8 0 8})\end{array}$ & $\begin{array}{c}\text { Medium Mesh } \\
\left(\begin{array}{c}\# \text { of elements } \\
=\mathbf{1 1 9 3 3 3 9})\end{array}\right.\end{array}$ & $\begin{array}{c}\text { Fine Mesh } \\
\left(\begin{array}{c}\text { of elements } \\
\mathbf{4 6 3 6 3 2 7})\end{array}\right.\end{array}$ \\
\hline Mth & 0.541 & 0.557 & 0.558 \\
\hline DC(60) & 0.343 & 0.289 & 0.282 \\
\hline PR & 0.979 & 0.984 & 0.984 \\
\hline
\end{tabular}

Results shown in the table 3.7 clearly indicate that current setup with medium mesh is sufficient for the current study. Surface meshes created for the mesh dependency analysis are shown in the figure 3.22 . 


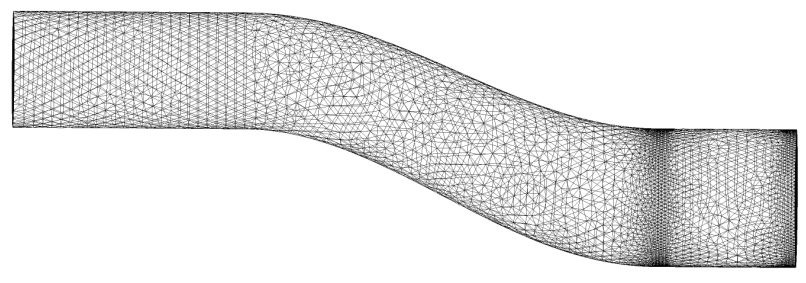

$\stackrel{\leftrightarrow}{\longrightarrow}$

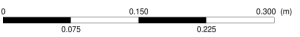

(a) Coarse mesh
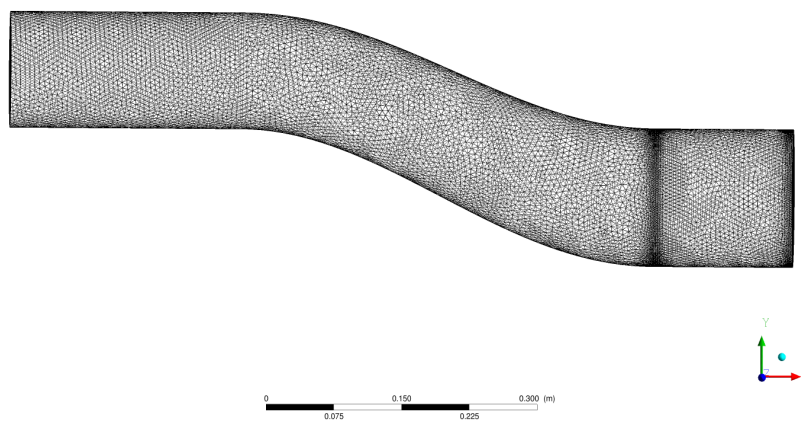

(b) Medium mesh

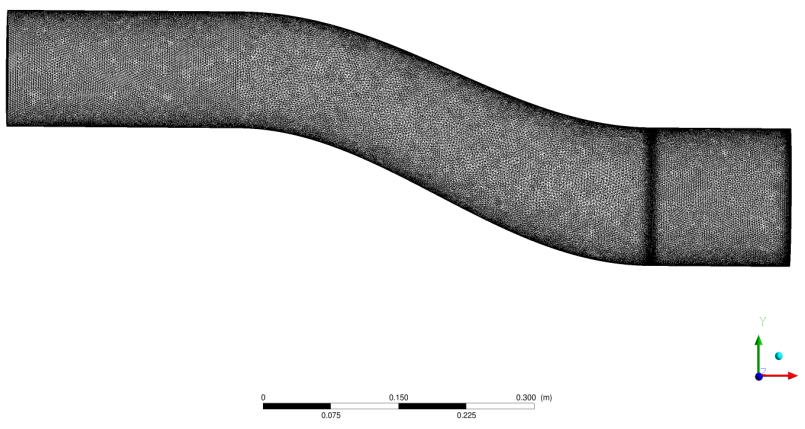

(c) Fine mesh

Figure 3.22: Surface meshes on M2129 intake without cowl lip

For all computations Least Square Cell base Coupled solver is used with second order upwind scheme. Boundary conditions applied during the computations are Pressure 
Inlet $\mathrm{BC}$ at the entrance, Pressure Outlet $\mathrm{BC}$ at the end of the flow domain and intake walls are modeled as no-slip wall. At pressure inlet near sea level values are applied as it is used in the several papers [44, 16, 6]. At the same time for pressure outlet constant static pressure values were given in order to reach different values of throat Mach number. In order to capture flow at the near wall region 20 layers of boundary layer elements are created with $\mathrm{Y}+$ value near 1 . Furthermore, for all computations CFL number and number of total iteration are held constant as 15 and 2000 respectively. Actually, computational setups used for both M2192 intake with and without cowl lip are identical except the given boundary condition at the upstream of the diffuser.

\subsubsection{Results Obtained with Clean M2129 Intake}

Although experimental data is available for throat Mach numbers ranging between 0.2 and 0.8 , in the current study only throat Mach numbers between 0.4 and 0.8 are investigated. The main reason for omitting low throat Mach numbers is following, for low throat Mach number values distortion becomes insignificant. More importantly low throat Mach numbers are only seen in very limited time for the high speed missile applications. Therefore, no significant effect on the engine efficiency or health is possible and no effort was given for low throat Mach numbers in the present study. In order to reach a complete conclusion about relative success of turbulence models, 13 CFD simulations covering throat Mach number values 0.4 to 0.8 were collected for each turbulence model for clean duct case. Comparison of the experimental and computationally obtained $\mathrm{PR}$ and $\mathrm{DC}(60)$ values are given in the figures 3.23 and 3.24 respectively. 


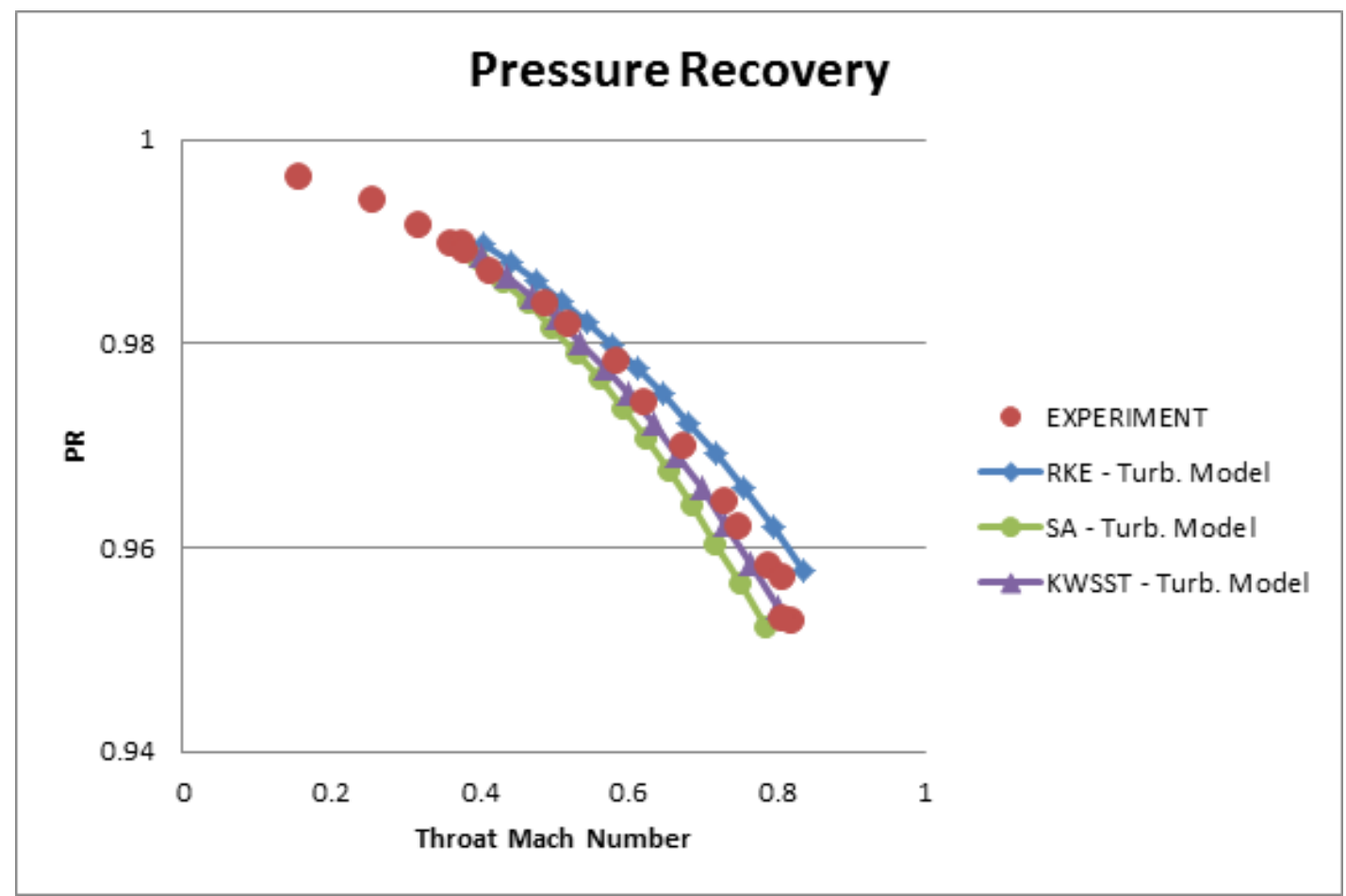

Figure 3.23: Comparison of the total pressure recoveries at the engine face - clean M2129 intake without cowl lip

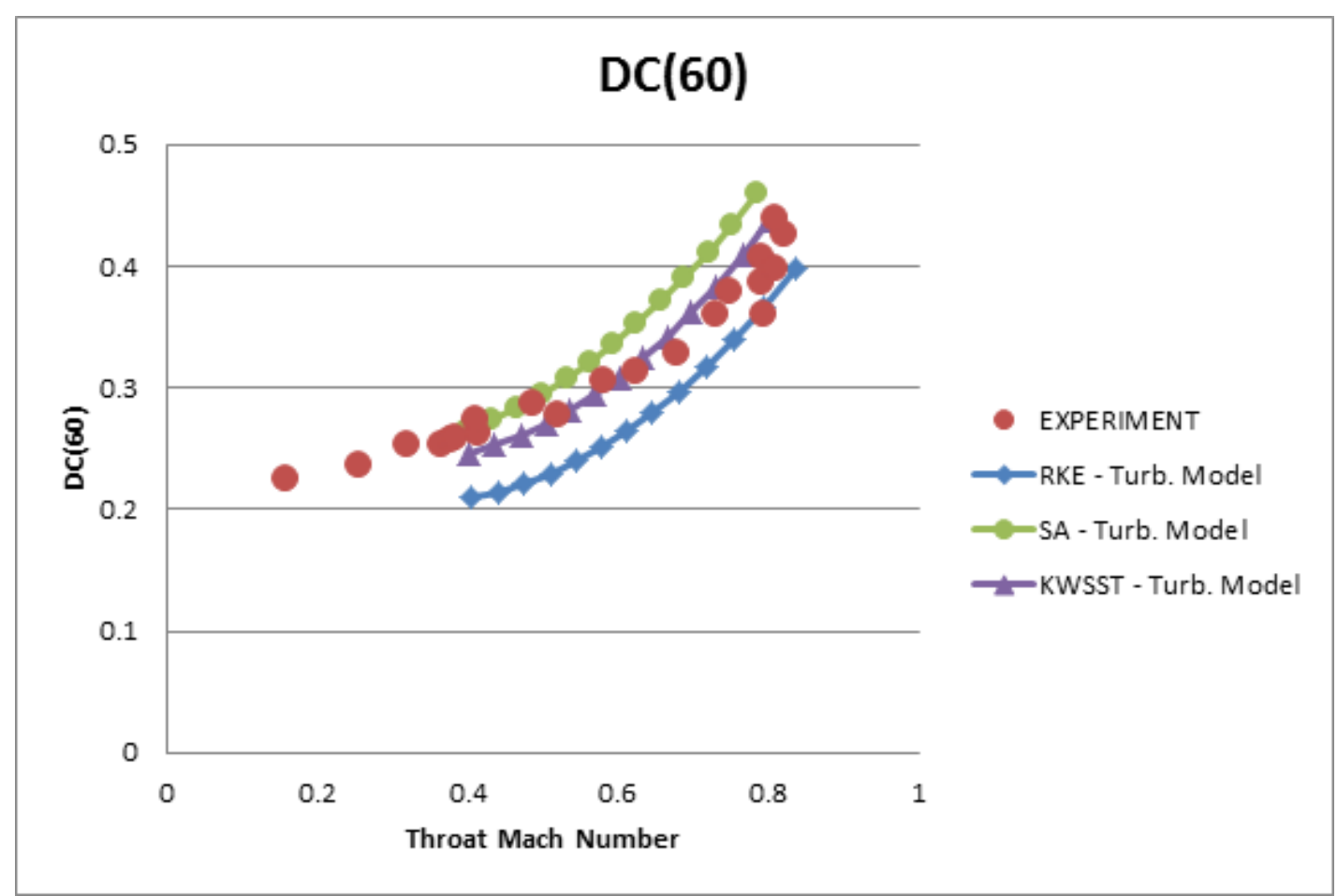

Figure 3.24: Comparison of the DC(60) values at the engine face - clean M2129 intake without cowl lip 
When comparison is made between the computed and experimentally found PR values, it is seen that all computational results are close to each other and experimental values. With the decrease in throat Mach number values, results become even more closer. Among three turbulence model, computations obtained with SA show lowest $\mathrm{PR}$ values whereas computations with RKE indicate highest PR values. Although all computations result in similar PR values, KWSST turbulence model is more successful in predicting $\mathrm{PR}$ values compared to other two turbulence model for whole throat Mach number range.

Although all turbulence models are successful in capturing general trend of the variation of intake performance parameters with varying throat Mach number, there are significant differences between the results obtained with different turbulence models. This difference is most significant at the prediction of $\mathrm{DC}(60)$ coefficient. As can be seen from the figure 3.24, computations obtained with SA turbulence model results in higher distortion at the high throat Mach number values compared to experimental and other computational results. However, at low throat Mach number values (around 0.45) experimental and computational results obtained with SA turbulence model show excellent agreement. At the same time computed $\mathrm{DC}(60)$ values with KWSST turbulence model are very close to experimental ones, however at low throat Mach number values near 0.45 , KWSST and experimental results deviate from each other and computations indicates slightly lower $\mathrm{DC}(60)$ values. Furthermore, when comparison is made between computational results obtained with RKE turbulence model, significant disparity is observed between experimental and computational results. Computational results obtained with RKE turbulence model indicates lower $\mathrm{DC}(60)$ values for investigated throat Mach number range compared to experimental or any other computational results. 


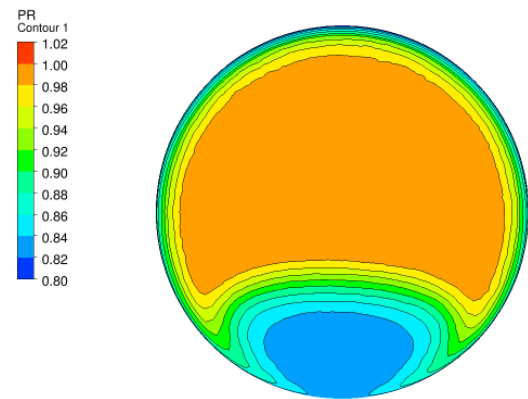

(a) Engine face total pressure recovery contours obtained with KWSST - throat Mach number 0.79
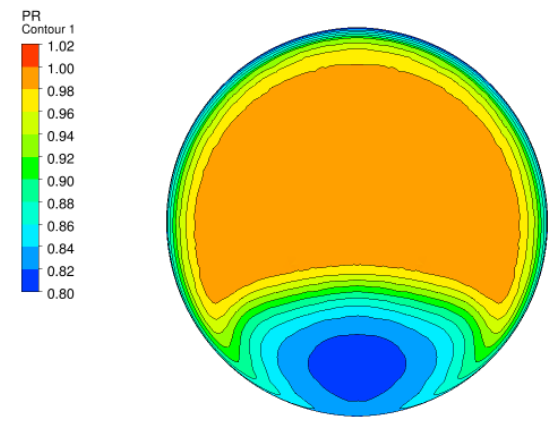

(c) Engine face total pressure recovery contours obtained with SA - throat Mach number 0.79

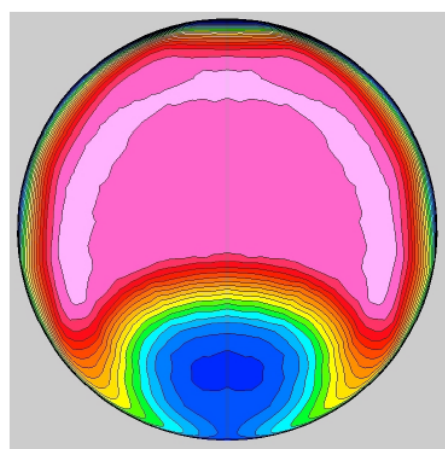

(e) Engine face total pressure recovery contours obtained with Wind-Us Flow Solver, unstructured mesh, SA [44 - throat Mach number 0.79

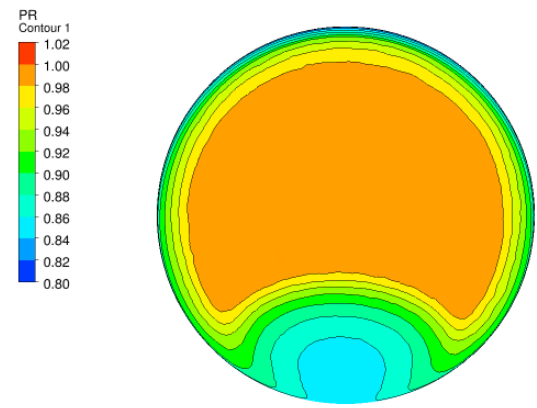

(b) Engine face total pressure recovery contours obtained with RKE - throat Mach number 0.79

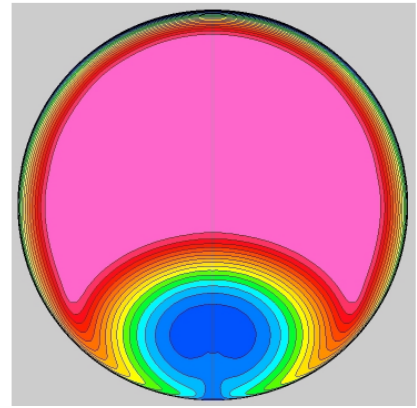

(d) Engine face total pressure recovery contours obtained with Wind-Us Flow Solver, structured mesh, SA [44] - throat Mach number 0.80

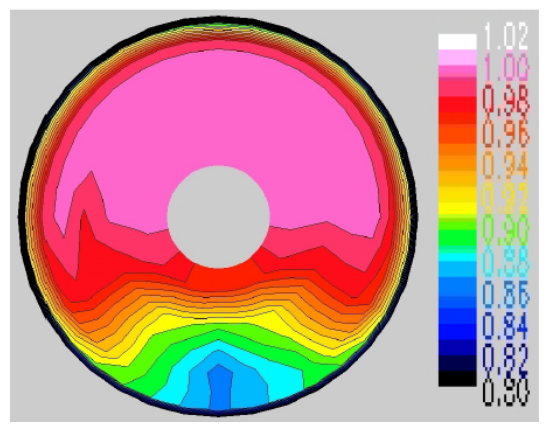

(f) Engine face total pressure recovery contours experimental result [44] - throat Mach number 0.79

Figure 3.25: Comparison of the computationally and experimentally obtained engine face total pressure recovery contours

Total pressure contours at the engine face can give further information about characteristics of the turbulence model. For the M2129 intake without cowl-lip case it 
is possible to compare experimentally and computationally obtained total pressure contours at the engine face for throat number 0.79 as it is presented in the study conducted by Mohler 44. Mohler was also investigate M2129 intake without cowl lip computationally. His computational results obtained with Wind-US flow solver which is developed in the NPARC Alliance. This comparison including results obtained in the Mohler's work with structured and unstructured meshes with SA turbulence model shown in figure 3.25

Experimentally obtained PR contours shows unsymmetrical characteristics at the engine face. This asymmetry was not captured in any computational result. Among computational results, it is observed that that SA turbulence model predicts widest low pressure region whereas RKE turbulence model predicts smallest one. This characteristic is parallel with the results shown in the figures 3.23 and 3.24 .

\subsubsection{Results Obtained with M2129 Intake with Vortex Generators}

Work conducted by Anderson and Gibb[6] investigates effects of several vortex generator set on the M2129 intake performance. His results show that VG170 configuration which includes 11 pairs of vortex generator is the most successful vortex generator set for increasing intake performance among investigated vortex generator sets. In the present study, for validation and turbulence model selection only computational results obtained with VG170 vortex generator set are compared with the experimental results available in the work conducted by Anderson and Gibb[6]. Properties of the VG170 vortex generator sets are given in the table 3.26 and nomenclature used in the reference study [6] is given in the figure 3.27 ,

\begin{tabular}{lcccc}
\hline \hline Designation & VG130 & VG160 & VG165 & VG170 \\
\hline Number of pairs, $n_{\mathrm{vg}}$ & 11 & 13 & 11 & 11 \\
Sector location, $X_{\mathrm{v}} / R_{i}$ & 3.0 & 1.0 & 1.0 & 2.0 \\
Blade height, $h / R_{i}$ & 0.075 & 0.060 & 0.065 & 0.070 \\
Chord length, $c / R_{i}$ & 0.300 & 0.240 & 0.260 & 0.280 \\
Lateral spacing, $d / R_{i}$ & 0.289 & 0.224 & 0.267 & 0.277 \\
Spacing angle, $\boldsymbol{\alpha}_{\mathrm{vg}}$ deg & 15.0 & 12.6 & 15.0 & 15.0 \\
Angle of incidence, $\boldsymbol{\beta}_{\mathrm{vg}}$ deg & 16.0 & 16.0 & 16.0 & 16.0 \\
Sector angle, $\theta_{s,}$ deg & 157.5 & 157.5 & 157.5 & 157.5 \\
\hline \hline
\end{tabular}

Figure 3.26: Matrix of the designed vortex generator sets used in the reference work [6] 


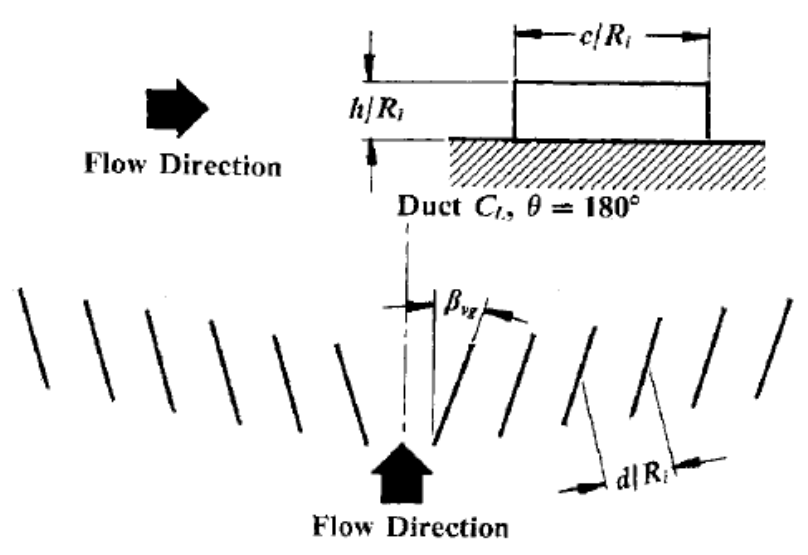

(a) Geometrical representation of vortex generator set used in the reference work 6 .

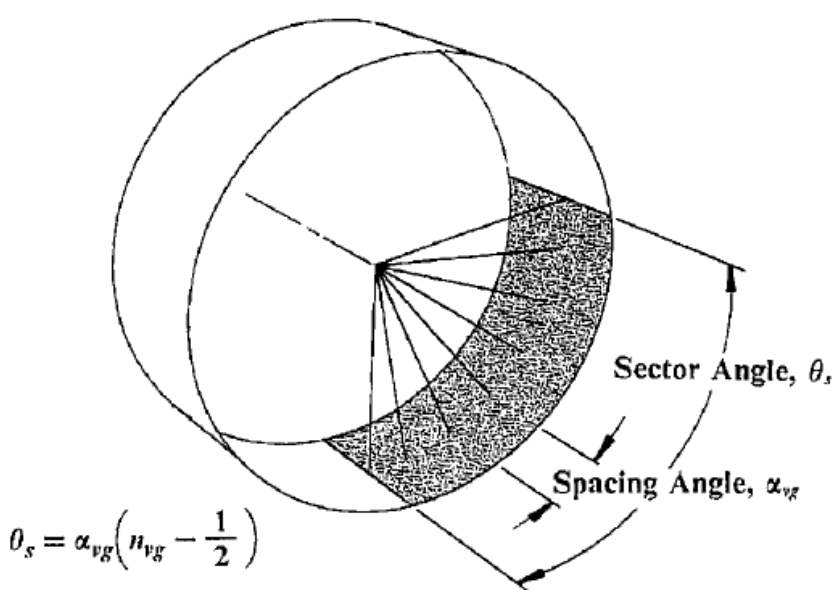

(b) Nomenclature used for vortex generator set positioning used in the reference work 6 .

Figure 3.27: Geometrical representation and nomenclature of the vortex generator sets used in the reference work[6]

For the case of M2129 intake with vortex generators no mesh dependency analysis are made. Instead very similar surface mesh used for the clean intake case is created with the very dense meshes on vortex generators. Surface mesh around M2129 intake with vortex generators with closer view of the surface mesh around vortex generators are show in the figure 3.28 . Total number of elements of the mesh used for this case is 2317064 . 

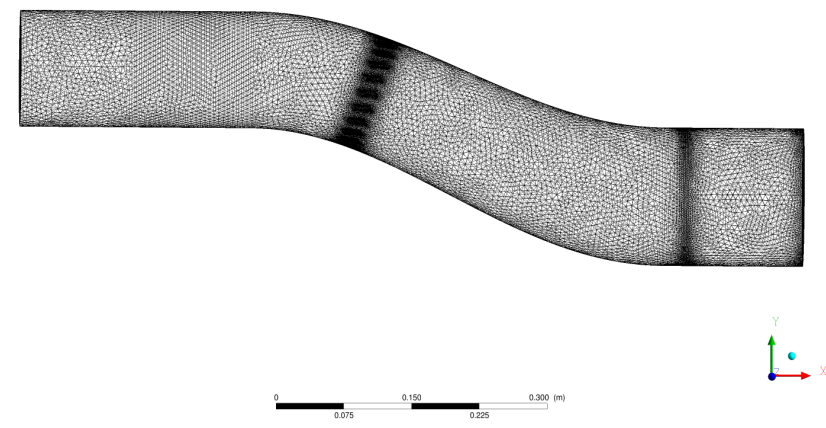

(a) Surface mesh around M2129 intake with vortex generator set VG170

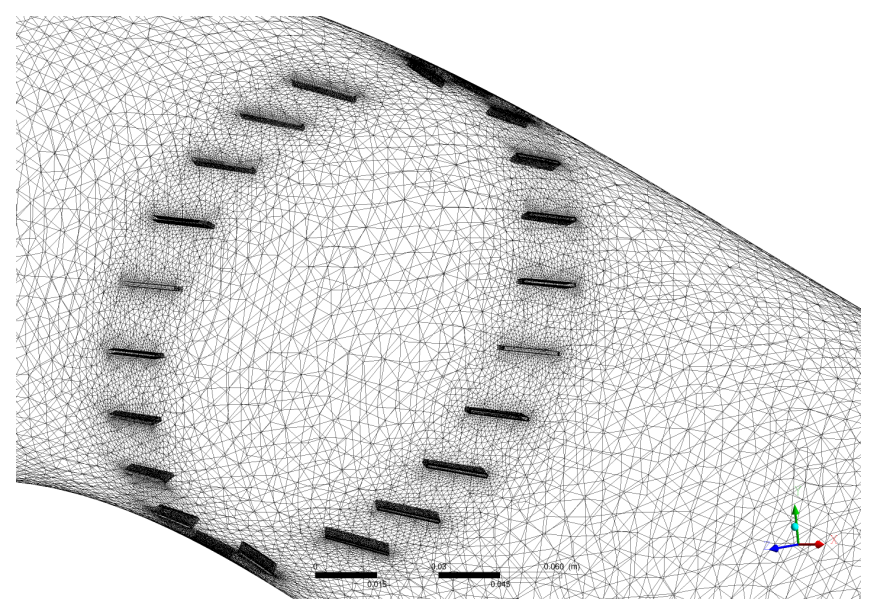

(b) Surface mesh around vortex generator set VG170

Figure 3.28: Surface mesh around M2129 intake with vortex generator set used for validation and turbulence model selection

Since $\mathrm{DC}(60)$ and $\mathrm{PR}$ are the two main intake performance parameter, comparisons between the experimental and computational data obtained in the current work are made between them. Comparison of the computationally obtained PR and DC(60) values with the experimental values are given in the figure 3.29 and figure 3.30 respectively. 


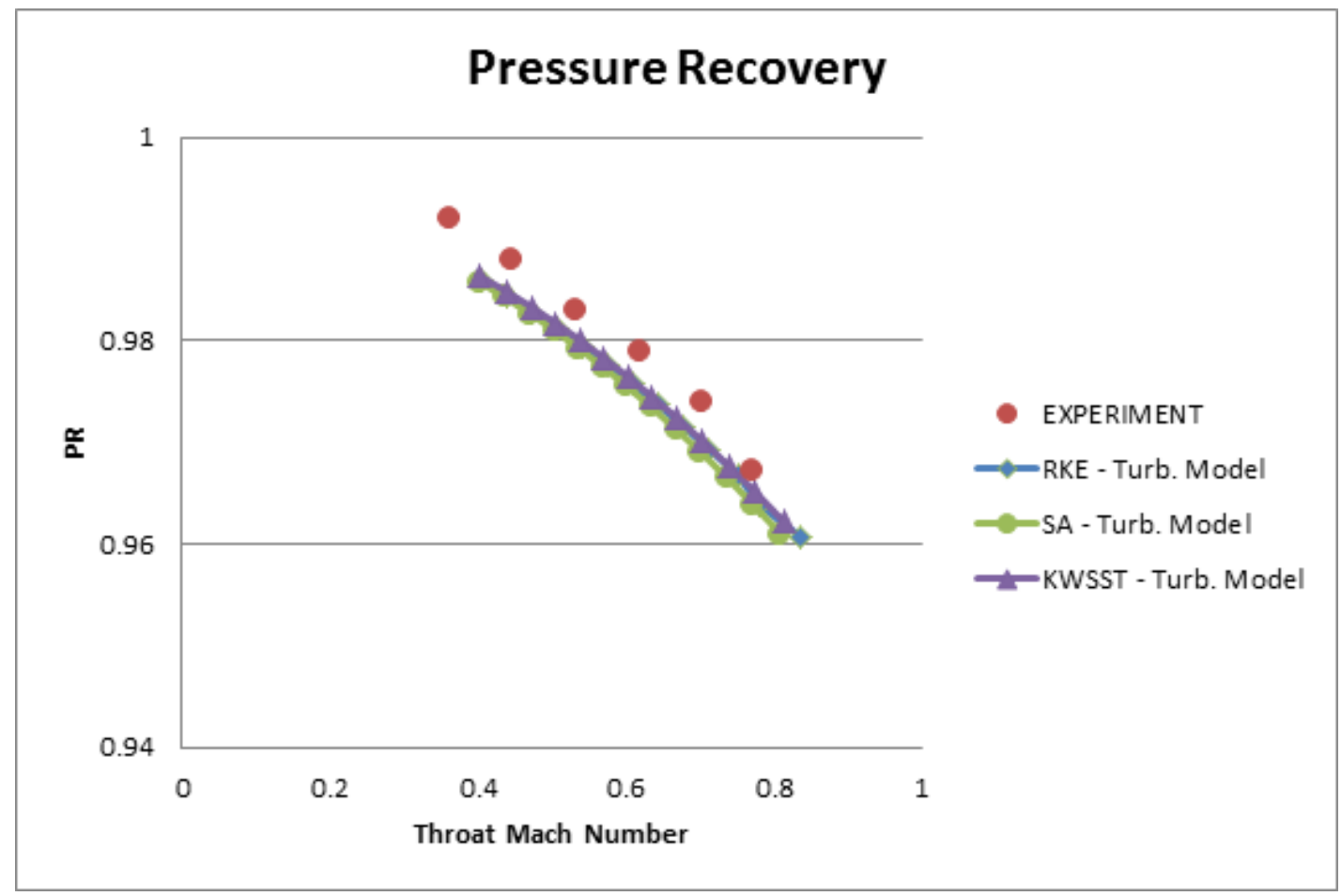

Figure 3.29: Comparison of the total pressure recoveries at the engine face - M2129 intake with vortex generator set

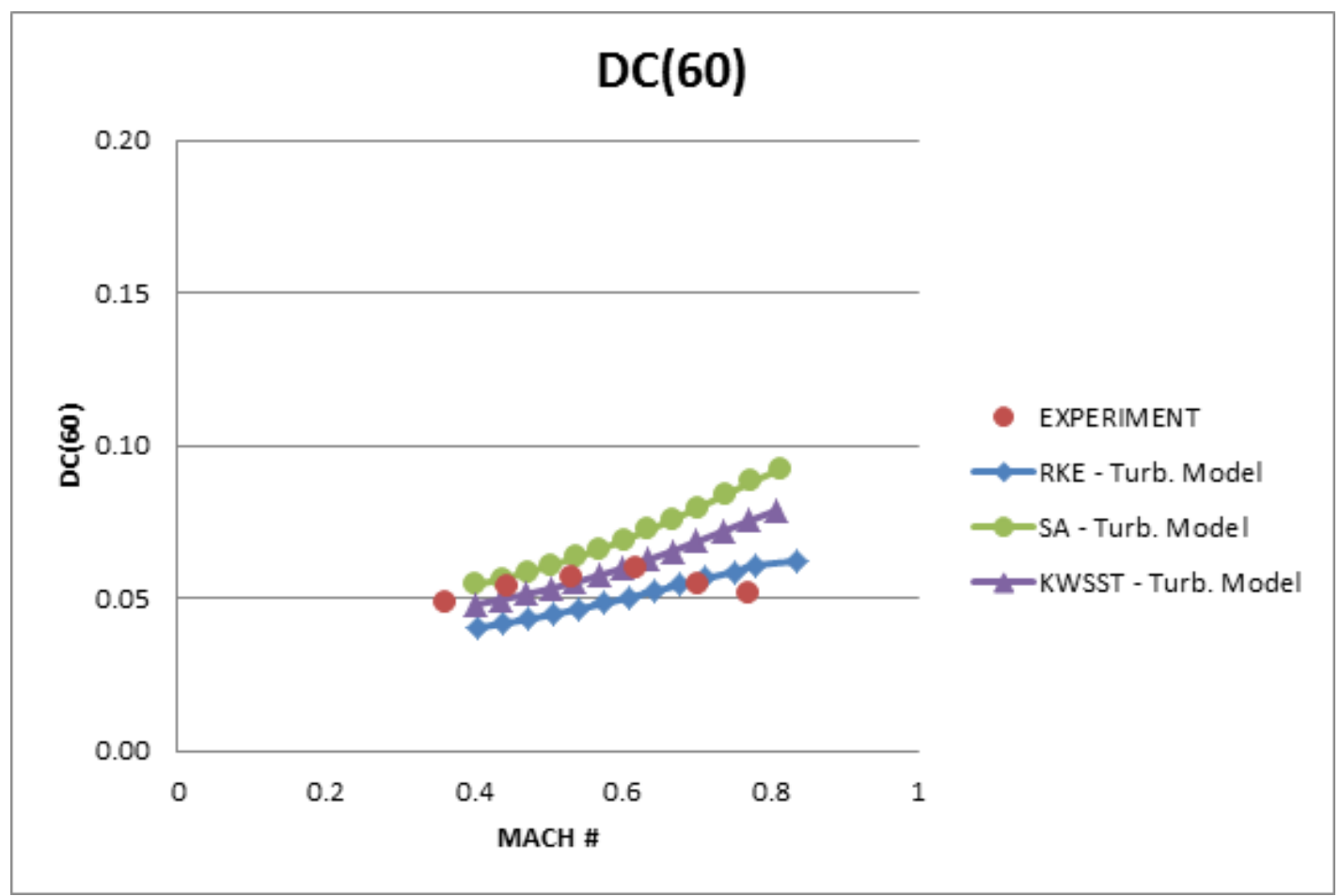

Figure 3.30: Comparison of the DC(60) values obtained at the engine face - M2129 intake with vortex generator set 
When a comparison is made between computationally and experimentally obtained pressure recovery values it is seen that computed values are smaller than the experimental ones regardless of turbulence model. Furthermore, predicted values are very close to each other. Therefore, in terms of accuracy of PR estimations none of investigated turbulence models are favorable than others.

On the other hand, computed distortion values are separated from each other and experimental values in some extent. Although computed $\mathrm{DC}(60)$ values show increasing trend with increasing throat Mach number, there is a significant decrease in the experimentally obtained DC(60) values after throat Mach number value of 0.6. From figure 3.30 it is seen that predictions with RKE turbulence model gives most accurate results for throat Mach number values above 0.6. At the same time computed $\mathrm{DC}(60)$ values with SA turbulence model results in highest $\mathrm{DC}(60)$ values which has biggest disparity compared to experimental values. Although computed DC(60) values with KWSST turbulence model somehow differs from the experimental values at high throat Mach numbers, they have excellent agreement for the throat Mach number values below 0.6.

Since total pressure contours obtained at the engine face can give crucial information about characteristics of the turbulence models which are investigated as in the case of clean M2129 intake, total pressure contours obtained at the engine face for M2129 intake with vortex generators are compared with the available experimental data and reference CFD result available in the Mohler's paper[4] for throat Mach number value of 0.77 . This comparison is given at the figure 3.31. As can be seen from this figure general characteristics of the pressure recovery contours appear similar. However, all contours obtained with both current and previous research show lower total pressure recoveries at the top and upper sides of the engine face. 

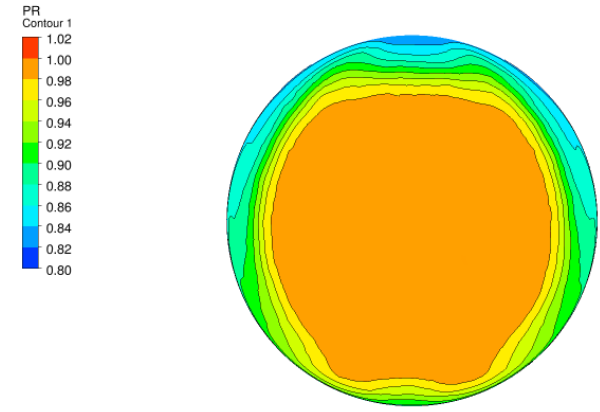

(a) Engine face total pressure recovery contours obtained with KWSST - throat Mach number 0.77 - M2129 intake with vortex generators
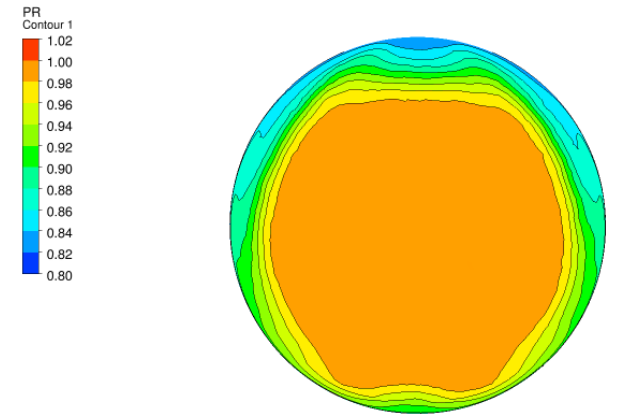

(c) Engine face total pressure recovery contours obtained with SA - throat Mach number 0.77 - M2129 intake with vortex generators

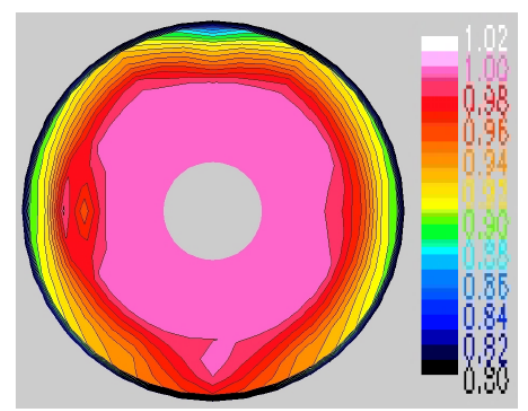

(e) Engine face total pressure recovery contours experimental result 44] - throat Mach number 0.77

Figure 3.31: Comparison of the computationally and experimentally obtained engine face total pressure recovery contours

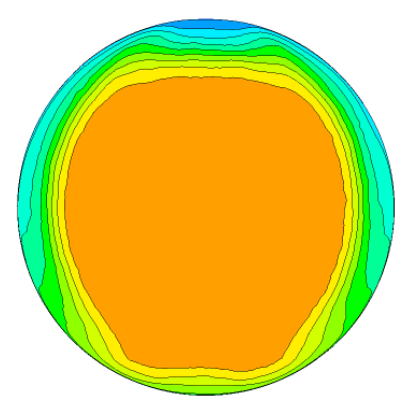

(b) Engine face total pressure recovery contours obtained with RKE - throat Mach number 0.77 - M2129 intake with vortex generators

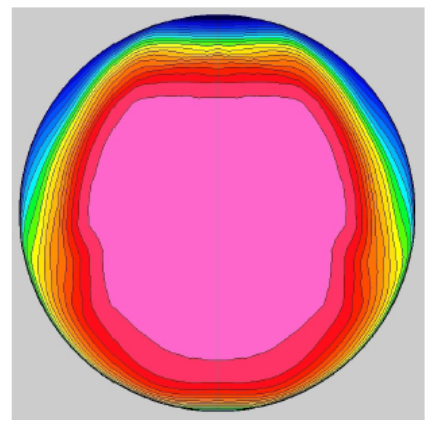

(d) Engine face total pressure recovery contours obtained with Wind-Us Flow Solver, structured mesh, SA [44] - throat Mach nNumber 0.77 


\subsection{Post Processing Uncertainties Related to M2129 Intake Flow Calculations and Modelling Errors}

During validation and turbulence model selection study several uncertainties are encountered. These uncertainties are mostly originating from the inadequate explanation of the calculation methodology for distortion and pressure recovery coefficients in the experimental study. It is possible to reach significantly different values of $\mathrm{DC}(60)$ from the computational results depending on the post processing technique. Although it is possible to calculate $\mathrm{DC}(60)$ values by area averaging technique for determined circumferential extent in computational studies, this can not be done in experimental investigations. It is known that experimentally obtained total pressure recoveries and distortion values which are subject of validation study are depicted from 72-probe pitot rake placed at the engine face as shown in the figure 3.32 .

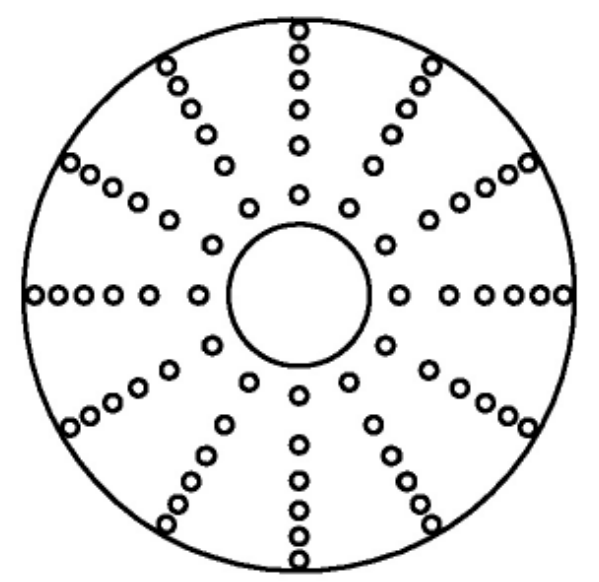

Figure 3.32: 72 probe rake used in experimental investigations [4]

In order to be consistent with the experimental calculations, probe locations shown in the figure 3.32 are also used for current computational investigations. However there is still uncertainties related to interpolation method followed in the experimental study. The interpolation method performed in the experimental study is not clearly indicated. Hence, linear interpolation is performed in the current study.

Furthermore, although effect of bullet (i.e center body) is sensed during the investigation of M2129 intake with cowl lip, in the calculations collected for the M2129 intake without cowl-lip, center body (i.e bullet) was not modeled. This is the common 
trend followed by many previous investigators interested in this intake [44, 16, 6]. It is assumed that effect of center body, which covers only $7 \%$ of the engine face area, is limited and it has no significant effect on computed total pressure distribution on the engine face.

\subsection{Comments About Validation Study}

In this work, capabilities of the KWSST, SA and RKE turbulence models in computing S-duct flows are investigated with the commercial CFD code Fluent14. These three turbulence model are extremely popular in the aerospace industry because of their usefulness in various flow condition with their advantage in providing significant amount of time saving.

Although there is no best turbulence model for all type of flow problems, selection of the most suitable turbulence model for the single type of flow is possible. The most suitable turbulence model actually depends on the flow type and also the available amount of time. Among the all turbulence models SA which is a one-equation model provides lowest cost and relatively good performance over a wide range of aerospace applications. The other two turbulence model investigated in this work, KWSST and RKE are two-equation turbulence models and they also offer ease of use and low cost with relatively good performance for various flow types.

In the light of results obtained in this study several conclusions can be made about the relative success of the turbulence models used in this work in computing S-Duct flows. First of all for the case of M2129 intake with cowlip, it is clear that regardless of the turbulence model, when separation is more dominant as in the case of HMFR, all turbulence models calculate higher total pressure distortion compared to the experimental values. Although this difference can be originating from the nature of the turbulence models, there is an another possibility which is the post processing uncertainties that are mentioned before. However for the HMFR case, where separation is more dominant, computationally and experimentally obtained wall static pressure distributions are also differ from each other. This difference actually indicates reason of the computing high distortion coefficient, because predicted static wall pressure distributions shows higher acceleration and deceleration rates near the first bend of the duct which 
is actually main reason of the vortex lift-off and total pressure distortion at the engine face. Therefore, for the HMFR case where separation is dominant there is apparent lack of capability of the computations in computing distortion coefficient regardless of the turbulence model at least used ones in this work. Furthermore, computed and experimentally obtained pressure recovery values at HMFR case differ from each other in a greater extent compared to the LMFR case. Therefore, it is observed that HMFR case cannot be solved with an high precision with the available tools.

At the same time from the computational results regarding M2129 intake without cowllip it is seen that CFD computations are capable of capturing general characteristics of the variation of the intake performance criteria with varying throat Mach number accurately. Furthermore, when vortex generators are applied, significant decrease in the distortion coefficient was captured with all turbulence models investigated in the current work.

Convergence properties are also important for selecting turbulence model for a specific flow problem. Since all three turbulence models used in this work shows similar convergence characteristic as mentioned earlier, there is no superior turbulence model among SA, RKE and KWSST in terms of ease and accessibility of convergence.

Among the three turbulence models, KWSST arises as the most applicable model for analyzing flow in S-Ducts. Computation with KWSST turbulence model shows excellent agreement with the experimental result obtained for LMFR case and for computations performed with M2129 intake without cowl-lip. Earlier investigators are also sum up with the similar conclusions. Aaron M. Kirk et al[33], found that KWSST is most suitable turbulence model for analyzing S-Duct flows. Another available work[2] investigating S-Duct flows and effect of vortex generators over the transonic boundary layer ingesting S-Duct offers KWSST turbulence model for this kind of applications. Furthermore, many investigators use a KWSST turbulence model for their simulations for not only flow simulation inside the clean S-duct but also for simulations to observe effect of vortex generators, icing and the inflow conditions on the flow inside the S-ducts[44, 16, 59, 13].

The main idea of designing the KWSST turbulence model is composing the robust and accurate characteristics of the original KW turbulence model at the near wall region 
with the advantage of the KE model at the outer part of the boundary layer [42]. Moreover it is known that this turbulence model is especially suitable for adverse pressure gradients and even more, vortex lift off which is due to the centrifugal forces originating from the curvature of the S-Ducts are predicted quite successfully with this turbulence model[42].

In the end of the validation study it can be concluded that when separation is moderate turbulent CFD simulations can be used for precise prediction of the intake performance criteria; distortion and pressure recovery. However if the separation is dominant, predicted performance criteria can misguide the intake designer. Furthermore, in terms of predicting intake performance criteria with and without application of vortex generators, KWSST turbulence model arises as a most suitable option in the light of not only obtained results from the current study but also results found in the literature. 


\section{CHAPTER 4}

\section{PROBLEM DEFINITION}

In this chapter information about investigated diverterless intake duct which is designed for subsonic and transonic flow conditions is provided. This intake is designed with high diffusion rate and sharp centerline curvature which provide higher packaging efficiency and less weight. Moreover, intake is embedded into the airframe such that hot spots of the engine face are mostly sheltered.

\subsection{Geometrical Properties of Investigated Intake}

Throat area, centerline curvature and area distribution along the streamwise direction are the main factors that are effecting performance of an air intake. During the design process effect of all these parameters must be well understood. In some cases, where reducing RCS area has a strategical importance, geometrical angles which forms shape of intake wetted area must be carefully adjusted in order to reduce RCS of overall air vehicle.

Entrance of the investigated intake duct has a trapezoidal shape as shown in the figure 4.1 in which all lengths are non dimensionalized with the engine face diameter. 


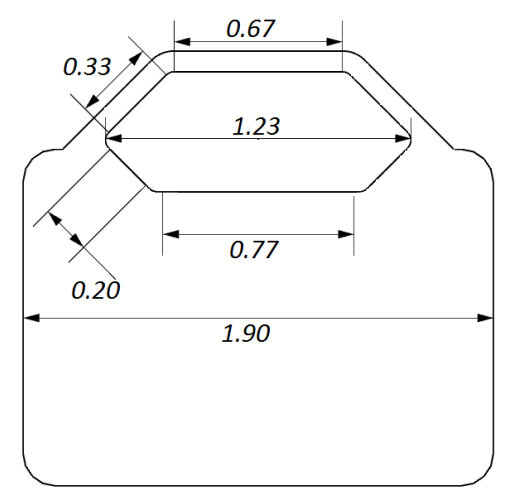

Figure 4.1: Inlet entrance and missile body (all lengths are non-dimensionalized with engine face diameter)

Furthermore expansion ratio from intake entrance to the engine face is 1.6 which indicates high diffusion rate thus high adverse pressure gradients inside the intake. Ratio of the centerline offset to the length of the S-duct is 0.20 as shown in the figure 4.2. High expansion rate and centerline curvature are the two main factors that make this intake very aggressive design with high compactness.

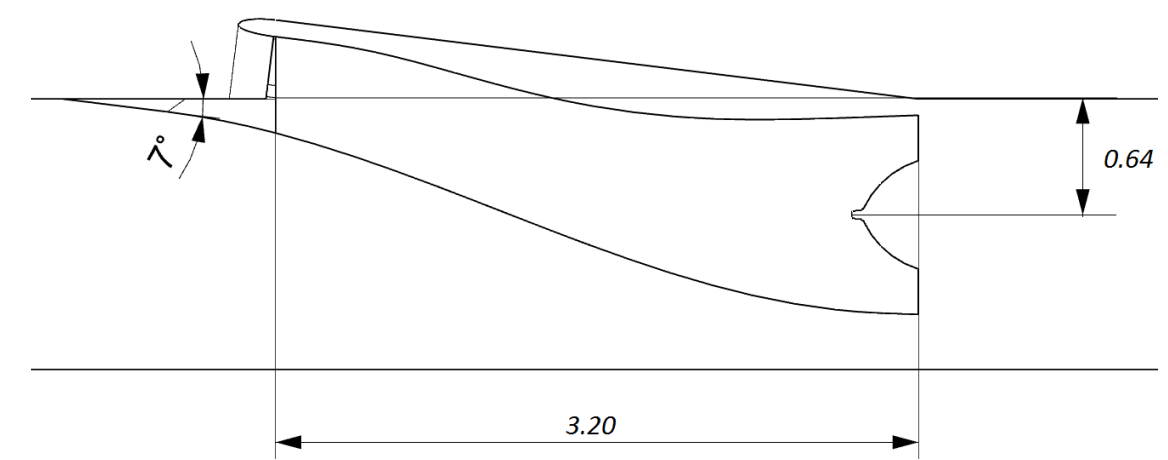

Figure 4.2: Inlet side view (all lengths are non-dimensionalized with engine face diameter)

Furthermore as can be seen from figure $4.2 \mathrm{ramp}$ angle is defined as $7^{\circ}$. This specific value is an optimum one such that below friction and above adverse pressure gradient losses become dominant. This ramp angle is used commonly in many aerodynamic shaping problems. This specific value is also suggested by the Seddon and Goldsmith[56] for intake ramp angles. 
Lip separation is an another source of loss inside intakes and its magnitude basically driven by location of stagnation point. At design conditions where capture flow ratio is lower than unity, stagnation occurs inside portion of the intake lip. In such condition, flow inside the intake slowly accelerates from stagnation point and it moves through downstream. However, external flow is exposed to high acceleration rates leads flow separation outside the intake lip. In a opposite scenario where capture flow ratio higher than unity stagnation point shifts to the outside portion of the intake lip such that inside portion of the intake lip is exposed to high acceleration rates and possible separation which degrades performance of intake. Thick lip designs can eliminate the possibility of flow separation in a great extent.

Intake lips provide designer to adjust contraction ratio which is defined as ratio of the highlight area to the throat area. Highlight radius which defines disk area formed by most upstream point of the intake lip and throat radius are illustrated in the figure 4.3

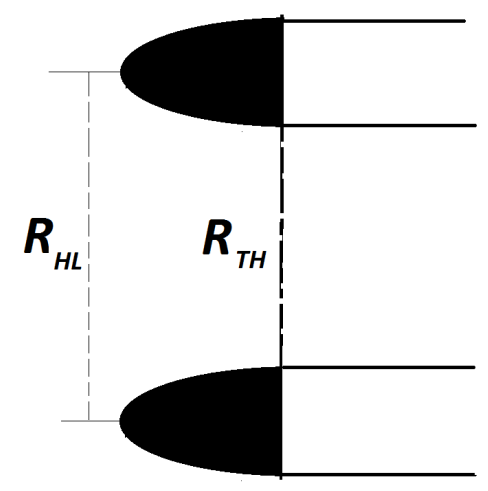

Figure 4.3: Highlight and throat radius

Contraction ratio provides a region at the just upstream of throat where favorable pressure gradient is present. In order to provide high internal flow quality, lip design and contraction ratio plays important role especially for flow conditions where high engine mass flow demand present at low speed flights as in the case of ground take off. At the same time for design conditions where stagnation point occur at the inner side of the lips, there is no practical way for internal flow separation originating from intake lips which possibly degrades intake performance[56]. Therefore, determination 
of the lip shaping and the contraction ratio is crucial for off-design flow conditions.

Goldsmith and Seddon[56] investigated effect of lip shape and contraction ratio on the losses occurred at the intake lips at off design conditions. They concluded that elliptic lip shaping provides decrease in lip loss compared to the semi-circular lip shaping. Furthermore their results show clear evidence that as contraction ratio increases lip losses show decreasing trend. Their results are given in the figure 4.4.

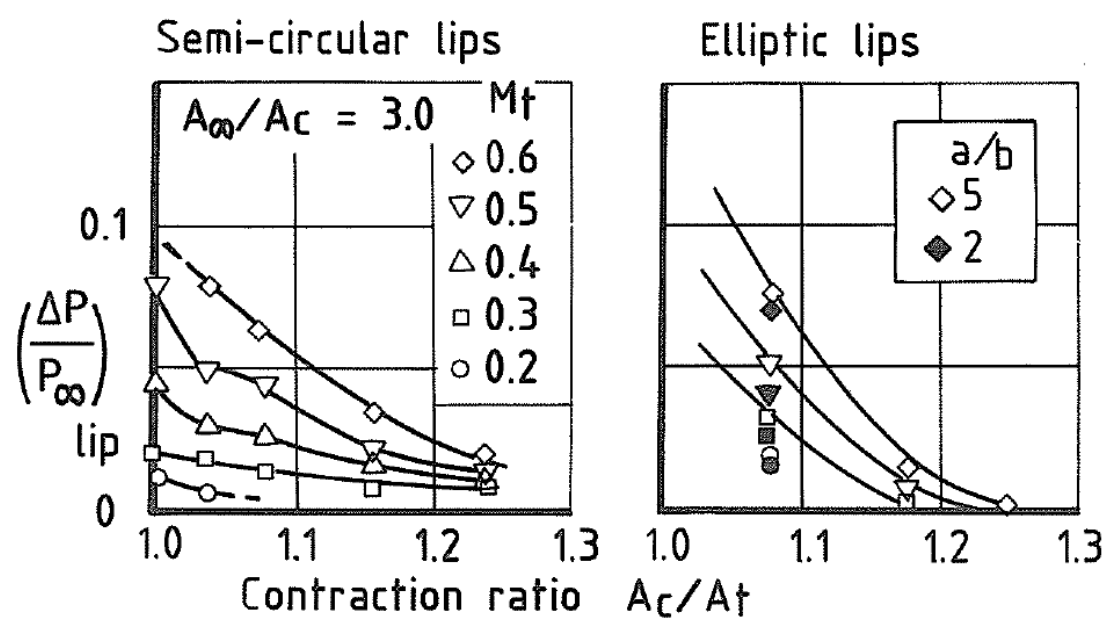

Figure 4.4: Effect of contraction ratio and lip shaping on the lip loss [56]

In the present work lips are formed in line with the findings of Goldsmith and Seddon[56]. Investigated intake has elliptic lips with fineness ratio equal to 2 and contraction ratio equal to 1.18 .

\subsubsection{Engine Face and Hub Geometry}

Effect of hub geometry was mentioned in the validation case. Since hub geometry effects the total pressure distribution at the engine face modeling hub geometry at the engine face is important. Details of the hub geometry is given at figure 4.5 . 

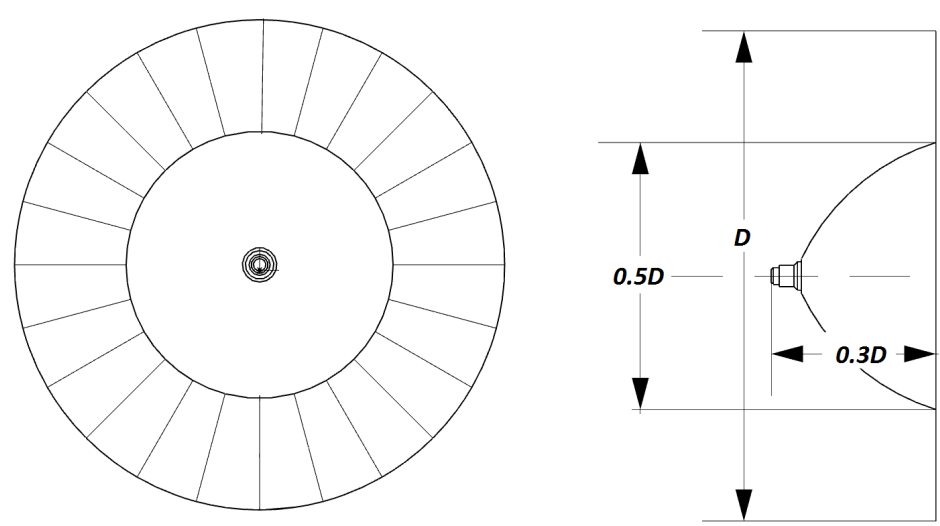

Figure 4.5: Engine face and hub geometry

\subsubsection{Centerline Curvature and Area Ratio}

Centerline curvature is one of the most dominant parameter effecting intake performance. In the present work selected centerline curvature is originated from the work conducted by Zhang et al[68. Moreover, this centerline curvature was also subject of an earlier TUBITAK-SAGE's work conducted by Basoglu et al[11].

Centerline curvature is defined according to following formula;

$$
z(x)=s\left[(n+1)\left(\frac{X}{L}\right)^{n}-n\left(\frac{X}{L}\right)^{n+1}\right]
$$

where $\mathrm{s}$ and $\mathrm{L}$ are the centerline offset and total length of the serpentine inlet respectively. Parameters used in above equation are shown in the figure 4.6 . 


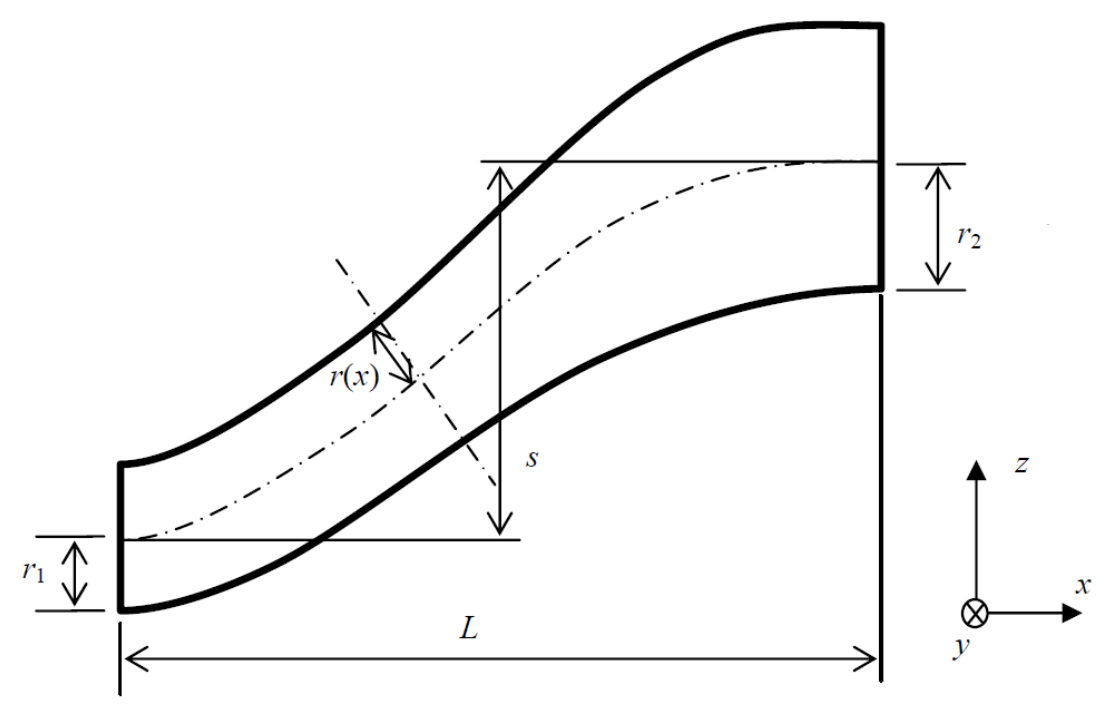

Figure 4.6: Definition of inlet centerline curvature 68

In the work conducted by Basoglu et al.[11, it was computationally shown that factor "n" seen in the equation 4.1 has significant effect on total pressure distribution at the engine face whereas pressure recovery changes only in limited extent with varying $\mathrm{n}$ value. Morever, they show that minimum distortion coefficient is obtained with equation 4.1 when $n$ is equal to 2 . Thus, $n=2$ is chosen for the centerline curvature of the investigated duct.

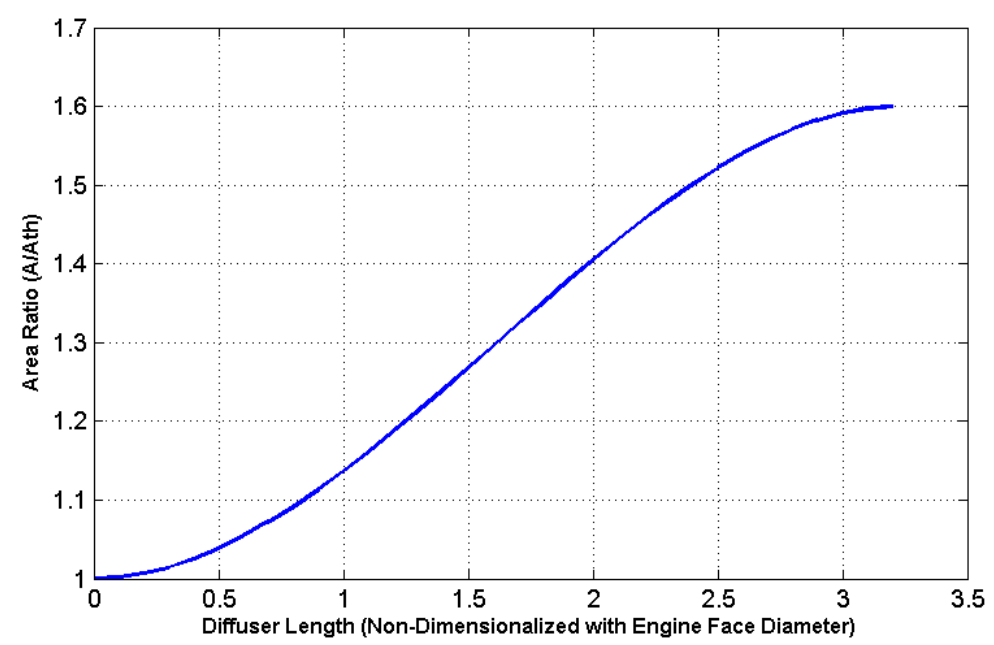

Figure 4.7: Area distribution

Area distribution through the intake in streamwise direction is another parameter that 
intake designer must take into account. Since sudden area increase create high adverse pressure gradients, smooth area changes in streamwise direction provide reduction in total pressure loss and distortion. Variation of area ratio of the investigated intake duct in stream wise direction is given in the figure 4.7. This gradual area distribution offers near linear diffusing rate starting from the throat to the engine face in order to minimize losses originating from diffusion.

\subsubsection{Throat Area}

Air intake must supply engine mass flow demand through the all regimes of the flight envelope. Therefore, determination of proper throat area plays crucial role in design of air intake. Smaller throat areas than required lead to insufficient mass flow rate reaching engine. On the other hand, larger throat areas lead high spillage drag. Throat area is a direct function of engine mass flow demand therefore engine specifications must be cleared off before determining throat area. Once engine mass flow demand are collected for various flow regimes, a critical condition selected at which engine mass flow demand is the largest. This specific condition generally corresponds to the low altitude and low temperature flight. After determination of critical condition, throat area can be adjusted with 1-D ideal gas equations as explained below;

- Continuity equation at the inlet throat;

$$
\dot{m}=\rho A V
$$

- Assuming air is an ideal gas;

$$
\rho=\frac{P_{s}}{R T_{s}}
$$

- Inserting equation 4.3 into the equation 4.2 ,

$$
\frac{\dot{m}}{A}=\frac{P_{s}}{R T_{s}} V
$$

- Since;

$$
V=M a \quad a=\sqrt{\gamma R T_{s}}
$$

- Inserting above equations into the equation 4.4 , it becomes;

$$
\frac{\dot{m}}{A}=\frac{P_{s}}{R T_{s}} M \sqrt{\gamma R T_{s}}
$$


- Rearranging equation 4.5 ,

$$
\begin{aligned}
& \frac{\dot{m}}{A}=\frac{P_{s}}{\sqrt{\gamma R T_{s}}} M \gamma \\
& \frac{\dot{m}}{A}=\frac{P_{s}}{\sqrt{T_{s}}} \sqrt{\frac{\gamma}{R}} M
\end{aligned}
$$

- Assuming flow is isentropic;

$$
\frac{T_{t}}{T_{s}}=\left(1+\frac{\gamma-1}{2} M^{2}\right) \quad \frac{P_{t}}{P_{s}}=\left(1+\frac{\gamma-1}{2} M^{2}\right)^{\left(\frac{\gamma}{\gamma-1}\right)}
$$

- Inserting isentropic relationships into equation 4.6

$$
\begin{aligned}
& \frac{\dot{m}}{A}=\sqrt{\frac{\gamma}{R}} \frac{P_{t}}{\sqrt{T_{t}}} \frac{M}{\left(1+\frac{\gamma-1}{2} M^{2}\right)^{\frac{\gamma+1}{2(\gamma-1)}}} \\
& \frac{\dot{m} \sqrt{T_{t}}}{P_{t} A}=\sqrt{\frac{\gamma}{R}} \frac{M}{\left(1+\frac{\gamma-1}{2} M^{2}\right)^{\frac{\gamma+1}{2(\gamma-1)}}}
\end{aligned}
$$

- Right hand side of the equation 4.7 is only a function of local Mach number and gas constants. This special part of the equation 4.7 is called as mass flow parameter and its variation with Mach number given in the figure 4.8

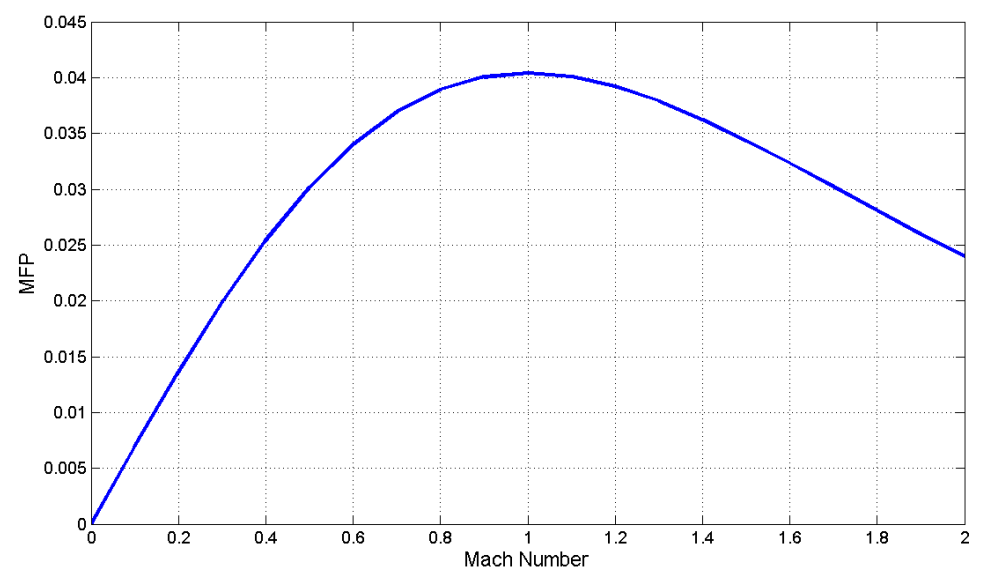

Figure 4.8: MFP vs Mach number

- Since mass flow parameter defined accordingly;

$$
M F P(M)=\sqrt{\frac{\gamma}{R}} \frac{M}{\left(1+\frac{\gamma-1}{2} M^{2}\right)^{\frac{\gamma+1}{2(\gamma-1)}}}
$$


- By using MFP and rearranging equation 4.7 a simple equation is obtained which basically defines throat area for a pre-defined mass flow rate.

$$
A_{\text {throat }}=\frac{\dot{m} \sqrt{T_{t}}}{P_{t}} \frac{1}{M F P(M)}
$$

As can be seen from figure 4.8 smallest throat area is reached when throat Mach number is adjusted as unity. However, in such condition flow is choked at the throat which degrades intake performance dramatically. If smaller Mach number is selected in the definition of the MFP a larger throat area is obtained which eliminates negative effects of flow chocking. Another problem is related to possible effects of transonic flow occurring at the intake throat. Since real flow is not one dimensional local supersonic regions may be formed although average throat Mach number is still transonic. Therefore, intake throat generally sized such that throat Mach number does not exceed 0.8[40]. This strategy leads to growth in throat area such that transonic effects and errors coming from the one dimensional and isentropic flow assumptions are eliminated.

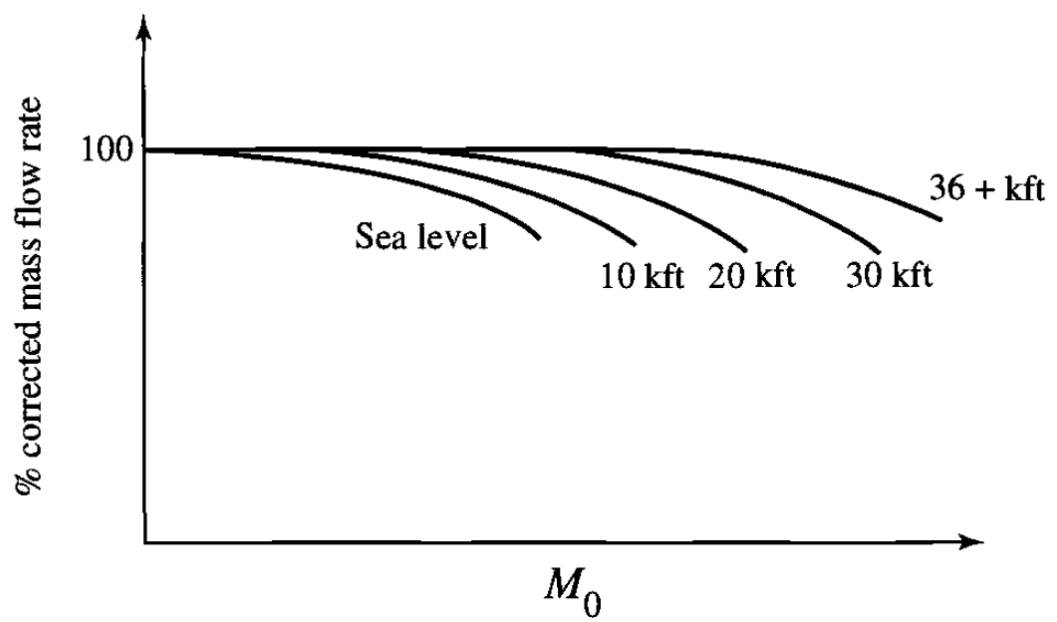

Figure 4.9: A typical subsonic engine corrected mass flow demands 40]

Furthermore, since engine mass flow demand can change with operating altitude for same Mach numbers, corrected mass flow rate is defined by the engine manufacturers such that engine mass flow demand become independent of operating altitude. A typical subsonic engine corrected mass flow demands at different flight altitudes and Mach 
numbers are given in the figure 4.9 . Corrected mass flow rate is defined accordingly;

$$
\dot{m}_{c}=\dot{m} \frac{\sqrt{\theta}}{\delta}
$$

where

$$
\theta=\frac{T_{t}}{T_{r e f}} \quad \delta=\frac{P_{t}}{P_{r e f}}
$$

Introducing corrected mass flow rate to the equation 4.7 it becomes;

$$
A_{\text {throat }}=\frac{\dot{m}_{c} \delta}{\sqrt{\theta}} \frac{\sqrt{T_{t}}}{P_{t}} \frac{1}{M F P(M)}
$$

This was the procedure followed for area sizing of the investigated intake throat with MFP equal to 0.8 , for maximum engine mass flow demand.

\subsection{Flow Conditions and Intake Performance Requirements}

In this study intake performance enhancement with the application of vortex generators will be provided at a single flight condition which corresponds to free stream Mach number of 0.75 and Reynolds number of 2.7 million based on engine face diameter. Since cruise missiles fly with a small angle of attack and a small sideslip angle in a large part of the flight envelope, simulated side slip angle and angle of attack are held constant as $0^{\circ}$. Simulated flight conditions are summarized in the table 4.1 .

Table4.1: Simulated Flight Conditions

\begin{tabular}{|c|c|}
\hline Free Stream Mach Number & 0.75 \\
\hline Angle of Attack (degree) & 0 \\
\hline Side Slip Angle (degree) & 0 \\
\hline Reynolds Number & 2.7 Million \\
\hline
\end{tabular}

Furthermore, the studied intake performance requirements which are driven from the engine itself are similar to its analogous design examples. Therefore, with application of the vortex generators as a passive flow control devices, it is expected that intake will 
provide sufficient air to the engine such that its $\mathrm{DC}(60)$ value on the engine face must be smaller than 0.20 which is the safe operation state for typical military turbojet engine with reasonable level of safety and PR value provided by the intake must be greater than 0.92 such that excessive amount of fuel injection to the combustion chamber will be avoided and reasonable cruise range can be reached.

\subsection{CFD Modelling and Mesh Dependency Analysis for Baseline In- take}

As mentioned before, ANSYS 14.0 software package is used for the grid generation and simulations. High quality unstructured meshes are created with ANSYS Mesh module. In order to capture near wall region flow 20 layers of boundary layer elements are created with $\mathrm{Y}+$ value near 1 . For the simulations half model is used in order to reduce computational time. Calculations collected by using pressure based coupled solver with least square cell based method. For all calculations 2nd order upwind scheme with KWSST turbulence model is applied. Actually this setup is validated during the validation study.

For CFD simulations all external boundaries excluding symmetry plane are defined as a pressure far field whereas pressure outlet boundary condition is given to AIP. The other parts of the modeled geometry are defined as wall with no-slip condition. Fixed static pressure value determined from engine mass flow demand is applied to the engine face boundary condition with total temperature equal to the free stream value. For the purpose of defining fixed static pressure value given at the pressure outlet engine mass flow demand taken from the performance chart of a specific engine is used.

In order to define static pressure value at the engine face an initial PR value corrected according to CFD solution and this value is used for determining total pressure value at the engine face.

$$
P_{t e}=P R \times P_{t_{\infty}}
$$

Predetermined mass flow rate with isentropic flow assumption can be used for deter- 
mination of Mach number at the engine face accordingly;

$$
\dot{m}=\sqrt{\frac{\gamma}{R}} \frac{M_{e}}{\left(1+\frac{\gamma-1}{2} M_{e}^{2}\right)^{\left(\frac{\gamma+1}{2(\gamma-1)}\right)}} \frac{P_{t e}}{\sqrt{T_{t e}}} A_{e}
$$

After solving equation 4.12 for engine face Mach number, static pressure at the pressure outlet can be determined with one dimensional isentropic relation;

$$
P_{s e}=\frac{P_{t e}}{\left(1+M_{e} \frac{\gamma-1}{2}\right)^{\frac{\gamma}{\gamma-1}}}
$$

where e and $\infty$ subscripts stand for engine face and free stream respectively.

\subsubsection{Mesh Dependency Analysis}

In order to measure mesh dependency for baseline geometry, 5 different meshes are generated. These 5 Meshes around intake can be seen in the figure 4.10 . 


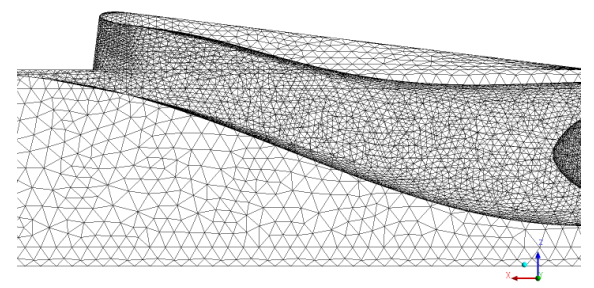

(a) Coarse mesh

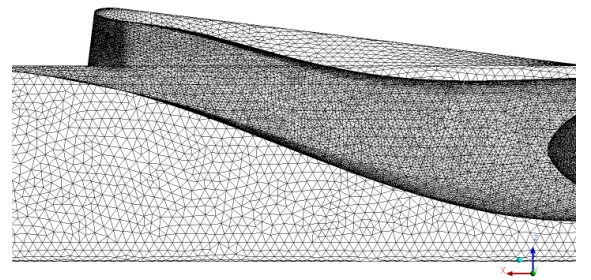

(c) Medium2 mesh

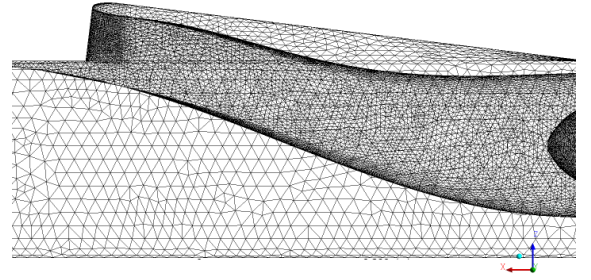

(b) Medium1 mesh

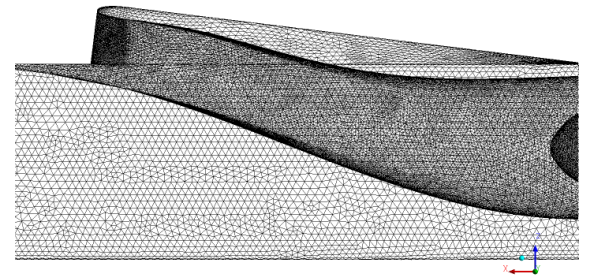

(d) Fine mesh

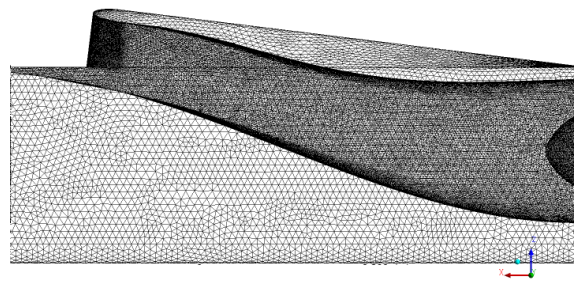

(e) Finest mesh

Figure 4.10: Surface meshes around investigated intake

Obtained DC(60) and PR values from these 5 different meshes are compared for quantitative validation. Furthermore, qualitative comparison is made with PR contours obtained at the engine face. Qualitative comparison plays a crucial role especially for increasing resolution of the total pressure distribution collected at the engine face. Results of the mesh dependency analysis for baseline intake are given in the table 4.2 As it can be depicted from table 4.2, difference in the obtained PR values is in only limited extent whereas difference in obtained $\mathrm{DC}(60)$ values is much more significant from coarse to fine 2 mesh. Furthermore as it can be depicted from the table 4.2 with increasing mesh density intake performance descriptors become more preferable for intake designers. 
Table4.2: Mesh dependency analysis for baseline intake

\begin{tabular}{|c|c|c|}
\hline Mesh Type & DC(60) & PR \\
\hline $\begin{array}{c}\text { Coarse } \\
\text { (\# of elements = 771014) }\end{array}$ & 0.5174 & 0.939 \\
\hline $\begin{array}{c}\text { Medium 1 } \\
\text { (\# of elements = 1330771) }\end{array}$ & 0.505 & 0.942 \\
\hline $\begin{array}{c}\text { Medium 2 } \\
(\# \text { of elements }=\mathbf{2 1 8 4 9 2 6})\end{array}$ & 0.497 & 0.942 \\
\hline $\begin{array}{c}\text { Fine 1 } \\
\text { (\# of elements }=\mathbf{3 2 5 6 1 1 2})\end{array}$ & 0.482 & 0.943 \\
\hline $\begin{array}{c}\text { Fine 2 } \\
(\# \text { of elements }=\mathbf{4 2 3 2 0 8 7})\end{array}$ & 0.480 & 0.943 \\
\hline
\end{tabular}

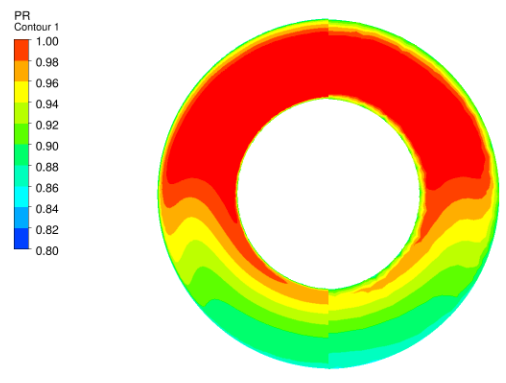

(a) Fine 2 vs Coarse mesh

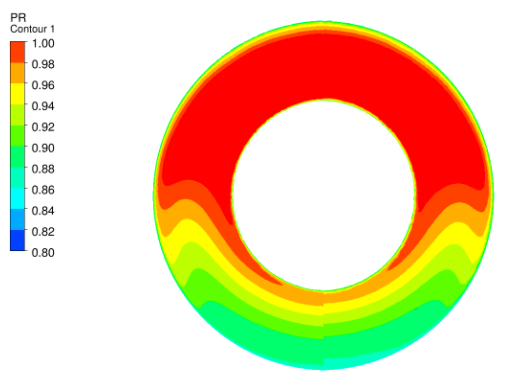

(c) Fine 2 vs Medium 2 mesh

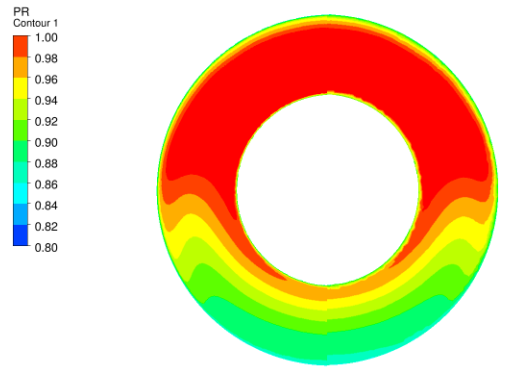

(b) Fine 2 vs Medium 1 mesh

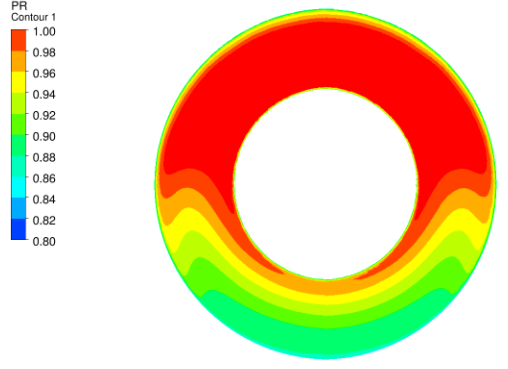

(d) Fine 2 vs Fine 1 mesh

Figure 4.11: PR contours obtained from different size meshes

Among the obtained DC(60), PR and MFR values from these 5 meshes, Fine 1 and Fine 2 meshes creates almost identical results. Actually differences seen between computations obtained with the Fine 2, Medium 2 and even Medium 1 meshes are also in very limited. However comparison of the total pressure distribution contours obtained at the engine face indicates an observable difference which may lead to erroneous results at the further study when effect of vortex generators are investigated. Comparisons of 
the obtained total pressure contours at the engine face are shown at the figure 4.11 From these figures higher confidence about the mesh selection can be reached. Since both table 4.2 and figure 4.11 shows that there is only a small difference between the results obtained from Fine 1 and Fine 2 meshes, Fine 1 mesh is selected for the base geometry solutions which provide a basis for the investigation of the mesh dependency for intake with vortex generators.

Convergence characteristics are also important in selecting the optimum mesh for specific problem. In this study not only the continuity residuals are investigated but also history of variation of total pressure values at the engine face is carefully followed. The convergence histories of continuity and total pressure values at the engine face are shown at the figure 4.12 and figure 4.13 respectively. During the solutions 1500 iterations are performed. As can be seen from these figures there is no difficulty in convergence for any meshes. The setup used in the current work which is validated during the validation case is robust enough to continue to the analyses.

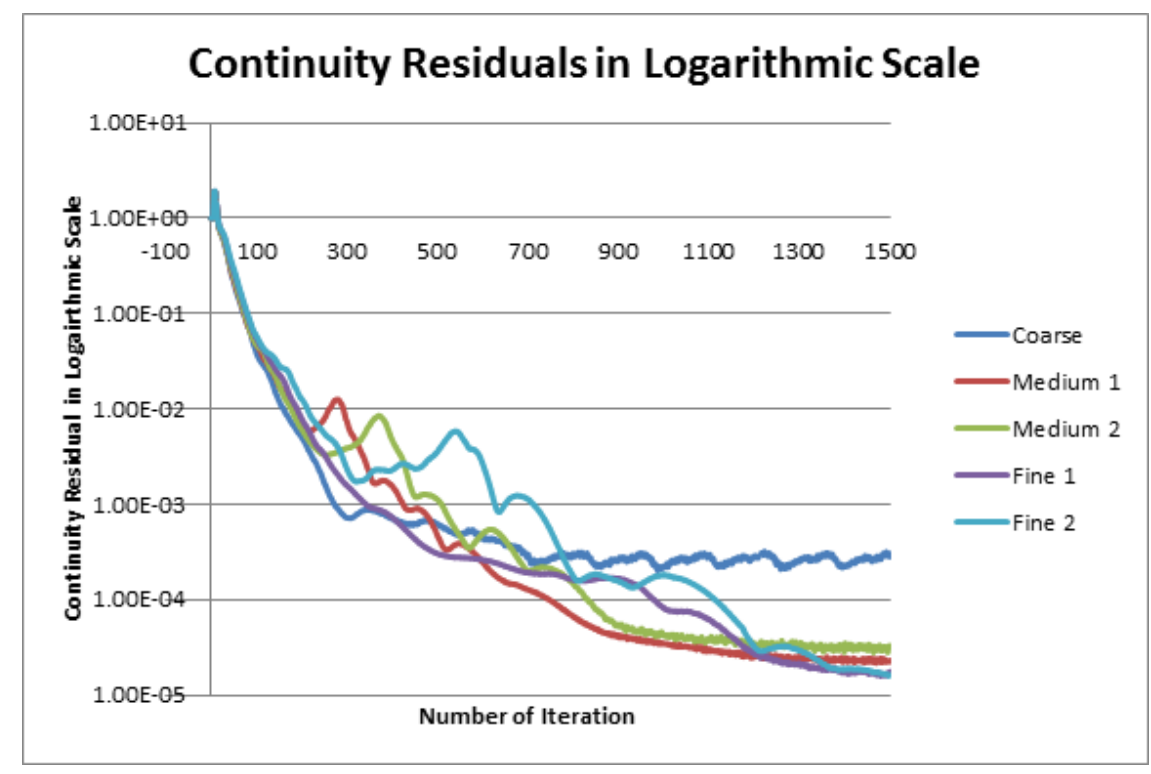

Figure 4.12: Continuity residuals in logarithmic scale for baseline intake 


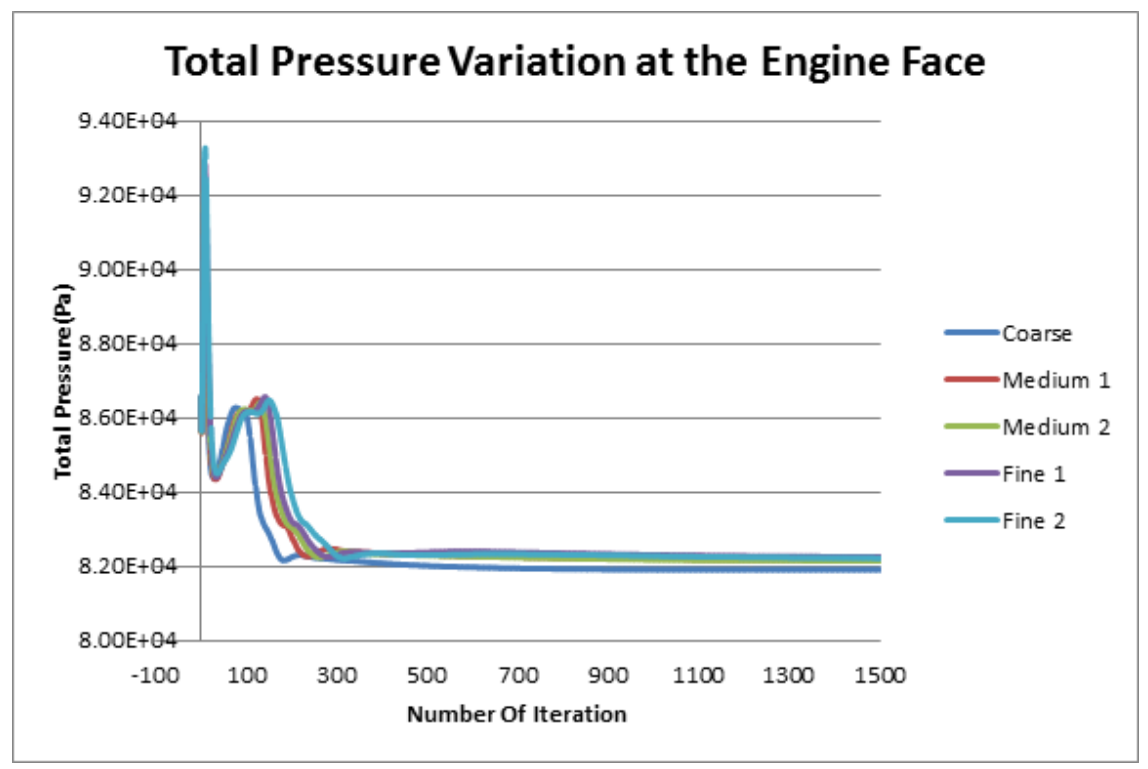

Figure 4.13: Variton of total pressure obtained at the engine face for baseline intake

\subsection{Application of Vortex Generators}

Although, vortex generators are generally used for mixing low momentum fluid near the wall region with the high energetic core flow, it is also possible to benefit them for managing secondary flows that are seen in the serpentine inlets by redirecting flow and creating new flow structure. In the present work purpose of the application of vortex generators is managing secondary flows rather than mixing. Therefore, vortex generators are placed in co-rotating arrangement.

Height of the vortex generators with respect to boundary layer thickness, vortex generator angle of incidence and number of the vortex generators thus lateral spacing are taken as design parameters. Distance between the vortex generator set and separation point is another important parameter that may affect success of vortex generators in managing secondary flows. For this purpose, effects of vortex generator sets are investigated in two different axial locations. First set of vortex generators are located at the intake throat and second set of vortex generators are placed between the intake throat and separation point. It is proven that 29] effect of thickness and chord length of the vortex generators is very limited thus, they are held constant as $2 \mathrm{~mm}$ and $0.5 \delta$ respectively. Geometrical characteristics of the vortex generators investigated in the current study are shown in the figure 4.14 . 

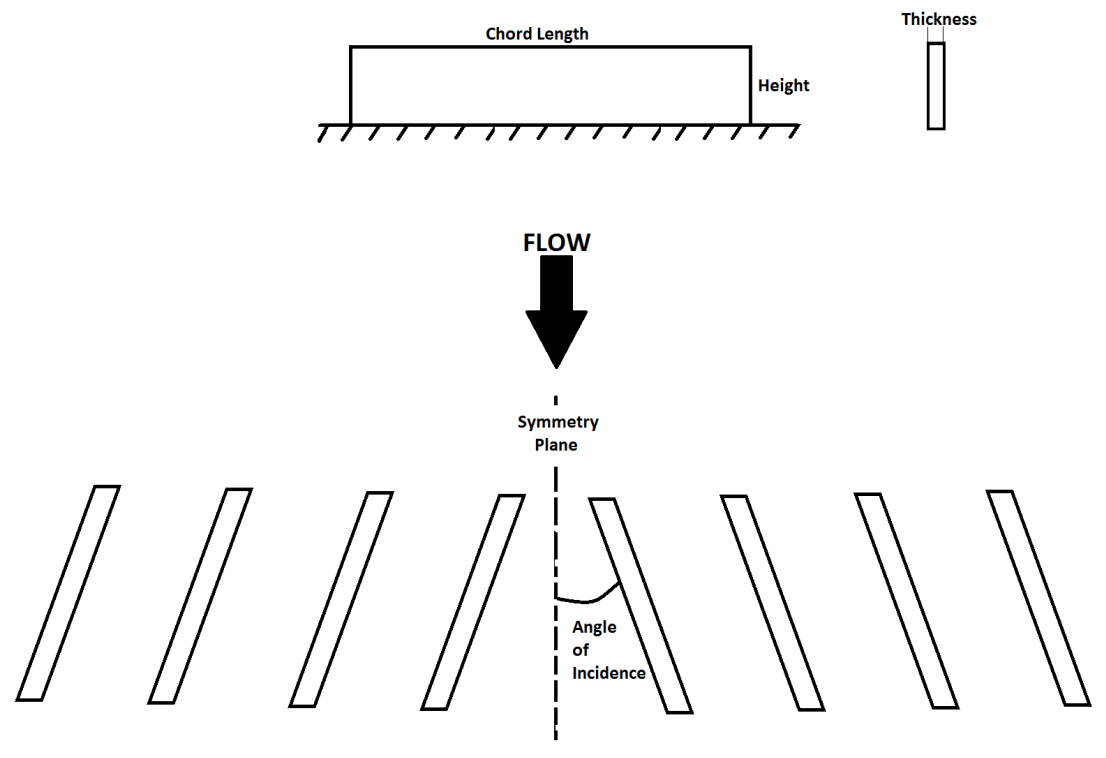

Figure 4.14: Geometrical representation of vortex generators

Geometrical properties of the vortex generators that are used in this study are summarized in the table 4.3 .

Table4.3: Geometrical properties of investigated vortex generators

\begin{tabular}{|c|c|}
\hline Height of the VGs $h / \delta$ & $0.1,0.3,0.5$ \\
\hline$\beta$ (angle of incidence) & $10,20,30$ \\
\hline \# of VGs & $4,6,8$ \\
\hline Axial location from throat & Statin 1, Station 2 \\
\hline Chord Length $c / \delta$ & 0.5 \\
\hline Thickness $(\mathbf{m m})$ & 2 \\
\hline
\end{tabular}

At this point it must be noted that, number of vortex generators indicated in the table 4.3 holds for half of the geometry due to the symmetry boundary condition used in the computational analysis. For complete geometry number of vortex generators are twofold of the indicated values in the table 4.3 .

Since it is strongly advised to place set of vortex generators upstream of the separation point [36], numerical result obtained from clean geometry is examined in order to define first separation point. Velocity vectors which are created in different axial locations from the intake throat can be seen in the figure 4.15 


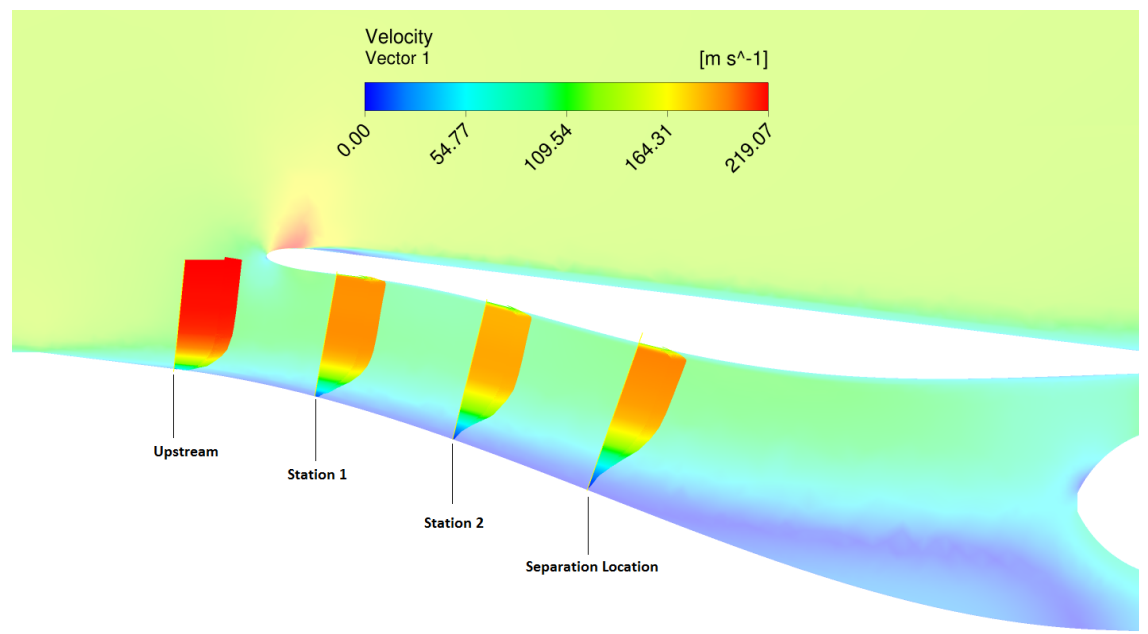

(a) Velocity vectors at different axial locations

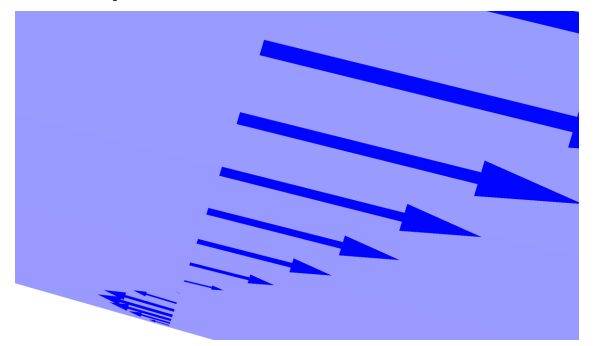

(b) Velocity vectors near the separation point(Close View)

Figure 4.15: Velocity vectors for determination of separation point

From this figure it is seen that separation point roughly corresponds to the one engine face diameter downstream of the intake throat. Therefore, it is decided to place first set of vortex generators at the intake throat where incoming flow has highest energy and second set of vortex generators is placed $0.5 \mathrm{D}$ closer to the separation point.

Since boundary layer thickness at where vortex generators are placed defines the vortex generator height, velocity profiles at the upstream location, station 1 and station 2 shown in the figure $4.15 \mathrm{a}$ are obtained.

Boundary layer profiles at these three stations are shown at figure 4.16. Vertical axis of this figure indicates ratio of the boundary layer thickness to the height of the intake throat whereas horizontal axis indicates ratio of velocity magnitude in the boundary layer to the core velocity region where shear stress on the wall is no longer effective. From this figure, sudden thickening of the boundary layer and displacement thickness through the intake where adverse pressure gradient is high is observable. Furthermore 
it is seen that studied intake duct exposed to high level of boundary layer ingestion such that ingested boundary layer thickness corresponds to the $40 \%$ of the intake throat height. From the extracted velocity profiles, boundary layer thicknesses are estimated at the station 1 and station 2 where vortex generators are to be placed so that heights of the vortex generators are determined.

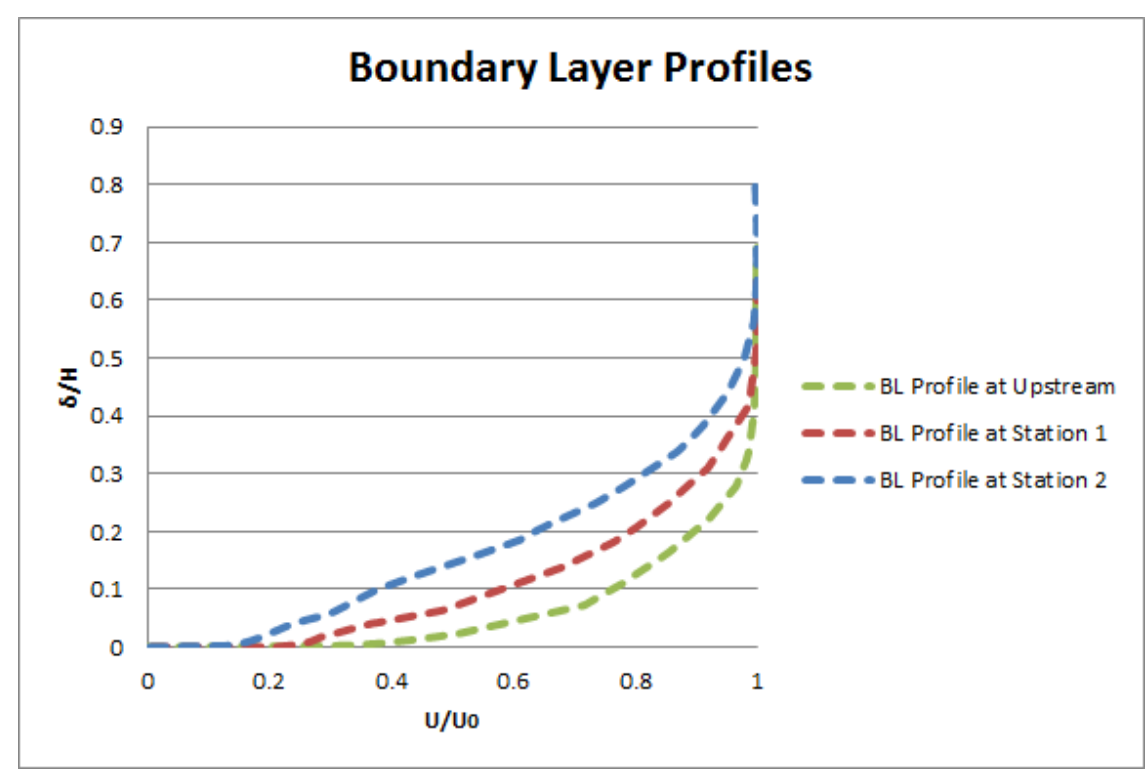

Figure 4.16: Comparison of the boundary layer profiles at three different stations

Since present work seeks a dependency of effects of vortex generators on boundary layer thickness, vortex generator sets are placed only to the wall which has interaction with the boundary layer developed on the airframe. For all investigated vortex generator sets total lateral distance from symmetry plane to the leading edge of the farthermost vortex generator is kept constant. Geometrical representations of the vortex generator sets consist of 8 vortex generator with 30 angle of incidence and height of 0.3 of the local boundary layer thickness are shown in the figure 4.17 . 


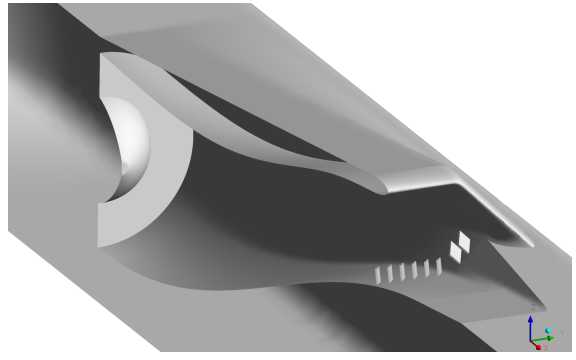

(a) Vortex generator set at Station1

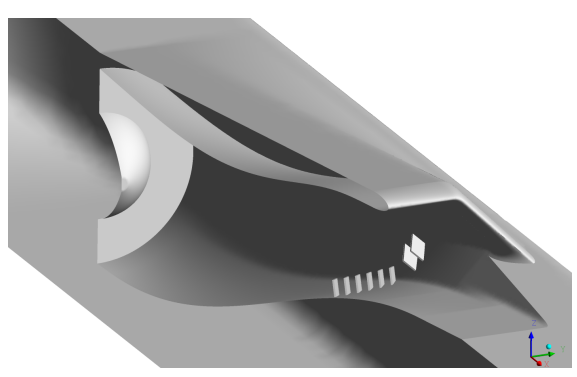

(b) Vortex generator set at Station2

Figure 4.17: Vortex generator sets placed at Station1 and Station2

\subsection{Mesh Dependency Analysis for Intake with VGs}

For the investigation of the mesh dependency of the intake with vortex generators, experience gained by the mesh dependency investigation work collected for the baseline intake geometry is used as a basis. The first mesh for the intake with vortex generators created such that mesh size on the walls are very similar with the baseline intake geometry and only difference between these two meshes originating from the meshes on the vortex generators. The second mesh created with smaller element sized meshes in order to create higher density grid. First mesh created for the investigation of the mesh dependency of intake with VGs called medium and second mesh called fine which are consist of 4001736 and 6515665 cells respectively.

For the mesh dependency analysis obtained $\mathrm{DC}(60)$ and $\mathrm{PR}$ values are compared to each other for the quantitative comparison and as in the mesh dependency investigation collected for the baseline geometry PR contours obtained at the engine face compared to the each other in order to reach further confidence about mesh adequacy.

Table4.4: Mesh dependency analysis for intake with VGs

\begin{tabular}{|c|c|c|}
\hline Mesh Type & DC(60) & PR \\
\hline $\begin{array}{c}\text { Medium - VG } \\
\text { (\# of elements }=\text { 4001736) }\end{array}$ & 0.182 & 0.927 \\
\hline $\begin{array}{c}\text { Fine - VG } \\
\text { (\# of elements }=\mathbf{6 5 1 5 6 6 5})\end{array}$ & 0.184 & 0.927 \\
\hline
\end{tabular}

As can be seen from the table 4.4, predictions obtained with two meshes one with around 4 million and the other with 6.5 million elements leads to very similar results. 
Obtained PR values are same whereas $\mathrm{DC}(60)$ values differs only at the third digit after the decimal point.

Furthermore as in the investigation of the mesh dependency work conducted for the baseline intake geometry, PR contours obtained at the engine face from the solutions obtained with Fine and Medium meshes compared to each other. This comparison can be seen at the figure 4.18. From this figure it is seen that PR contours at the engine face are very similar.

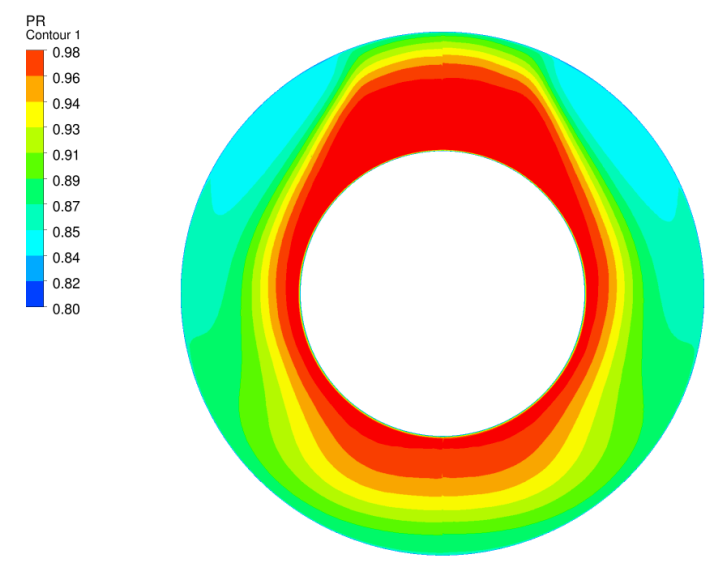

Figure 4.18: Comparison of the PR contours obtained from Fine VG and Medium VG meshes

The convergence histories of continuity and the total pressure at the engine face are shown at the figure 4.19 and figure 4.20 respectively. From these two figures it can be seen that there is no convergence problem and current solution setup is robust enough. 


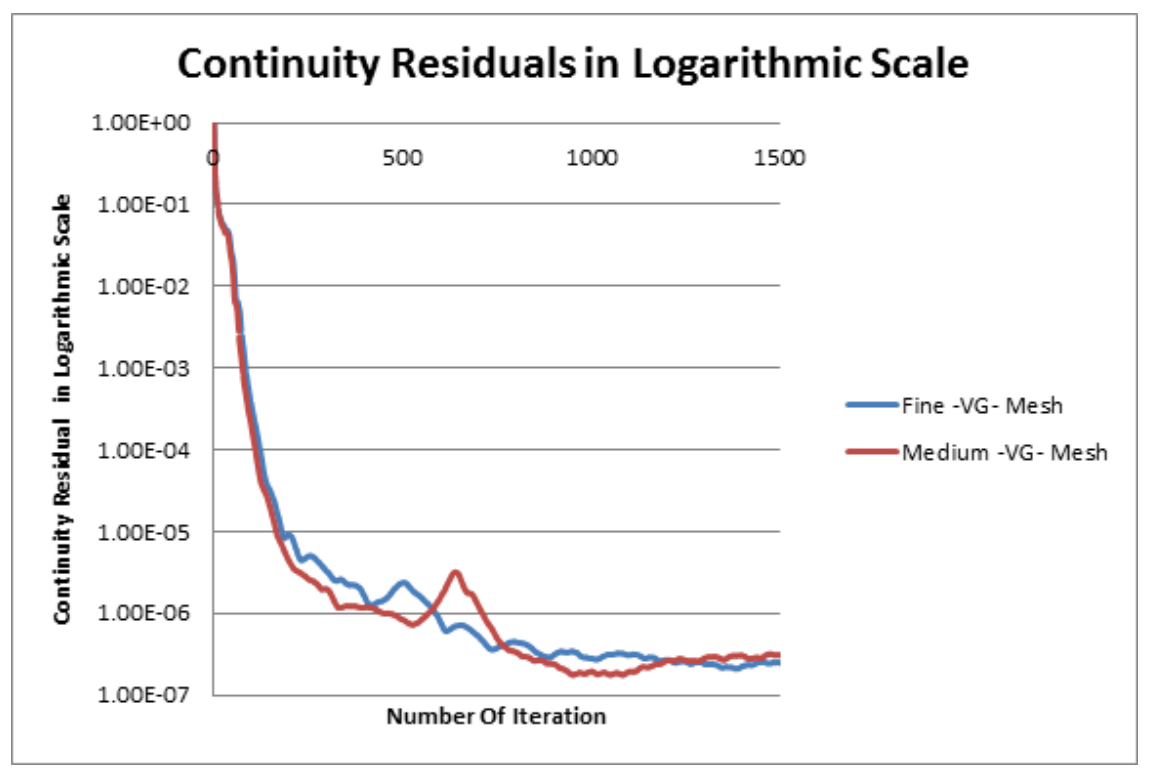

Figure 4.19: Continuity residuals in logarithmic scale for intake with VGs

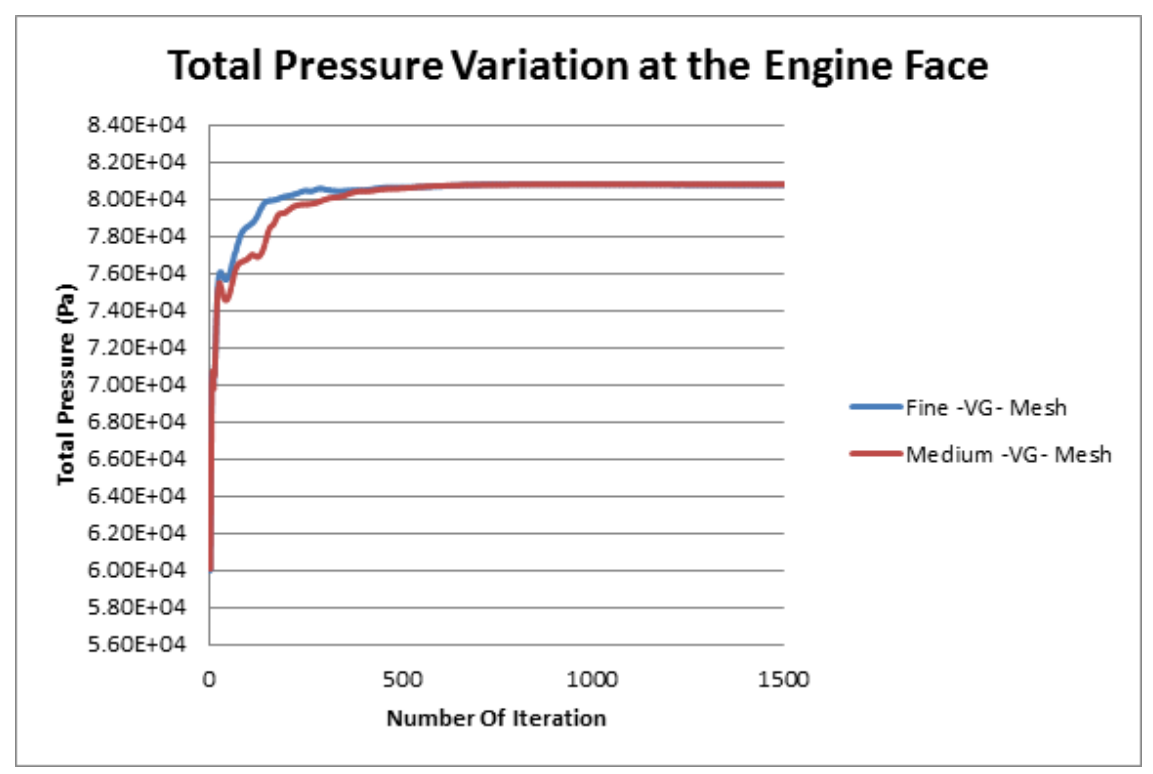

Figure 4.20: Variton of total pressure obtained at the engine face for intake with VGs

In the light of results summarized above, medium mesh composed of 4001736 elements is selected for the further investigation of the effect of vortex generator geometries on the intake performances. Final mesh around intake and vortex generator set is shown in the figure 4.21 . 


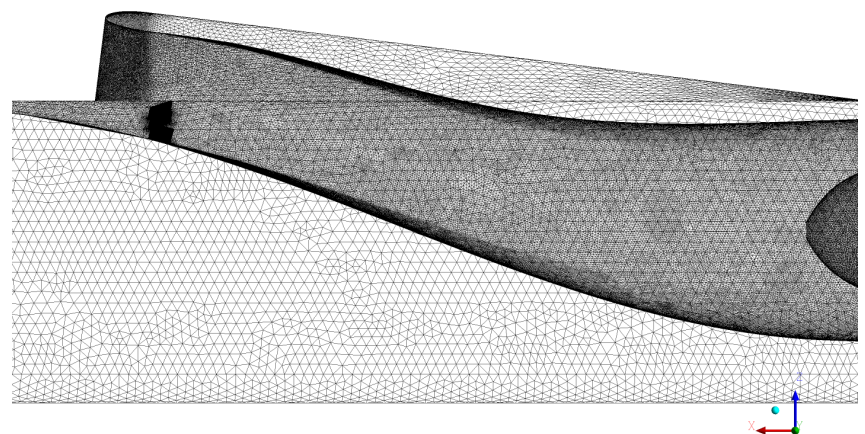

(a) Surface mesh around Medium-VG-Mesh

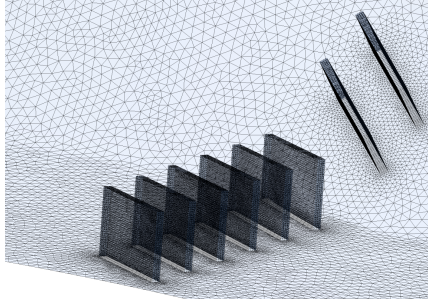

(b) Surface mesh around vortex generator set

Figure 4.21: Surface mesh around intake with vortex generators 


\section{CHAPTER 5}

\section{RESULTS AND DISCUSSION}

In this chapter results obtained from vortex generator installation study are summarized with the effects of each parameter on intake performance. As mentioned in the previous chapter, height of the vortex generators with respect to boundary layer thickness, vortex generator angle of incidence and number of the vortex generators thus lateral spacing are taken as design parameters. Furthermore, effects of distance between the vortex generator set and separation point are also investigated.

\subsection{Effects of Distance Between Vortex Generator Set and Separa- tion Point}

In order to investigate effects of the distance between the vortex generator set and separation point on intake performance, vortex generator sets are placed at two axial locations; one set is at intake throat and other set is at $0.5 \mathrm{D}$ downstream of intake throat. As mentioned in the previous chapter Station 1 and Station 2 corresponds to the intake throat and $0.5 \mathrm{D}$ downstream of intake throat respectively.

DC(60) vs PR figures are created for each vortex generator set with same geometrical properties, placed different stations to understand relative success of vortex generator sets placed at Station 1 and Station 2. 


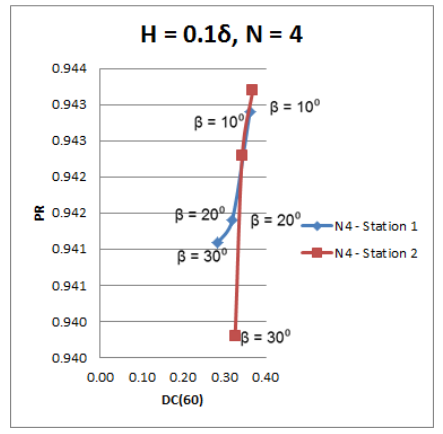

(a) $\mathrm{H}=0.1 \delta$ and $\mathrm{N}=4$

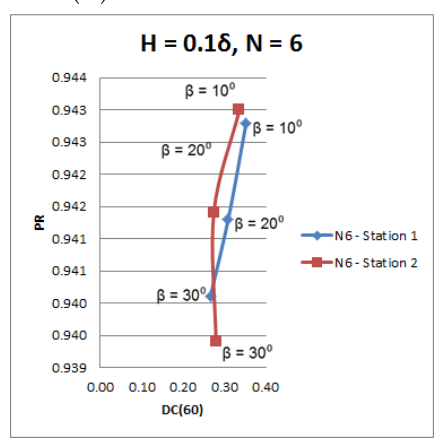

(d) $\mathrm{H}=0.1 \delta$ and $\mathrm{N}=6$

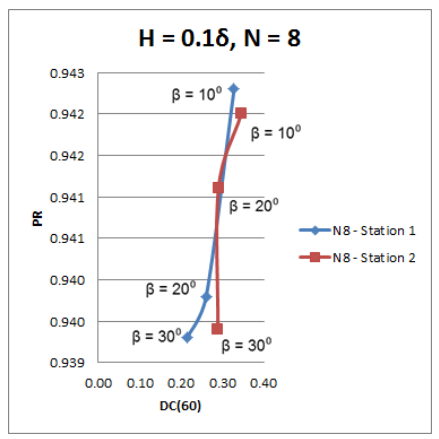

(g) $\mathrm{H}=0.1 \delta$ and $\mathrm{N}=8$

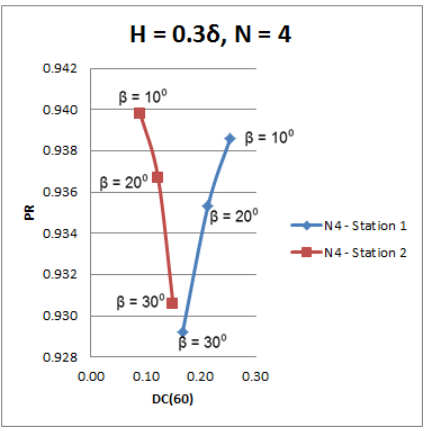

(b) $\mathrm{H}=0.3 \delta$ and $\mathrm{N}=4$

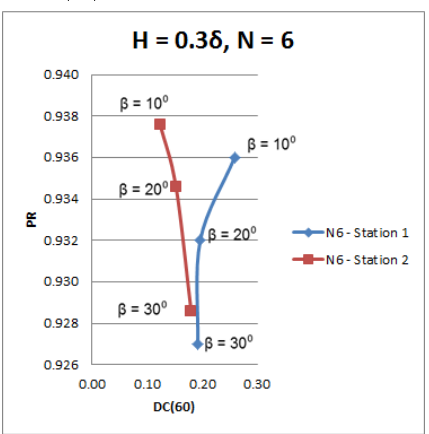

(e) $\mathrm{H}=0.3 \delta$ and $\mathrm{N}=6$

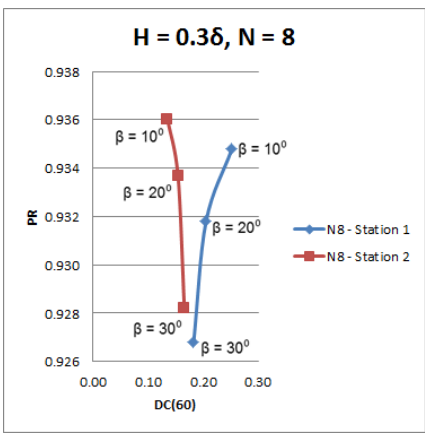

(h) $\mathrm{H}=0.3 \delta$ and $\mathrm{N}=8$

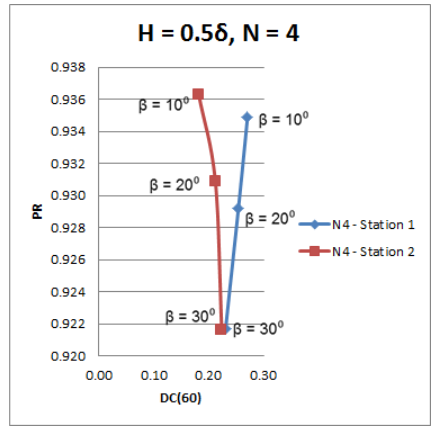

(c) $\mathrm{H}=0.5 \delta$ and $\mathrm{N}=4$

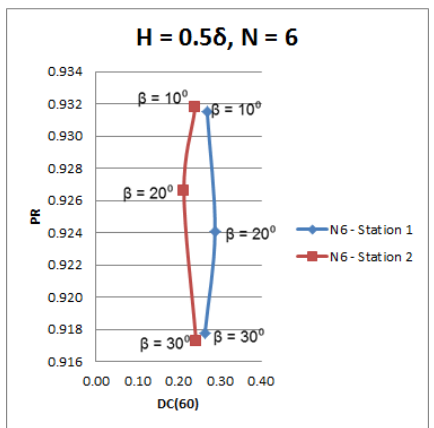

(f) $\mathrm{H}=0.5 \delta$ and $\mathrm{N}=6$

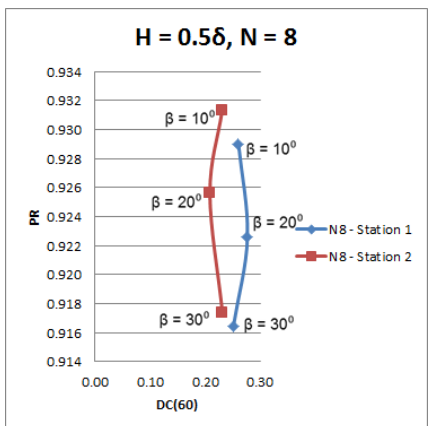

(i) $\mathrm{H}=0.5 \delta$ and $\mathrm{N}=8$

Figure 5.1: Effect of distance between vortex generator set and separation point

As can be seen from figure 5.1, relatively low $\mathrm{DC}(60)$ and high $\mathrm{PR}$ values are obtained with vortex generators placed at Station 2 for the same type of vortex generator geometries. Furthermore, both lowest $\mathrm{DC}(60)$ and highest $\mathrm{PR}$ values are obtained with vortex generator sets placed at the Station 2. Therefore, it can be concluded that in general vortex generator sets placed downstream of the throat are superior compared to vortex generator sets placed at the intake throat. 


\subsection{Effects of Vortex Generator Height and Angle of Incidence}

In this section effect of the vortex generator height relative to local boundary layer thickness and angle of incidence are investigated for Station 1 and Station 2 individually through the figures 5.2 and 5.3

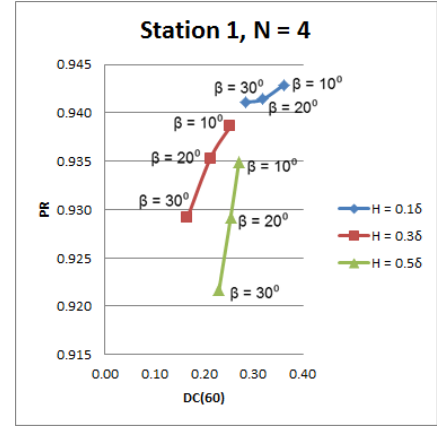

(a) Station 1, N=4

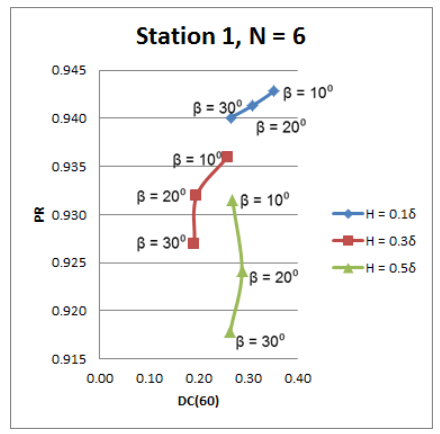

(b) Station $1, \mathrm{~N}=6$

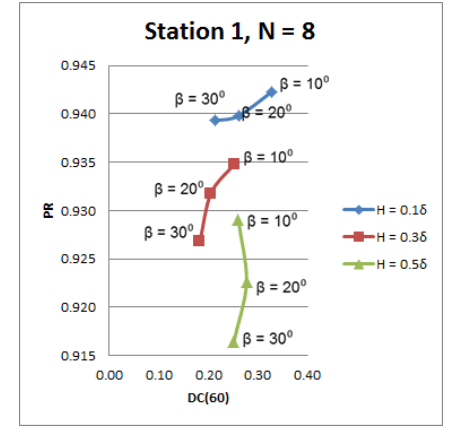

(c) Station 1, N=8

Figure 5.2: Effect of vortex generator height at Station 1

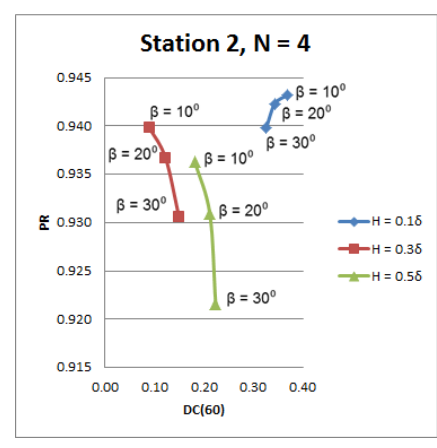

(a) Station 2, N=4

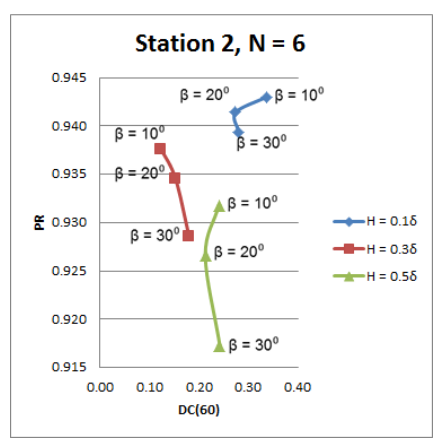

(b) Station 2, N=6

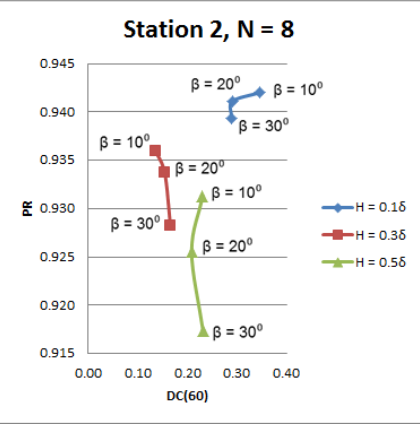

(c) Station 2, N=8

Figure 5.3: Effect of vortex generator height at Station 2

It is interesting to note that, as can be seen from above figures effect of angle of incidence on DC(60) coefficient show significantly different trend at two locations. At Station 1, DC(60) show decreasing trend with the increasing angle of incidence in general. However, at Station 2 trend is just opposite and $\mathrm{DC}(60)$ coefficient increases with increasing angle of incidence for effective vortex generator applications. Furthermore, for both stations most effective vortex generator height is equal to 0.3 times to the local boundary layer thickness. When this height is reached to the 0.5 times to the local boundary layer thickness DC(60) increases and PR decreases. Similarly, for lower vortex generator height vortex generators become in effective and they cannot redirect 
the flow effectively, especially when number of vortex generators are few.

$\mathrm{PR}$ values higher than to the clean duct are only obtained with the vortex generator sets placed at station 2 which are composed of number of 4 and 6 vortex generators with a height of $0.1 \delta$. However, obtained $\mathrm{DC}(60)$ values are not sufficient with these vortex generator sets and PR increase is very limited. In general, there is no increase in $\mathrm{PR}$ value compared to the clean duct. An increase in the angle of incidence, vortex generator height and number of vortex generators lead to reduction in PR value. However, all PR values are in acceptable range mentioned in the previous chapter except PR values obtained with the vortex generator sets consist of 6 and 8 number of vortex generators and each heights 0.5 times to the local boundary layer thickness.

\subsection{Effect of the Number of Vortex Generators}

For examining the effect of number of vortex generator thus lateral spacing on intake performance, $\mathrm{DC}(60)$ vs $\mathrm{PR}$ figures are presented in the figures 5.4 and 5.5 separately for each vortex generator height and each station.

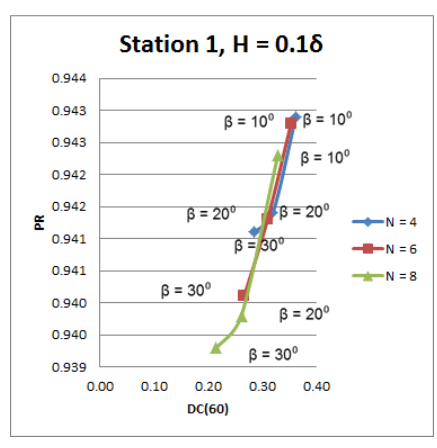

(a) Station $1, \mathrm{H}=0.1 \delta$

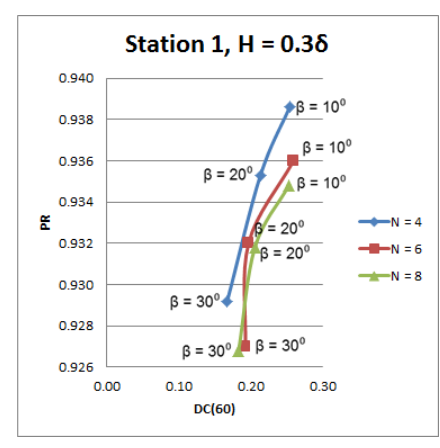

(b) Station $1, \mathrm{H}=0.3 \delta$

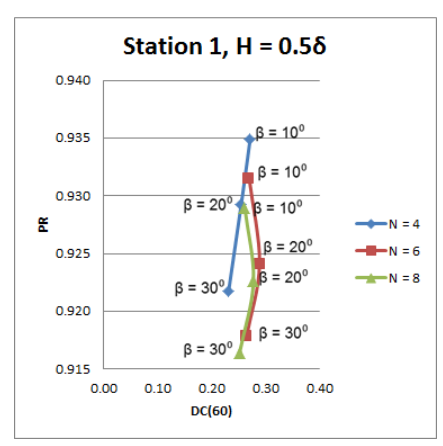

(c) Station $1, \mathrm{H}=0.5 \delta$

Figure 5.4: Effect of number of vortex generators at Station 1 


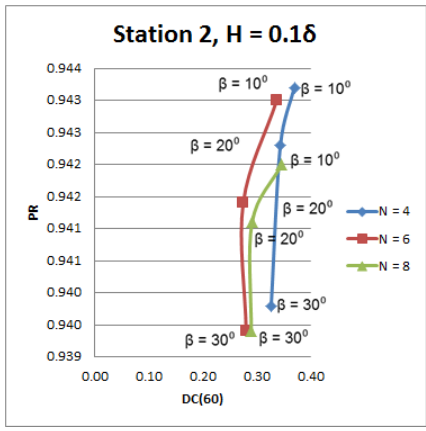

(a) Station 2, $\mathrm{H}=0.1 \delta$

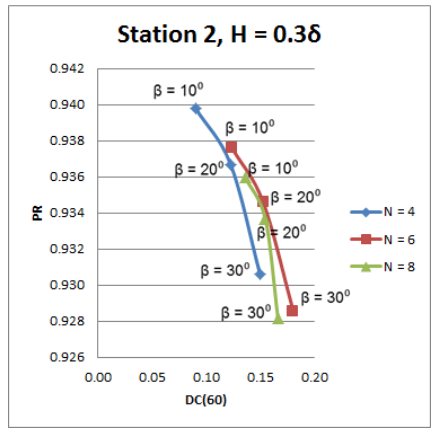

(b) Station $2, \mathrm{H}=0.3 \delta$

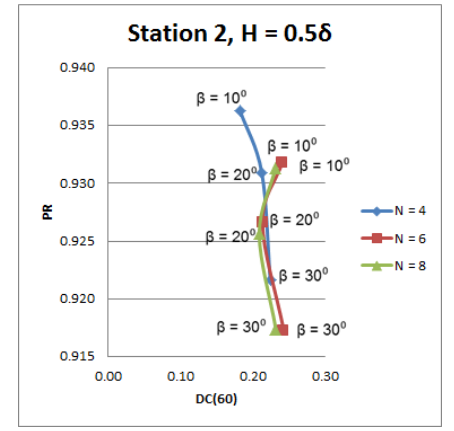

(c) Station 2, $\mathrm{H}=0.5 \delta$

Figure 5.5: Effect of number of vortex generators at Station 2

As can be seen from the above figures, there is no significant effect of the number of vortex generators on $\mathrm{DC}(60)$. Actually, increase in effectiveness with the increased number for vortex generators are only seen in the vortex generators having lowest height. On the other hand, increasing number of vortex generators leads to a decrease in $\mathrm{PR}$ values for all flow control applications. Since low $\mathrm{DC}(60)$ and high $\mathrm{PR}$ values are obtainable with lower number of vortex generators it is beneficial to implement them in real life case in in order to reduce possibility of FOD and to reach higher values of $P R$.

\subsection{Overview of Effect of Vortex Generators}

Vortex generators as passive flow control devices proved their effectiveness in a wide range of aerodynamic applications. In the current work, 27 low profile vortex generators having different geometrical parameters located at two different stations are modelled and their effect on boundary layer ingesting inlet performance is investigated. It is found that every co-rotating vortex generator application modelled in the current work was able to reduce distortion occurred at the engine face in some extent. However, this decrease was not so significant when vortex generator height is equal to 0.1 times to the local boundary layer thickness regardless of location where vortex generators are placed. At the same time, it was shown that increasing vortex generator height does not lead to decrease in distortion continuously. Clearly, vortex generators which have height equal to 0.3 times to local boundary layer thickness are most effective in terms of decreasing distortion at the engine face. 
During this study it was observed that distortion is very sensitive to the angle of incidence which has opposite effect on distortion at two different stations. With the exception of vortex generator sets consisting high number of vortex generators coupled with high angle of incidence and heights, acceptable PR values are reached. There is no significant increase in PR values with any vortex generator sets, however some effective vortex generator set can provide the same level of PR values with the clean duct.

Among the investigated vortex generator sets, the most effective set in reducing distortion is the one which is placed at station 2 and consists of 4 vortex generators each have height equal to $0.3 \delta$ with $10^{\circ}$ angle of incidence. This vortex generator set is able to reduce $\mathrm{DC}(60)$ from 0.48 to 0.09 while keeping $\mathrm{PR}$ very close to the base duct. Comparison of the PR contours at the AIP obtained with the application of this vortex generator set and clean duct is presented in the figure 5.6
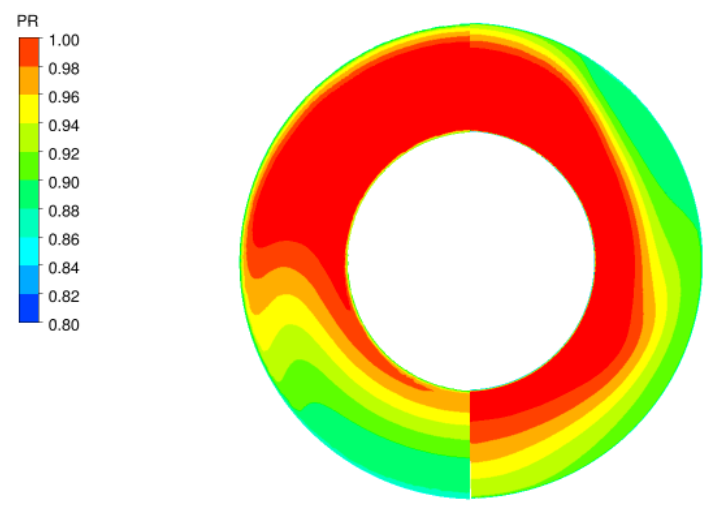

Figure 5.6: PR comparison (Clean duct vs Application of VGs)

As can be seen from figure 5.6 completely new pressure distribution is obtained with the application of vortex generators. Low total pressure region observed in the clean duct totally eliminated with application of vortex generators. However, new low total pressure region is formed which is much more smaller in shape and magnitude. Furthermore, effect of vortex generator application on total pressure distributions from intake throat to the engine face can be observed in the figure 5.7 


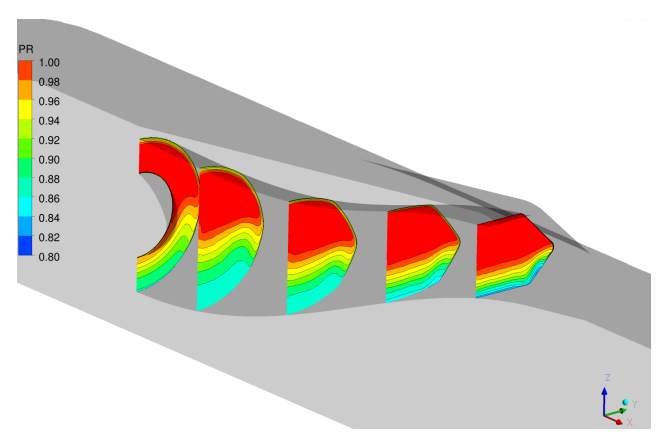

(a) Clean intake

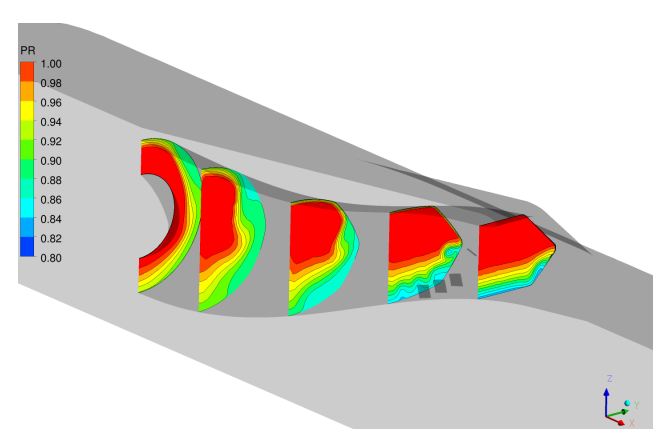

(b) Intake with Application of VGs

Figure 5.7: Effect of vortex generators on total pressure distribution through intake

As can be seen from figure 5.7 there is no effect of vortex generators on the upstream. However, just after the vortex generators a new flow structure is developed. The effect of co-rotating vortex generators is observable around symmetry plane most clearly. Just after the vortex generator set, a large low total pressure region originating from vortex lift-off effect around the symmetry plane disappears. Effect of vortex generator application on the vortex-lift off region can be seen in the figure 5.8 .

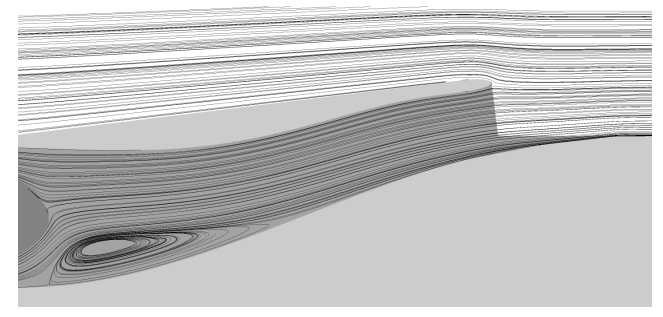

(a) Clean intake

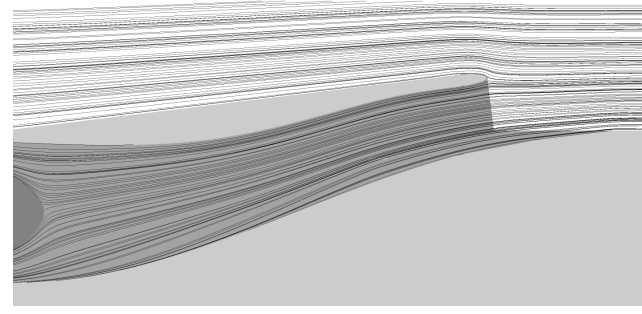

(b) Intake with Application of VGs

Figure 5.8: Effect of vortex generators on vortex-lift off region

\subsection{Intake Performance with Flow Control Application in Other Flight Conditions}

Although it is shown that, application of vortex generators provide significant decrease in distortion with very low reduction in $\mathrm{PR}$ value at a single flight condition, it is crucial to investigate intake performance over a wider range of flow conditions. Since cruise missiles usually does bank to turn maneuvers rather than skid to turn, only very small side slip angles are encountered during the flight envelope. Therefore, off-design simulations are only conducted for angle of attacks varying between $-6^{\circ}$ and $6^{\circ}$ while 
keeping side slip angle as $0^{\circ}$. Effect of flow control on intake performance at off-design conditions are shown in the figure 5.9 and figure 5.10 .

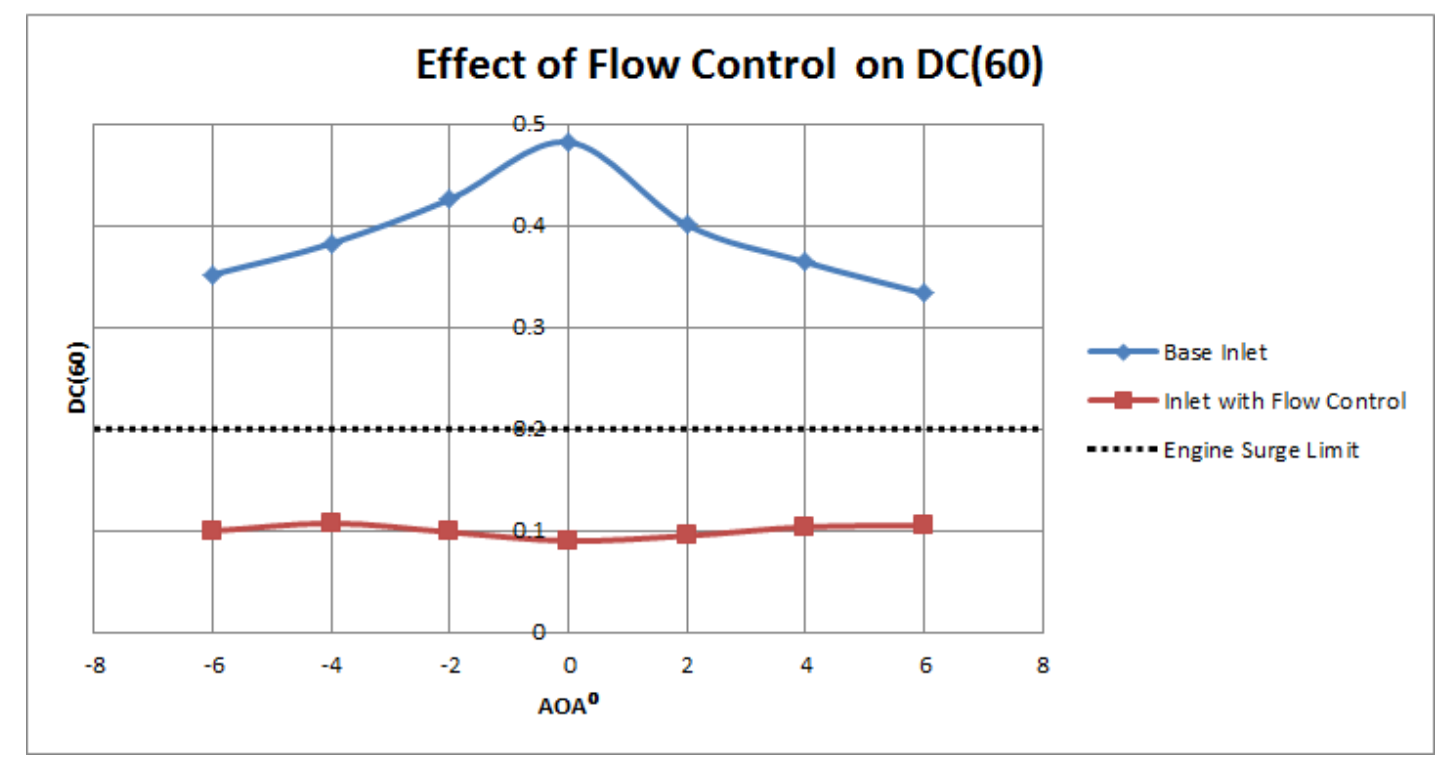

Figure 5.9: Effect of flow control on $\mathrm{DC}(60)$

From figure 5.9 it is seen that, intake with flow control show stable character at all investigated angle of attacks in terms of $\mathrm{DC}(60)$. There is a significant reduction in $\mathrm{DC}(60)$ value regardless of angle of attack such that distortion values is around half of the engine surge limit. Therefore it can be concluded that, with flow control application engine health is ensured for flight conditions that are mostly encountered in flight envelope. 


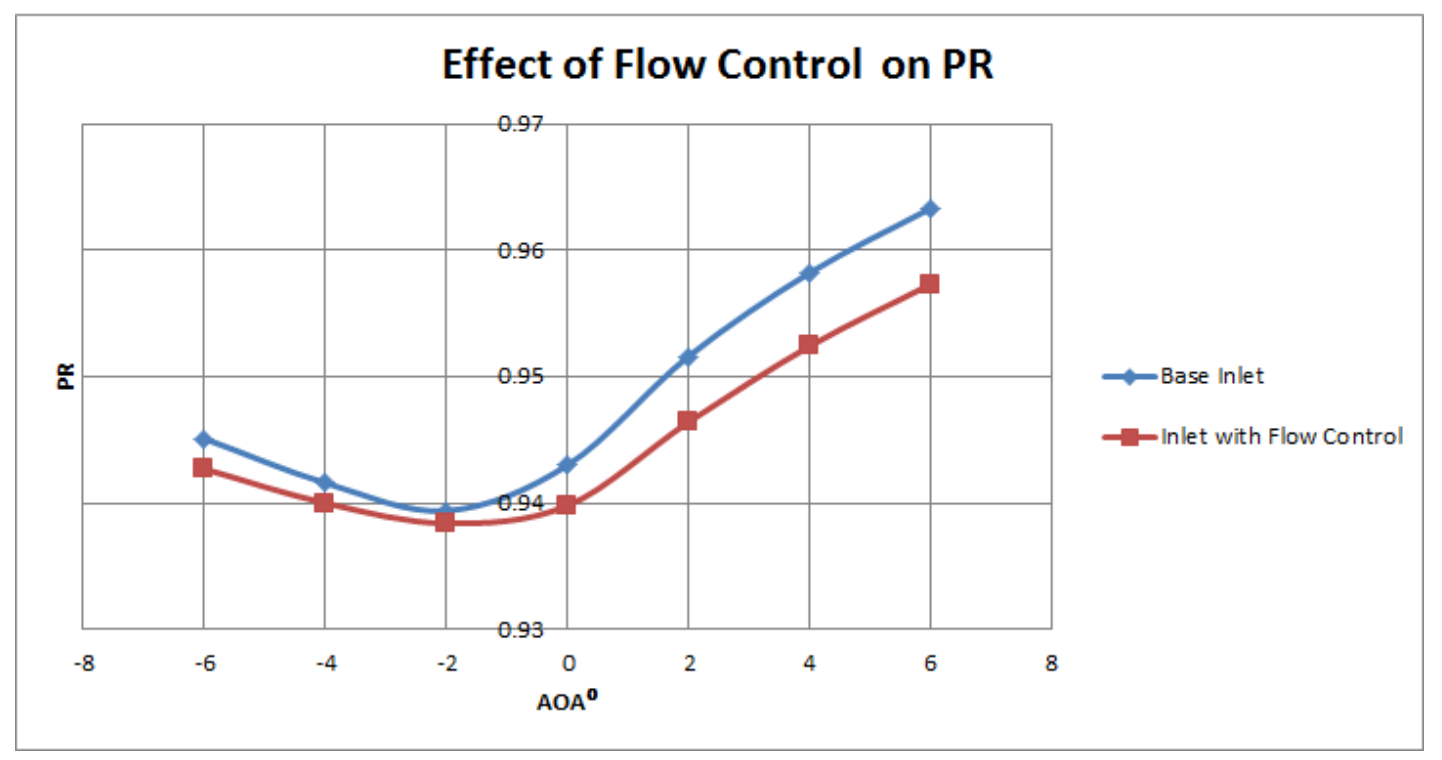

Figure 5.10: Effect of flow control on PR

When effect of flow control on PR value which has a direct correlation with the target range of the cruise missile is analyzed, it is seen that although application of flow control leads reduction in obtained PR values, they are still higher than the lower limit required for target range as mentioned in the previous chapter. 


\section{CHAPTER 6}

\section{CONCLUSION AND FUTURE WORK}

In this thesis, passive flow control in boundary layer ingesting semi submerged inlet is investigated with the commercially available flow solver ANSYS Fluent 14.0. Flow inside serpentine inlets is complicated due to the presence of the stream line curvature and adverse pressure gradients both in streamwise and circumferential directions. Therefore, validation study is carried out with three different turbulence models that are most popular in the aerospace industry. Results of the validation work indicate computations obtained with KWSST turbulence model outperforms with and without application of flow control compared to computations obtained with RKE and SA turbulence models. Furthermore, pressure based algorithm which has higher rate of solution convergence compared to density based approaches is robust and accurate enough for predicting inlet performance criteria.

In addition, a conventional design approach for a semi submerged intake is explained and a base intake geometry is formed. To explore the effect of vortex generators on intake performance criteria; $\mathrm{DC}(60)$ and $\mathrm{PR}, \mathrm{CFD}$ calculations are performed with flow control design space composed of 27 different vortex generator sets each with a co-rotating arrangement placed at 2 axial locations. Vortex generator height relative to the local boundary layer thickness, angle of incidence, number of vortex generators thus lateral spacing and distance between the separation point and vortex generator set are taken as design parameters. According to results of the vortex generator installation study several conclusions are made as presented accordingly;

- Lower DC(60) with higher PR values are obtained with the vortex generator sets placed closer to the separation point for the flow control applications at which signifi- 
cant reduction in $\mathrm{DC}(60)$ is reached.

- Although higher PR values are obtainable with vortex generator sets consist of lowest vortex generator height with limited number, their effectiveness in reducing $\mathrm{DC}(60)$ is very limited. Vortex generator sets composed of vortex generator height of $0.3 \delta$ provide the lowest $\mathrm{DC}(60)$ values with a small reduction in $\mathrm{PR}$.

- There is a strong dependence of both $\mathrm{DC}(60)$ and $\mathrm{PR}$ values to the angle of incidence. Although PR decreases with the increasing angle of incidence regardless of the station, effect of angle of incidence on $\mathrm{DC}(60)$ coefficient exhibits visible difference between two stations. For station 1 which is most upstream location $\mathrm{DC}(60)$ decreases with increasing angle of incidence whereas just the opposite trend is seen for effective vortex generator sets placed at station 2 .

- Although it is observed that increasing number of vortex generators leads to decrease in PR for conditions at which flow control application is effective, there is no significant effect of number of vortex generators on the DC(60). Since, low $\mathrm{DC}(60)$ and high PR values are obtained with less number of vortex generators it is more appropriate to use less number of vortex generators in order to reach higher efficiency with lower risk of FOD.

- Vortex generator height, angle of incidence with the distance between vortex generator sets and separation point are the main parameters that have strong influence on flow control effectiveness.

Best vortex generator set is composed of 4 vortex generators each have height of $0.3 \delta$ with $10^{\circ}$ angle of incidence placed at station 2 . This set is able to reduce $\mathrm{DC}(60)$ to 0.09 from 0.48 with only $0.35 \%$ reduction in PR compared to the base intake at design condition. In order to investigate performance of intake with flow control application at off-design conditions additional CFD computations were carried out for angle attacks varying between $-6^{\circ}$ to $6^{\circ}$. It is shown that flow control application provide satisfactory stability margin for engine with a negligible decrease in PR for all flight conditions that are investigated.

This study can be extended with a response surface optimization to obtain more refined flow control design methodology. In addition, investigation of the effect of other flow 
control methods such as blowing and suction can provide further inside on the effects of flow control methods on boundary layer ingesting semi submerged intake performance. 


\section{REFERENCES}

[1] Air intakes for high speed vehicles. In Advisory Group For Aerospace Research and Development (AGARD), Fluid Dynamics Panel Working Group 13, AR-270, Fort Worth, Sept 1991.

[2] B. G. Allan and L. R. Owens. Numerical modeling of flow control in a boundarylayer-ingesting offset inlet diffuser at transonic mach numbers. AIAA paper, 845:2006, 2006.

[3] B. G. Allan, L. R. Owens, and J. C. Lin. Optimal design of passive flow control for a boundary-layer-ingesting offset inlet using design-of-experiments. AIAA paper, 1049, 2006.

[4] A. J. Anabtawi, R. F. Blackwelder, P. B. S. Lissaman, and R. H. Liebeck. An experimental investigation of boundary layer ingestion in a diffusing s-duct with and without passive flow control. In 37th AIAA Aerospace Sciences Meeting and Exhibit. AIAA, 1999.

[5] B. Anderson, D. Reddy, and K. Kapoor. A comparative study of Full NavierStokes and Reduced Navier-Stokes analyses for separating flows within a diffusing inlet S-duct, volume 106250. National Aeronautics and Space Administration, 1993.

[6] B. H. Anderson and J. Gibb. Vortex-generator installation studies on steady-state and dynamic distortion. Journal of aircraft, 35(4):513-520, 1998.

[7] B. H. Anderson, P. S. Huang, W. A. Paschal, and E. Cavatorta. A study on vortex flow control of inlet distortion in the re-engined 727-100 center inlet duct using computational fluid dynamics. In AIAA 30th Aerospace Sciencies Meeting and Exhibit. AIAA, 1992.

[8] B. H. Anderson, D. N. Miller, G. A. Addington, and J. Agrell. Optimal micro-jet flow control for compact air vehicle inlets. Technical report, NASA TM-2004212937, 2004.

[9] O. U. Baran. Passive flow control in a boundary layer ingesting semi submerged engine inlets at transonic flow. In \%. Ankara International Aerospace Conference. AIAC, 2013.

[10] A. Barka, B. Fromentin, and S. Langlet. Modal expansion functions combined with efie applied to air intake/engine rcs computations. In 20th Annual Review of Progress in Applied Computational Electromagnetics. ACES, 2004. 
[11] O. Basoglu, L. Yalcin, and A. E. Yllmaz. Computational study on the design parameters of s-type subsonic inlets. In 46th AIAA Aerospace Sciences Meeting and Exhibit, 7-10 January, Reno, Nevada, 2008.

[12] C. Bauer and G. Kurth. Importance of the bleed system on the overall air intake performance. In 47th AIAA/ASME/SAE/ASEE Joint Propulsion Conference and Exhibit, San Diego, California, 2011.

[13] S. Brehm, T. Kachele, and R. Niehuis. Cfd investigations on the influence of varying inflow conditions on the aerodynamics in an s-shaped inlet duct. In 50th AIAA/ASME/SAE/ASEE Joint Propulsion Conference, 2014.

[14] N. K. Delany. An investigation of submerged air inlets on a 1/4- scale model of a fighter-type airplane. Technical report, NACA RM A8A20, 1948.

[15] R. Dey, S. Bharani, S. Singh, and V. Seshadri. Flow analysis in s-shaped diffusers with circular cross-section. Arabian Journal for Science and Engineering, 27(2; PART C):197-206, 2002.

[16] J. C. Dudek. Modeling Vortex Generators in the Wind-US Code. 2010.

[17] R. Florea, M. Haas, L. W. Hardin, C. E. Lents, and M. B. Stucky. Optimization of bleed-flow-control for an aggressive serpentine duct. In 43rd AIAA Aerospace Sciences Meeting and Exhibit, 2005.

[18] E. Goldsmith and J. Seddon. Practical intake aerodynamic design. AIAA education series. American Institute of Aeronautics and Astronautics, 1993.

[19] S. A. Gorton, L. R. Owens, L. N. Jenkins, B. G. Allan, and E. P. Schuster. Active flow control on a boundary-layer-ingesting inlet. In 42nd AIAA Aerospace Sciences Meeting and Exhibit. AIAA, 2004.

[20] S. Guillot and W. Ng. Ejector pump flow control, Sept. 26 2002. US Patent App. $09 / 781,590$.

[21] G. Harloff, C. Smith, J. Bruns, and J. DeBonis. Navier-stokes analysis of threedimensional s-ducts. Journal of aircraft, 30(4):526-533, 1993.

[22] G. J. Harloff and G. E. Smith. Supersonic-inlet boundary-layer bleed flow. AIAA journal, 34(4):778-785, 1996.

[23] G. J. Harloff and G. E. Smith. Supersonic-inlet boundary-layer bleed flow. AIAA journal, 34(4):778-785, 1996.

[24] D. K. Harper. Boundary layer control and wall-pressure fluctuations in a serpentine inlet. Master's thesis, Virginia Polytechnic Institute and State University, 2000 . 
[25] N. A. Harrison. Active flow control of a boundary layer ingesting serpentine diffuser. Master's thesis, Virginia Polytechnic Institute and State University, 2005.

[26] N. A. Harrison, J. Anderson, J. L. Fleming, and W. F. Ng. Computational analysis of active flow control of a boundary layer ingesting serpentine inlet diffuser. In 44th AIAA Aerospace Sciences Meeting and Exhibit, Reno, NV, 2006.

[27] C. S. Jell. Air intake aerodynamics. Technical report, Tech. Rep. 754, Advisory Group for Aerospace Research and Development.

[28] W. Jin, R. R. Taghavi, and S. Farokhi. A computational investigation of icing effects on an s-duct inlet. International Journal of Turbo and Jet Engines, 27(34):277-294, 2010.

[29] A. Jirasek. Design of vortex generator flow control in inlets. Journal of aircraft, 43(6):1886-1892, 2006.

[30] R. D. Joslin and D. N. Miller. Fundamentals and applications of modern flow control. American Institute of Aeronautics and Astronautics, 2009.

[31] M. Keerthi and A. Kushari. Effectiveness of vortex generator jets and wall suction on separated flows in serpentine-duct diffuser. Aerospace Science and Technology, 34:12-19, 2014.

[32] H. D. Kim and J. L. Felder. Control volume analysis of boundary layer ingesting propulsion systems with or without shock wave ahead of the inlet. In 49th AIAA Aerospace Sciences Meeting, American Institute of Aeronautics and Astronautics, Reston, VA, 2011.

[33] A. M. Kirk, J. I. Gargoloff, O. K. Rediniotis, and P. G. Cizmas. Numerical and experimental investigation of a serpentine inlet duct. International Journal of Computational Fluid Dynamics, 23(3):245-258, 2009.

[34] S. Kumar, B. Sasanapuri, K. A. Kurbatskii, and A. Lestari. Pressure-based coupled simulation of pressure recovery and distortion in an s-shaped intake diffuser. In Joint Propulsion Conference, San Jose, CA, 2013.

[35] J. Kurzke. Effects of inlet flow distortion on the performance of aircraft gas turbines. Journal of engineering for gas turbines and power, 130(4):041201, 2008.

[36] J. C. Lin. Review of research on low-profile vortex generators to control boundarylayer separation. Progress in Aerospace Sciences, 38(4):389-420, 2002.

[37] F. K. Lu, Q. Li, Y. Shih, A. J. Pierce, and C. Liu. Review of micro vortex generators in high-speed flow. In 49th AIAA Aerospace Sciences Meeting, pages 2011-31, 2011. 
[38] J. Masud and F. Akram. Effect of passive bleed system on an integrated diverterless supersonic inlet. In 49th AIAA Aerospace Sciences Meeting including the New Horizons Forum and Aerospace Exposition, Orlando, Florida, 2011.

[39] J. Mattingly. Aircraft Engine Design. American Institute of Aeronautics \& Astronautics, 2002.

[40] J. D. Mattingly. Elements of propulsion. Department of Aeronautics, US Air Force Academy, 1989.

[41] R. S. Mazzawy. Multiple segment parallel compressor model for circumferential flow distortion. Journal of Engineering for Gas Turbines and Power, 99(2):288296, 1977.

[42] F. R. Menter. Two-equation eddy-viscosity turbulence models for engineering applications. AIAA journal, 32(8):1598-1605, 1994.

[43] R. D. Menzies. Investigation of S-shaped intake aerodynamics using computational fluid dynamics. PhD thesis, University of Glasgow, 2002.

[44] S. R. Mohler Jr. Wind-us flow calculations for the m2129 s-duct using structured and unstructured grids. 2004.

[45] L. R. Owens, B. G. Allan, and S. A. Gorton. Boundary-layer-ingesting inlet flow control. Journal of Aircraft, 45(4):1431-1440, 2008.

[46] A. Plas, M. Sargeant, V. Madani, D. Crichton, E. Greitzer, T. Hynes, and C. Hall. Performance of a boundary layer ingesting (bli) propulsion system. Paper No. AIAA-2007-0450, 2007.

[47] A. A. P. Plas. Performance of a boundary layer ingesting propulsion system. $\mathrm{PhD}$ thesis, Massachusetts Institute of Technology, 2006.

[48] A. Rabe, W. Ng, and R. Burdisso. Effectiveness of a serpentine inlet duct flow control technique at design and off-design simulated flight conditions. In ASME Turbo Expo 2004: Power for Land, Sea, and Air, pages 139-148. American Society of Mechanical Engineers, 2004.

[49] O. Rediniotis, R. Bowersox, A. Kirk, A. Kumar, and N. Tichenor. Active control of jet engine inlet flows. Technical report, DTIC Document, 2007.

[50] B. Reichert and B. Wendt. Improving curved subsonic diffuser performance with vortex generators. AIAA journal, 34(1):65-72, 1996.

[51] M. Rein, S. Koch, and M. Rütten. Experimental investigations on the influence of ingesting boundary layers into a diverterless s-duct intake.

[52] M. Rowe. Measurements and computations of flow in pipe bends. Journal of Fluid Mechanics, 43(04):771-783, 1970. 
[53] K. Sabo and M. Drela. Benefits of boundary layer ingestion propulsion.

[54] H. Schlichting, K. Gersten, and K. Gersten. Boundary-Layer Theory. Physic and astronomy. Springer, 2000.

[55] D. Schulte, A. Henckels, and U. Wepler. Reduction of shock induced boundary layer separation in hypersonic inlets using bleed. Aerospace science and technology, 2(4):231-239, 1998.

[56] J. Seddon and E. Goldsmith. Intake Aerodynamics. AIAA education series. Blackwell Science, 1999.

[57] J. W. Slater. Verification assessment of flow boundary conditions for CFD analysis of supersonic inlet flows. National Aeronautics and Space Administration, Glenn Research Center, 2002.

[58] L. H. Smith. Wake ingestion propulsion benefit. Journal of Propulsion and Power, 9(1):74-82, 1993.

[59] R. R. Taghavi and W. Jin. Effects of ice formation on the flowfield of an aircraft engine inlet. In ASME 2008 Fluids Engineering Division Summer Meeting collocated with the Heat Transfer, Energy Sustainability, and 3rd Energy Nanotechnology Conferences, pages 117-128. American Society of Mechanical Engineers, 2008.

[60] N. Titchener and H. Babinsky. The effects of various vortex generator configurations on a normal shock wave/boundary layer interaction. In 51st AIAA Aerospace Sciences Meeting including the New Horizons Forum and Aerospace Exposition AIAA 2013-0018, 2013.

[61] S. Tournier. Flow analysis and control in a subsonic inlet. PhD thesis, Massachusetts Institute of Technology, 2005.

[62] J. Watterson and S. Raghunathan. Computational study of passive boundary layer control to a supersonic intake. In 36th AIAA Aerospace Sciences Meeting and Exhibit. AIAA, 1998.

[63] S. R. Wellborn, B. A. Reichert, and T. H. Okiishi. An experimental investigation of the flow in a diffusing s-duct. In 28th Joint Propulsion Conference and Exhibit, Nashville, Tennessee, 1992.

[64] S. R. Wellborn, B. A. Reichert, and T. H. Okiishi. Study of the compressible flow in a diffusing s-duct. Journal of Propulsion and Power, 10(5):668-675, 1994.

[65] B. Wendt and W. Hingst. Flow structure in the wake of a wishbone vortex generator. AIAA journal, 32(11):2234-2240, 1994.

[66] Y. Wu, E. Ng, and K. Wong. Numerical study of the swirl flow in f-5e intake with subsonic speeds. Mathematical and Computer Modelling, 48(3):447-467, 2008. 
[67] J. Yi, B. J. Lee, and C. Kim. Efficient design optimization of vortex generators in subsonic offset inlet by discrete adjoint approach. In 20th AIAA Computational Fluid Dynamics Conference, 2011.

[68] Z. Zhang and K. Lum. S-shaped inlet design optimization using the adjoint equation method. In 42nd AIAA/ASME/SAE/ASEE Joint Propulsion Conference and Exhibit, Sacramento, USA, 2006. 